UC-13

\title{
Investigation of International Energy Economics
}

March 1977

Prepared for the Energy Research and Development Administration under Contract EY-76-C-06-1830 


\section{NOTICE}

This report was prepared as an account of work sponsored by the United States Government. Neither the United States nor the Energy Research and Development Administration, nor any of their employees, nor ary of their contractors, subcontractors, or their employees, makes any warranty, express or implied, or assumes ariy legai liability or responsibility for the accuracy, completeness or usefulness of any information, apparatus, product or process disclosed, or represents that its use would not infringe privately owned rights.

PACIFIC NORTHWEST LABORATORY

operated by

GATTELLE

for the

ENERGY RESEARCH AND DEVELOPMENT ADMINISTRATION

Under Contract EY-76-C-06-1830

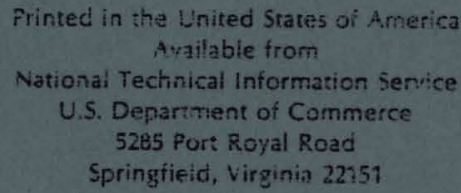

Price: Printed Copy \$____; Microfiche $\$ 3.00$

$\begin{array}{cc}\text { *Pages } & \text { Selling Price } \\ 001-025 & \$ 4.50 \\ 026-050 & 55.00 \\ 651-075 & \$ 5.50 \\ 076-100 & \$ 6.00 \\ 101-125 & \$ 6.50 \\ 726-150 & \$ 7.00 \\ 731-175 & 57.75 \\ 176-26.0 & 58.50 \\ 201-225 & 59.75 \\ 225.250 & 59.00 \\ 251-275 & \$ 70.00 \\ 276.300 & \$ 16.25\end{array}$


BNWLL-2134

UC- 13

33679000627176

INVESTIGATION OF INTERNATIONAL ENERGY ECONOMICS

by

D. E. Deonigi

M. Clement

T. J. Foley

S. A. Rao

BATTELLE

Pacific Northwest Laboratories

Richland, Washington 99352 


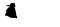

$x$

‘ 


\section{SUMMARY}

The Division of International Affairs of the Eneray Research and Development Administration established a procram to develop a methodology to evaluate the international economic impact of chanqes in technolony and use of eneray. This methodology is desianed to be appropriate for evaluating the international economic imnact of sianificant new sources of eneray. It also allows for assessing the relative advantage of countries that develop a new technology as compared to those countries which do not possess or have access to the new eneray technolony. For example, each assessment identifies eneray requirements, oil savings, capital requirements, trade flows, etc. Prior to this research proaram, existing methods provided only a partial evaluation and seldom addressed the overall problems associated with supply, demand, new technoloaies and relative advantanes of each source of energy.

Battelle, Pacific Northwest Laboratories (PNL), one of the orcanizations participating in this proaram, was to develop 1) a means of estimating the demands for major forms of eneray hy country, and 2) a means of identifying results or impacts on each country. The results for each country were then to re compared to assess relative advantages. PNL relied on its existing neneral econometric model, FXPLOR, to forecast the demand for energy by country. Before using the general version of EXPLOR, it had to he modified and expanded to mave it more suitahle for evaluatinn international energy economics. For example, in the case of Japan (a) three new energy intensive sectors were added to FXPLOR Japan which identified large users of eneray, the form of energy consumed, and the output of each eneray intensive sector. Four electric nower neneratina sectors were also added. For each of these sectors, EXPLOR identified the form of eneray consumed and the volume of electricity aenerated. With these expansions, EXPLOR Japan is well suited for evaluating the economic impact of anticipated new eneray technologies, the results of the Rand (1) study, or other eneray scenarios.

(a) Japan was seiected as an example to illustrate the results of the analysis. The same analysis could have been completed for seven European countries, Canada and the United States. 
Additional research expanded the number of commodities used to forecast the elements of private consumption or expenditure; i.e., the Linear Expenditure System (LES). The new commodities are energy related and are necessary for a detailed evaluation of changes in personal spending patterns during periods of rapidly increasing prices of selected commodities; e.g., energy products. This research was to determine whether minimal consumption of a group of substitutable products would be maintained during periods of rapidly increasing prices. For example, the forecasts showed that during recent periods of rapidly increasing oil prices, consumers purchased fewer gallons of gasoline, but they did acquire a minimum level of various forms of transportation to continue their daily activities.

EXPLOR Japan is now available for evaluating and comparing the results of changes relating to Japan's consumption of major and potentially new forms of energy. A sample analysis was completed for 1975 which closely approximated actual macro conditions for 1975 and included seven new energy related sectors; e.g., GNP for 1970 through 1975 actually grew at $5.34 \%$ per annum whereas EXPLOR shows GNP growing at $5.4 \%$ per annum.

Results of the EXPLOR model can also be compared to results from a model used at Brookhaven National Laboratory. The results of either model may now be used as input to the other model. 
TABLE OF CONTENTS

SUMMARY . . . . . . . . . . . . . . . . . .

INTRODUCTION

THE ROLE OF PACIFIC NORTHWEST LABORATORY . . . . . . . 2

INTRODUCTION TO EXPLOR MULTITRADE

COUNTRY FORECASTS - PHASE I . . . . . . . . . . . 4

TRADE FLOWS - PHASE II . . . . . . . . . . . . 7

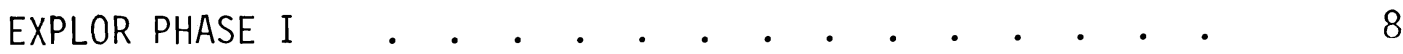

EXOGENOUS INPUT

EXPLOR FORECASTS •

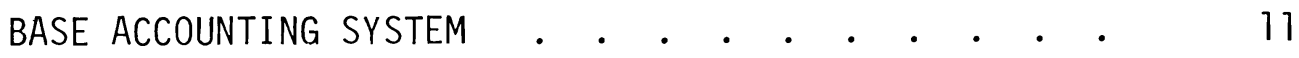

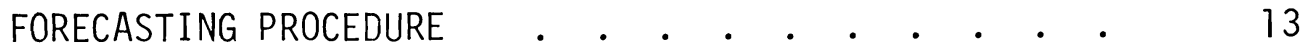

Step 1: Domestic Production . . . . . . 13

Steps 2 and 3: Intermediate Output . . . . 14

Step 4: Labor Requirements . . . . . . . 14

Step 5: Prices and Profits Via Minimization

Procedure . . . . . . . . . . . . . 15

Step 6: Market Prices . . . . . . . . . . 16

Steps 7 and 8: Private Expenditures . . . . 17

Step 9: Investment Requirements . $.0 . \quad . \quad . \quad 19$

Step 10: Investment Supplies .

Steps 11 and 12: Domestic Market and Imports . 21

Step 13: Exports . . . . . . . . . . . 22

Step 14: Net Final Demand . . . . . . . . 23

THE LINEAR EXPENDITURE SYSTEM SUBMODEL . . . . . . 24

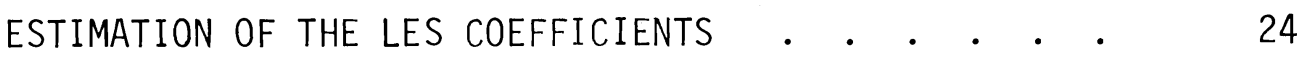

VALIDATION OF THE LES RESULTS . . . . . . . . .

IMPROVED FORECASTING • . . . . . . . . . . . 28

FORECAST FOR EIGHT MACRO GROUPS . . . . . . . . 28

POSSIBLE FUTURE USES OF LES SUBMODEL • • . . . . 31

DISAGGREGATION OF SELECTED ENERGY USING SECTORS • . 34

DISAGGREGATION OF SELECTED ENERGY PROVIDING SECTORS • 35 
CONTENTS (Continued)

JAPANESE DATA BASE ANALYSIS . . . . . . . . . . . . 39

APPENDIX A - PROPOSED METHODOLOGY FOR EVALUATING INTERNATIONAL

IMPACT IMPLEMENTING NEW ENERGY TECHNOLOGY

APPENDIX B - EXPLOR MULTITRADE SEMINAR AGENDA AND ATTENDEES • B- 1

APPENDIX C - EXPLOR MULTITRADE JAPAN - 1975 . . . . . . . C-1

APPENDIX D - SECTORIAL CONCORDANCE FOR PNL AND BNL VERSIONS

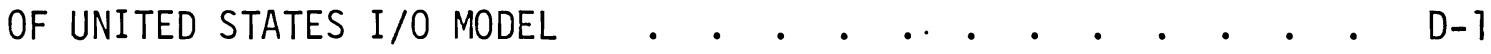




\section{LIST OF FIGURES}

1 EXPLOR MULTITRADE Interrelation of Phase I and Phase II 5

2 EXPLOR MULTITRADE Base Accounting System . . . . $\quad 9$

3 EXPLOR Phase I Flowchart - Generation of National Forecasts 10

4 Transition Matrix for Making Private Consumption Data

Compatible with EXPLOR Input/Output Tables . . . . . 19

5 Typical EXPLOR Forecasts of Requirements for Investment Capital in Specific Sectors . . . . . . . . . 20

6 Matrix for Converting Forecasts of Purchases of Commodities to Investment Supplies for Use in EXPLOR Model . . 121

A-1 Organization of Laboratories for Evaluation of International Economics . . . . . . . . . . . . A-2

\section{LIST OF TABLES}

1 Comparison of Actual and Predicted Expenditure (1970-1973) 26

2 Comparison of Battelle and NPA Personal Expenditure Projections for 1979 (1970 Constant \$Miliion) . . . . 27

3 Definition of Macro Groups in Terms of 39 Micro Groups for United States . . . . . . . . . . . . . 29

4 Comparison of Private Expenditure Forecasts for 8 Macro Groups, Summation of 39 Groups and Historical Data for the United States . . . . . . . . . . . 32

5 Comparison of Private Expenditure Forecast for Elements in Macro Groups with Forecasts for Each of the 39 Commodities for the United States . . . . . . 33

6 Disaggregated Energy Intensive Sectors . . . . . . 35

7 Disaggregated Energy Providing Sectors . . . . . . 36

8 Japan Electric Power Generation by Source of Energy (\%) 36

A-1 Examples of Key Outputs and Results . . . . . . A-9

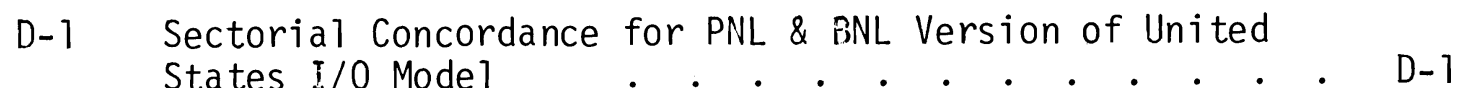


*

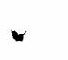

. 
Since the oil embarqo imposed hy the Arab nations in 1973, numerous methods have heen proposed to reduce Inited States dependency on foreign sources of energy and to prevent future emhargoes. These methods inciude: reduced consumption, conservation, expanded nuclear energy programs, and development of solar power, geothermal, and other alternate energy sources. Several research organizations and industrial firms are evaluating the technical and economic feasibility of these alternate eneray sources.

Other developed nations are similarly concerned with reducing their dependency on imported eneray sources. Nations such as the European countries and Japan are highly dependent; e.q., Japan imports more than $00 \%$ of its energy requirements. Any alternate energy source or less dependency on imported eneray should improve their economic position in international markets.

The Division of International Affairs of the Enerqy Research and Development Administration is assessing the long-range economic effects of energy research and development programs in the U.S. and other countries, particularly members of the International Energy Aqency (IEA). In support of this effort, a program was desianed to coordinate the capahilities of five research groups - Rand, Virqinia Poivtechric Institute, Brookhaven National Laboratory, Lawrence Livermore Laboratory, and Pacific Northwest Laboratory. The proqram could evaluate the international economics of proposed or anticipated sources of energy. This proaram is designed to be general, flexible and capahle of evaluating a diverse collection of potential eneray (nuclear and nonnuclear) related problems. For example, the newly developed methodolony could evaluate the international and domestic economic impact of nuclear related energy sources, but also existing nonnuclear and potential eneray sources such as solar, geothermal, wind, etc. Major items to be included would he the cost of exploration, cost of production, prices, profit, market penetration, investment requirements and investment goods, economic growth, chance in balance of payments, etc. In addition, the changes in cost of producing all goods and services would be identified for each new enerqy source. 
The methodology was designed such that it is capable of, but not limited to, evaluating the international and domestic impacts resulting from hypothesized energy developments such as:

- Accelerated development of solar power by Japan but not simultaneously by other countries.

- Accelerated development of nuclear energy by France.

- Accelerated price increase of crude oil by OPEC.

- Value of jointly funded energy ventures to each contributing party.

- Value of substitution and conservation of energy sources.

\section{THE ROLE OF PACIFIC NORTHWEST LABORATORY}

Pacific Northwest Laboratories' contribution to this larger integrated effort in cooperation with the other laboratories was centered about the assessment of recent demand for energy plus forecasting demand for energy and major elements of final demand. Pacific Northwest Laboratories utilized an expanded version of $i$ ts existing econometric model, EXPLOR, for assessing the elements of demand. The expansion was completed to orient the model more specifically toward energy analysis and make it more suitable for combined efforts with the other four laboratories. For purposes of testing the system, the additions were made to the Japanese model and consisted of:

- Addition of four energy intensive sectors.

- Disaggregation of electric power generation sector into electricity generated from: (1) coal, (2) nuclear, (3) oil and (4) hydro.

- Expansion of capability of LES (a system used in EXPLOR for forecasting private consumption of individual commodities) to assure adequate, minimal consumption of required products during times of rapidiy rising prices; i.e., adequate consumption of fuel for autos or equivalent transportation during periods of quadrupling prices.

Additional work completed by PNL which makes multilaboratory analysis possible was: 
- Preparation and presentation of a seminar explaining the merits and qualities of the expanded EXPLOR model. The seminar was we 11 attended by a diverse group of governmental officials and employees and fellow researchers from other laboratories. The seminar provided information illustrating the power of EXPLOR. In addition, the seminar considered the potential application of EXPLOR coupled with the resources of the other laboratories for evaluating alternate energy resources. (See Appendix $B$ for a list of attendees and an outline of the seminar.)

- Preparation of methodology for a systematic, international economic analysis of a complete energy system. (See Appendix A, "Proposed Methodology for Evaluating International Impact of Implementing New Energy Technology".) This methodology, as developed, would integrate the skills and assets of the five laboratories.

- Preparation of sectorial concordance for BNL and PNL's United States' model was essentially completed. (Both models are based upon "Standard Industrial Classification" system.)

\section{INTRODUCTION TO EXPLOR MULTITRADE}

EXPLOR MULTITRADE, a continuously evolving econometric model based upon input/output analysis, was originally developed by Battelle in the early 1960's. The EXPLOR model has a mid- to long-range view (5 to 15 years) and several unique qualities which makes it well suited for evaluation and comparative analysis of investment programs, new or anticipated technology and governmental policy and for assessing the demand for energy by ten developed countries. Use of EXPLOR and its role in an integrated energy assessment program was described in a recent seminar (Appendix A).

Originally, the model provided detailed forecasts of production based upon I/O tables for seven European countries. As the model evolved, a function for forecasting private consumption (Linear Expenditure System) was added. Then the vintage production for estimating capital and labor requirements was added followed by the expansion of the model to include 
Japan, Canada and the U.S. These expansions in the EXPLOR model allowed detailed forecasts to be recently completed through 1985 for 10 countries. These country forecasts are referred to as Phase I. Since then, the EXPLOR model has been again expanded and now has the capability to forecast trade flows (imports and exports) between the 10 EXPLOR countries and trade with the rest-of-the-world which was divided into five other regions (North Africa and Middle East, American developing countries, other developing countries, other developed countries and centrally planned countries). The forecasts of trade flows are referred to as Phase II. Figure 1 illustrates the basic accounting framework used in EXPLOR as well as the integration of Phase I and Phase II. The left-hand side of Figure 1 relates to Phase I and the right-hand side to Phase II.

Recent forecasts prepared for Phases I and II were based upon scenarios which emphasized energy and inflation.

\section{COUNTRY FORECASTS - PHASE I}

The EXPLOR model as used in Phase I with its 5 to 15-year time horizons was designed to evaluate changes in technology, possible ramifications of government policy, and proposed investment programs. (The 5 to 15-year time horizon is required to reflect resulting changes from implementing a new technology or government policy.) The EXPLOR model can be modified to reflect anticipated or hypothetical changes. The changes can be reflected by modifying technical coefficients in the " $A$ " matrix for each country or in the consumption functions. Changes in the "A" matrix are the usual method which requires that the EXPLOR model contain I/O tables for each country and for each year to be modeled. That is, individual country I/0 tables were used for 1970, 1975, 1980 and 1985 in preparing national forecasts for 1975,1980 and 1985 .

Currently, ten detailed EXPLOR country models exist. The country models provide comparable results and are all based upon the same methodology. The basic difference between the country models is the number of sectors used to describe a nation's economy; however, all are detailed and may include as many as 70 sectors. 


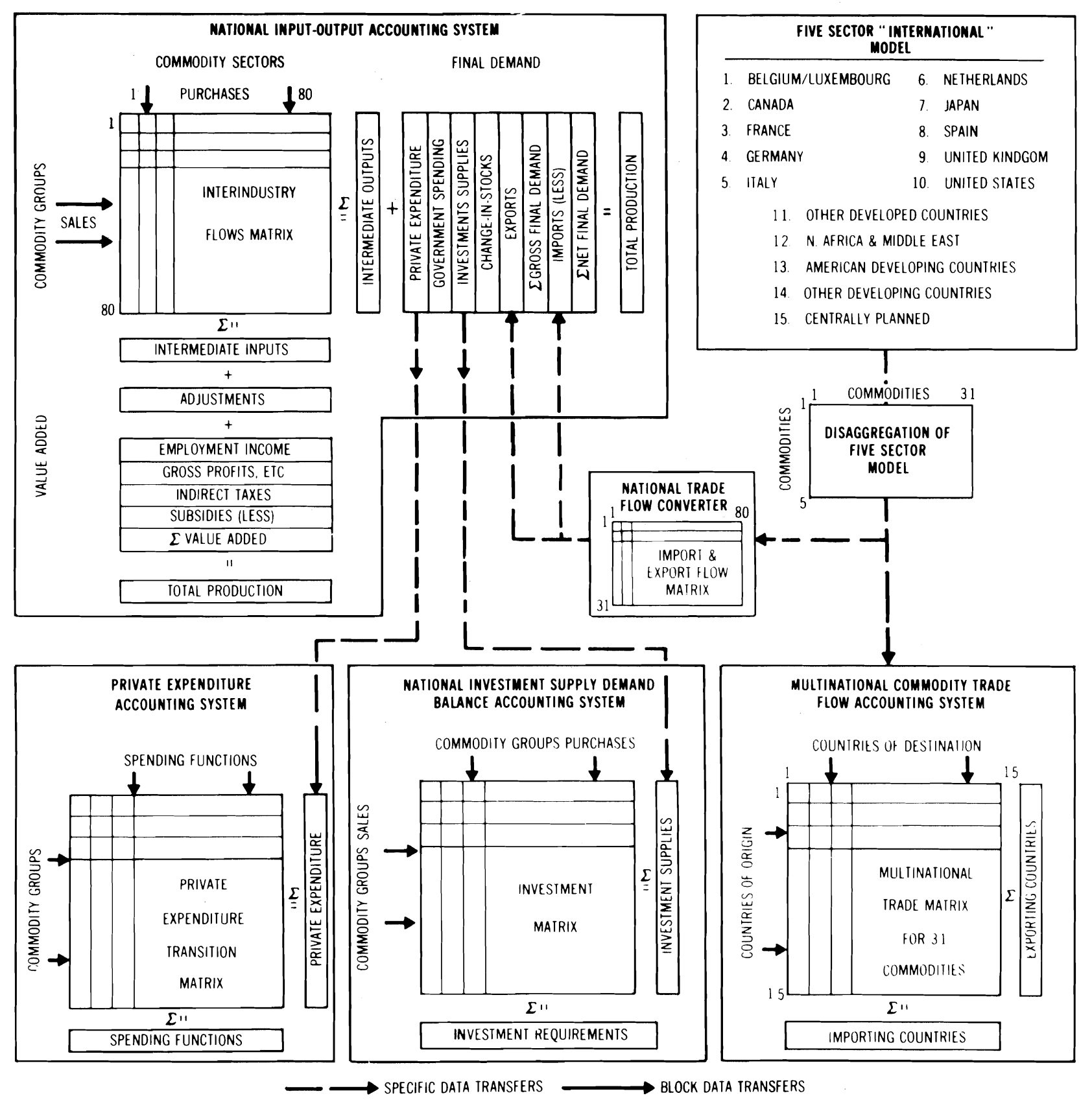

FIGURE 1. EXPLOR MULTITRADE Interrelation of Phase I and Phase II 
The EXPLOR Phase I model includes the three major elements required to produce a mid- to long-term forecast. The elements are:

- A system of demand functions which estimate future demands at final and industrial levels which are equal to production requirements.

- A system of production functions for estimating investment and labor requirements.

- A system of cost functions identifying costs of commodity purchases (intermediate inputs), employment compensation, profits, taxes and subsidies .

The EXPLOR model uses an iterative method when developing a forecast given constraints on total output or production, prices and profits.

The EXPLOR Phase I model was designed to have general appeal to a diverse group of government and industrial users. Recognizing that each user has individual needs, the program was designed with sufficient flexibility such that it could also be used to address a specific need of individual users. To satisfy both needs, a forecast is routinely prepared for each country. These country forecasts contain up to 70 sectors and are based upon a scenario developed by the group of users which makes the forecast of general interest to $\mathrm{a} 11$. (The recently prepared forecasts are based upon a scenario which emphasized increasing costs of energy and inflation in general.) More specific questions can then be addressed based upon the general EXPLOR Phase I forecasts. Examples of recently completed studies based upon the recently expanded EXPLOR forecasts are:

- Disaggregation of electric power generation sector into four sectors for Japan and seven sectors for the U.S.

- Evaluation of excelerated expansion of nuclear power generation in France.

- Evaluation of the impact of air pollution controls on the U.S. steel industry and a comparison of the relative competitive position of the U.S. steel industry versus the German steel industry assuming the U.S. has air pollution controls while the German industry does not.

- Extension of forecasts through the year 2000. 
- Forecast of investment requirements for the development of alternate energy sources in the U.S.

- Disaggregation of sectors which are intensive energy users for six countries (Canada, Japan, France, Germany, U.S., and United Kingdom).

- Forecast of demand for critical materials to be required by anticipated generators of electric power; e.g., CTR, solar, etc.

- Forecast of required consumption of critical materials; e.g., chrome, to satisfy an anticipated rate of economic growth.

\section{TRADE FLOWS - PHASE II}

Using the most recent extension of EXPLOR, Battelle can now forecast trade flows through 1985 for the 10 EXPLOR countries as we 11 as trade between the EXPLOR countries and the rest-of-the-world which was subdivided into five distinct groups; i.e., other developed countries, North Africa and Middle East, other developing countries (Africa, Oceania and Asia), American developing countries, and centrally planned countries. Using the expanded version of EXPLOR, trade flows (imports and exports) are being prepared for 31 identical sectors for each country.

The basis of the trade flow forecasts is a scenario based upon interviews with experts in foreign trade. A scenario was then constructed using cross impact analysis for evaluating the opinions of each interviewee. The scenario provided the exogenous inputs required by a five sector econometric model for each of the 15 "countries" through 1985. The sum of exports or imports for the 15 countries accounts for the world's total trade flows. A distribution function was also developed which can disaggregate trade at the five sector level into 31 identical sectors for each of the 15 countries. For the EXPLOR countries, one can also expand the 31 sectors into sectors equivalent to those contained in Phase I. The trade flow forecasts by country include import prices, export prices, exchange rates, trade balance, imports and exports. (In preparing the individual country forecasts, caution was exercised to assure that the world's imports equal the world's exports.) The results of these trade forecasts are: 
- Trade flows for the five sectors including origin and destination.

- Trade flows for the 31 sectors including origin and destination.

- Import and export prices for each commodity for each country.

- Exchange rates for each country.

These values are routinely provided for each forecast period.

\section{EXPLOR PHASE I}

A detailed description of the EXPLOR Phase I model follows. The discussion includes a description of the flow of the model and a description of the required process to obtain a solution. Figure 2 illustrates the basic accounting system utilized by EXPLOR and Figure 3 is a flow chart for the EXPLOR Phase I model.

\section{EXOGENOUS INPUT}

Like other econometric models, EXPLOR requires an input of a number of exogenous or external forecasts. Through continuous development, the list of these has been reduced and will continue to be reduced. Currently,. the input variables are as follows:

(1) total population

(2) total private expenditure

(3) government spending

(4) changes in stocks

(5) import ratios, a function of domestic market; export ratios, a function of total production

(6) import prices

(7) average annual wages

(8) tax and subsidy ratios

(9) nonproductive investment (dwellings and scrap, usually).

\section{EXPLOR FORECASTS}

The EXPLOR model has the ability to produce numerous forecasts and to compare the results of selected forecasts. The following list provides a 


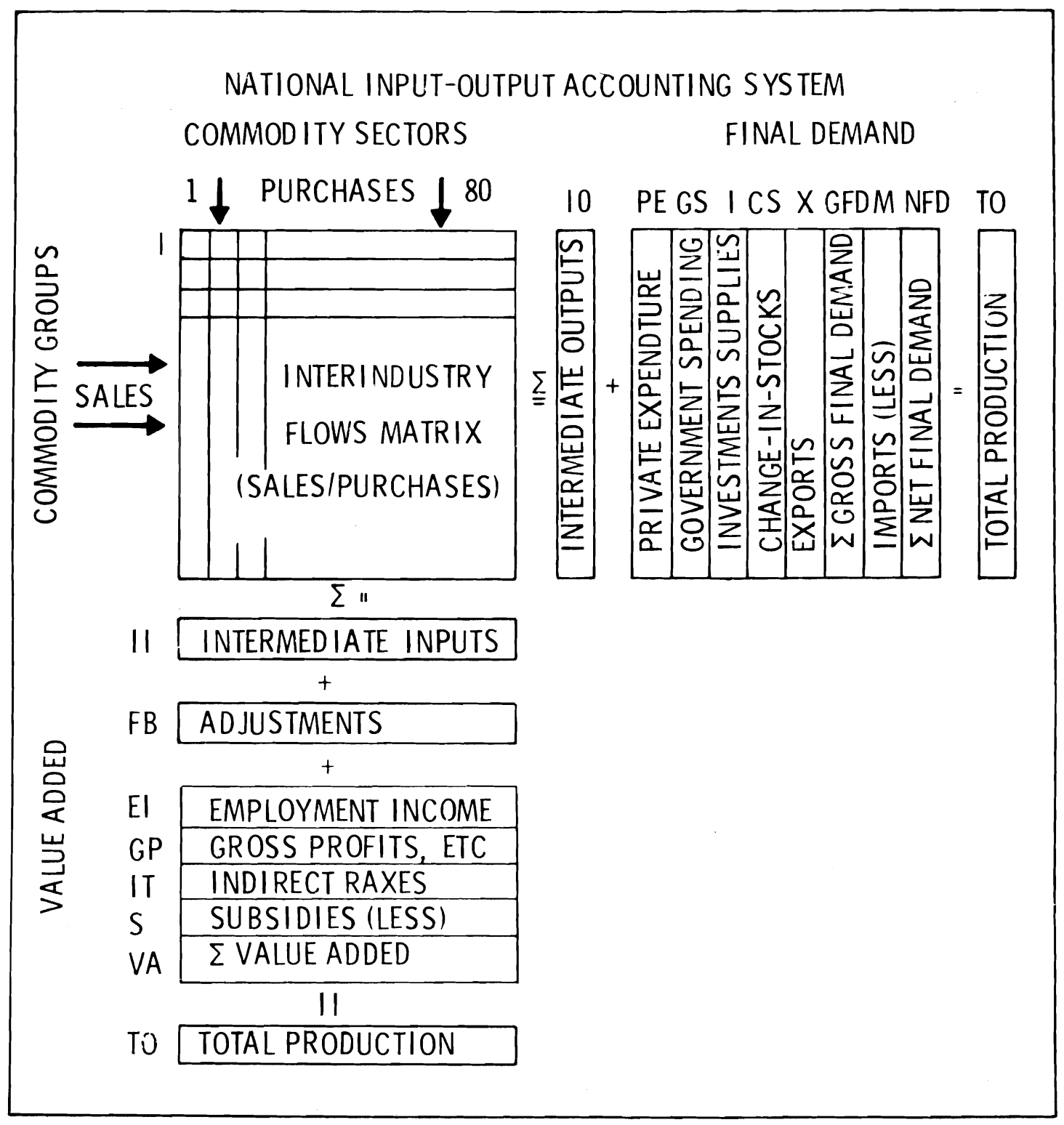

FIGURE 2. EXPLOR MULTITRADE Base Accounting Sys tem 


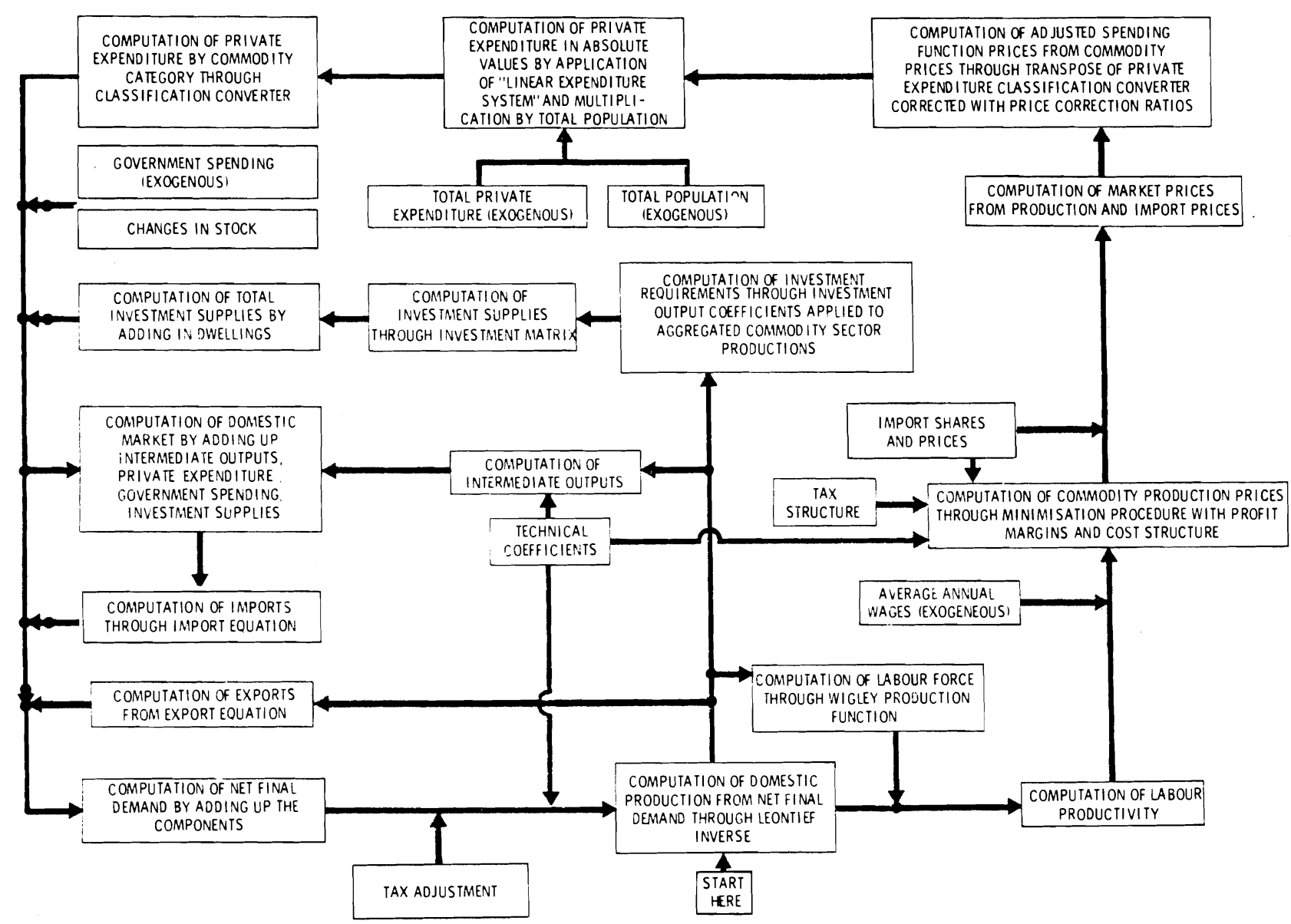

FIGURE 3. EXPLOR Phase I Flowchart - Generation
of National Forecasts

representative sample of forecasts available from the EXPLOR model. Appendix C contains a sample computer listing of each forecast for the years 1990 through 2000 under Scenario C. 
- Macroecononic demand components in constant 1970 prices; i.e., intermediate output, gross domestic product or net final demand, domestic production, private expenditure, government spending, productive investment, investment in dwellings, domestic market, imports, and exports.

- Commercial balance in current prices; i.e., the balance or difference between a country's imports and exports of goods and services.

- Macroeconomic cost components in current prices (employment income, gross profits, indirect taxes, subsidies, intermediate input, and domestic production).

- Average annual growth rates for domestic market, gross domestic product (GDP), domestic production, private consumption, etc.

- Implicit nominal price indexes for GDP, domestic production, import, and domestic market, and average annual growth rates for each of the price indexes.

- Investment prices and investment coverage by gross profits.

- Growth and absolute values for labor, productivity, and wages.

- Gross profits, indirect taxes, and subsidies as a percentage of domestic production at current prices.

- Changes in investment requirements and investment-to-output ratios.

- Growith of exports, imports, and share of domestically produced goods at constant prices.

These outputs are available for each of the commodity sectors, as well as the totals for all sectors for 1970, 1980, 1990, and 2000.

\section{BASE ACCOUNTING SYSTEM}

The EXPLOR model lises a traditional national input-output accounting framework to account for the relationships between producers and consumers of commodities, industries (producers of goods and services), components of final demand (consumers), and elements of value added. Figure 2 is a graphic illustration of these relationships. 
The matrix of interindustry flows ${ }^{(2)}$ (sales/purchases) shows the relationship or quantities of purchases and sales between and among different producing sectors of an economy. These sales, purchases and transactions involve the primary and intermediate goods and services or the purchases (inputs) and sales (outputs) in the production process. For example, moving across a row of the matrix, one can observe the sales of a sector's output to other producing sectors. On the other hatad, going down a column one can observe the purchases or inputs to the sector that are required in its production. Adding the sales (summing across a row in the table), one obtains the intermediate output. Similarly, summing down a column, one obtains the intermediate inputs, or total purchases.

To the right of the interindustry flows matrix (Figure 2) are the components of net final demand (NFD) or gross national product (GNP):

Private Expenditure (PE)

Government Spending (GS)

Inves tment Supplies (I)

Change in Stocks (CS)

Exports $(X)$

Imports (M)

$$
\text { GNP }=N F D=P E+G S+I+C S-M+X .
$$

These components of net final demand both generate and support the interindustry transactions embraced in the interindustry flows matrix. For each sector, the intermediate output plus the net final demand equal the total production. By definition, the summations of all components of net final demand are equivalent to the economy's gross national product, a commonly used measure of a nation's economic activity.

The value added ${ }^{(3)}$ portion of the input-output table is found below the interindustry flows matrix (Figure 2). Value added is a measure of the contribution of each producing sector to the economy in terms of revenue from production which pays for $i$ ts employment of labor (employment income, EI), capital and management (gross profits, GP), indirect taxes (IT), and subsidies (S). Similarly, as with net final demand, the summation of all components of value added is equivalent to GNP.

$$
\text { GNP }=V A=E I+G P+I T-S .
$$


FORECASTING PROCEDURE

Using the exogenous inputs described previously, the model provides a forecast for a nation's economy through an iterative process. Forecasts are usually provided for 5- or 10-year increments. For the analysis reported here, a 10-year increment was selected. The flow of this is illustrated in Figure 3. Important blocks in the model are numbered, and if the reader follows the numbers, he will be able to trace through one computational cycle of the model. The biock numbers are also referred to in the following sections to aid the reader.

The EXPLOR model is designed such that it requires initial estimates for total output, prices, profits and labor force for each sector. An estimate of the labor force is required for a "base year" or a recent year (1970) which serves as a basis for future forecasts. An initial value for total output is required for each of the future projections or years when forecasts are to be prepared; that is, 1980, 1990 and 2000. Given these initial estimates, the EXPLOR program begins to work toward a solution by calculating an initial estimate of export, import, investment requirement, intermediate output and private expenditure for each sector.

This estimate of initial values plus the previously provided exogenous forecasts for government expenditure and change in stock serve as a mathematical starting point for the EXPLOR model. Actual forecasts for the components of net final demand are obtained as the model iterates toward an equilibrium solution. The exceptions are government expenditures and changes in stocks, which are supplied exogenously. (No consistent economic basis is available which could be modeled and allow for an endogenous allocation of government expenditures and changes in stocks.)

Step 1: Domestic Production

The EXPLOR model begins its approach to an equilibrium solution from the initial estimate of net final demand for each of the commodity groups. A first approximation of total domestic production for each sector is estimated using the "Leontief Inverse." (Using the Leontief Inverse, EXPLOR calculates the total output required to satisfy a unit change in net final 
demand; $i . e$, the increase in totâl output required to increase net final demand by one unit.) This provides only a second approximation of total domestic production, investment supply, import, export, etc. for each sector. The final or acceptable solution is obtained by iterating through the model until predefined convergence criteria on profits, prices and total output for each sector are satisfied.

Steps 2 and 3: Intermediate Output

Using the previously estimated total domestic production for each sector, the intermediate output is calculated using the " $A$ " matrix of direct technical coefficients. (The "A" matrix contains a column and a row for each sector. The columns of the matrix express all components of each sector's input as a fraction of its total production.) The intermediate inputs are obtained by multiplying each column of fractions or coefficients by the sector's total production. This converts the coefficients to values, commoniy called flows and, in turn, a "flow table" is created.

The intermediate outputs are calculated by adding the values or flows across the row. Total output of each row or sector can then be obtained by adding the intermediate output to the sector's net final demand.

\section{Step 4: Labor Requirements}

The labor requirements for total domestic production are calculated using the Wigley production function. $(4,5)$ In forecasting labor requirements, the Wigley production function considers changes in productivity (output/labor) resulting from changes in investment and changes in labor costs for each sector. The result of the computation is a forecast of the labor force required to produce the estimated output for each sector. Annual data required by the computation are:

- Output

- Investment

- Labor force

- Material inputs or requirements

- Wages and salaries per employer

- Price indexes

- Land rents. 


\section{Step 5: Prices and Profits Via Minimization Procedure}

Having solved for total domestic production, labor requirements, wage bill intermediate inputs (through the interindustry flows matrix), and taxes (forecast exogenous $7 y$ ), the cost of production with the exception of profits is known.

The next operation is to calculate profits and the necessary price to cover production costs plus gross profits (profits before income taxes and depreciation). The cost system is based upon a minimization procedure between commodity prices and profit markup. The minimization procedure allows the model to more accurately reflect industrial behavior. That is, producers can usually only vary their price and/or profits as they are constrained by the technology being used as well as wage rates and taxes at any given time. The purpose of this procedure is to minimize the following objective function:

$$
\min _{i=1}^{n}\left[\left(\frac{P_{i}-P_{i \star}}{\alpha_{p} P_{i *}}\right)^{2}+\left(\frac{\sigma_{i}-\sigma_{2^{*}}}{\alpha_{\sigma} \sigma_{i^{*}}}\right)^{2}\right]
$$

Subject to the $n$ constraints represented in matrix notation by the equation, and

where $\quad P=$ the vector of commodity production prices generated in the model at each iteration

$\sigma=$ the vector of profit markups on prices generated by the model at each iteration

$P_{\star}=$ the vector of commodity production prices estimated independently and representative of the likely prices which could be expected

$\sigma_{*}=$ the vector of profit markups on prices estimated independently and expected to represent the profitability goals of the commodity sectors

$\alpha_{P}>\alpha_{\sigma}=$ confidence weights attached to $P_{\star}$ and $\sigma_{\star}$, respectively.

To start the computation, a production price $\left(P_{\star}\right)$ and a profit markup (ratio of profits to total output) for each sector are supplied with subjective weights for prices and profits respectively. (Recognizing that 
profit ratios are usually more stable than prices over a 5-year period, a heavier weight is usually placed upon the forecasted profit ratios as opposed to prices.) The minimization procedure then proceeds to provide a forecast of profits and production prices for each commodity group. Total production costs are calculated using the following equation.

$$
\text { Production cost }=\text { intermediate inputs }+ \text { taxes }+ \text { subsidies, }
$$

or

$$
y \hat{p}=\hat{y}\left(A^{\prime}\left[\hat{\Psi} p_{m}+(I-\hat{\Psi}) p\right]\right)+e+\pi^{*}+t+s^{*}
$$

where

$$
\begin{aligned}
& A^{\prime}=\text { transposed matrix with } n \text { rows and } m \text { columns } \\
& I^{\prime}=\text { transposed unit matrix with } n \text { rows and m columns } \\
& \hat{y}=\text { a diagonal matrix with terms equal to production by commodity } \\
& \quad \text { sector at constant prices } \\
& p=\text { production prices by commodity sector } \\
& p_{m}=\text { import prices by commodity } \\
& \hat{\psi}=\text { the shares of imports on the domestic market (see Steps } 11 \text { and } \\
& \quad 12 \text { ), a diagonal matrix } \\
& e=\text { employment income vector } \\
& \pi^{*}=\text { operating surplus or gross profits by commodity sector, a vector } \\
& t=\text { indirect taxes by commodity sector, a vector } \\
& s^{*}=\text { subsidies by commodity sector (negative values), a vector. }
\end{aligned}
$$

\section{Step 6: Market Prices}

The last step in the cost computation is the calculation of commodity market prices. Market price is a weighted average of the price for domestic production and imported commodities. The domestic production prices are obtained from the price-minimization function. The import prices were forecasted exogenousiy, but the volume of goods imported is a function of the model. The following equation is used for calculating domestic market price: 


$$
p_{d}=\hat{\Psi p}+(I-\hat{\Psi}) p
$$

where

$\mathrm{p}_{\mathrm{d}}=$ the domestic market price by commodity sector

$\hat{\Psi}=$ the domestic share of imports on the domestic market by commodity sector, a diagonal matrix

$\mathrm{p}=$ the domestic production price by commodity sector

$\mathrm{p}_{\mathrm{m}}=$ import prices

$\mathrm{I}=$ unit matrix with $\mathrm{n}$ rows and $\mathrm{n}$ columns.

The domestic market prices $\left(p_{d}\right)$ or price indexes represent the price for commodity inputs (industrial purchase prices) and the price to private consumers. The only additional requirement for private consumption is that a converter matrix is required to modify commodity prices to spendingfunction prices.

Steps 7 and 8: Private Expenditures

The linear expenditure system $(6,7)$ is used to estimate components of private expenditure upon the basis of historical consumer behavioral patterns. The LES evaluates and forecasts private consumption in terms of "committed or required" purchases and discretionary purchases, total private expenditures being the sum of committed plus discretionary expenditures. The committed portion of private consumption can be interpreted as a "minimum level of consumption" such as the purchase of at least the minimum quantity of food needed to sustain one life. According to the LES, consumers acquire all of their "committed" expenditures independent of price and utilize the balance of their income (excluding taxes and savings) for purchase of "discretionary" goods and services. Unlike the committed expenditures, purchases of discretionary goods are sensitive to price change; i.e., if the price of Commodity $A$ increases more than Commodity $B$, assuming the consumer has equal desires for both commodities, the consumer wil1 purchase more of Commodity B than of Commodity $A$. 
The LES is based upon the following relationships:

$$
\bar{p} \bar{q}=\bar{p}_{i} \bar{c}_{i}+b_{i}\left(R-\sum_{j=1}^{n} \bar{p}_{j} c_{j}\right) \text { for each } i=1, \ldots, n
$$

with the income identity for total expenditure:

$$
R=\bar{p} \cdot \bar{q}
$$

where

$\bar{p}_{i}=$ price of commodity

$\bar{q}_{j}=$ total purchase of commodity

$C_{i}=$ committed consumption of commodity

$b_{i}=$ discretionary budget coefficient of commodity $i$ (sum of $b$ coefficient $=1$ )

$R$ = total consumption by the consumers; $i . e$. , sum of all consumption $R=\sum_{i} \bar{p}_{i} \bar{q}_{i}$

$\Sigma \bar{p}_{j} C_{j}=$ total committed expenditures; $i . e .$. , the sum of all the values (current prices) of the "committed amounts" of all commodities

$\left(R-\sum p_{j} C_{j}\right)=$ discretionary expenditures.

The result of the LES is a forecast of private consumption for 39 items for personal consumption (Appendix B), taking account of committed expenditures, total private consumption (and, in turn, discretionary purchases), relative prices, and population changes.

Private consumption data are typically not the same commodities as those used in the input/output tables. To make the private consumption categories or spending functions compatible with the industrial sectors or commodity groups, a transition or converter matrix is used. The transition matrix is illustrated in Figure 4. 


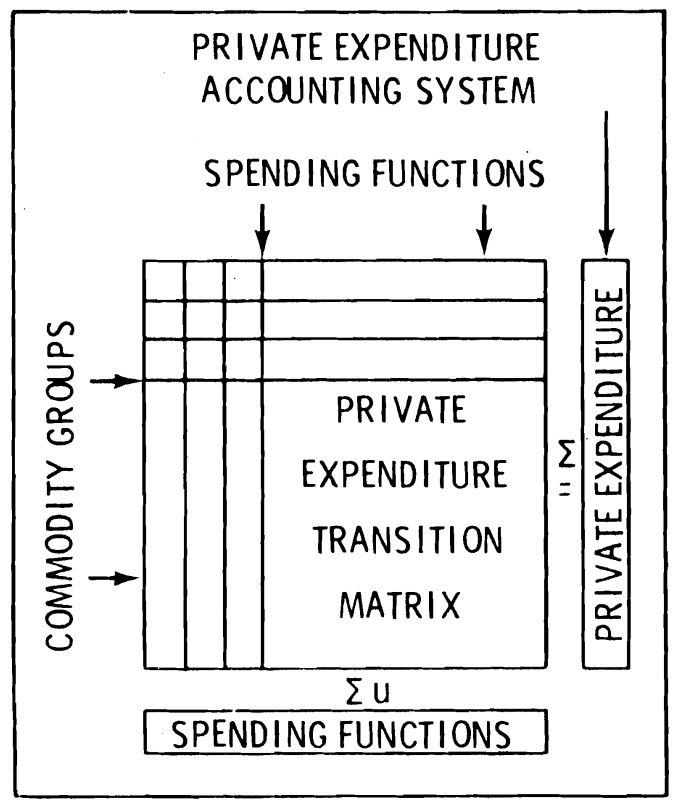

FIGURE 4. Transition Matrix for Making Private Consumption Data Compatible with EXPLOR Input/Output Tables

\section{Step 9: Investment Requirements}

Investment requirements present the expenditures (in dollars) made by a country's production process or industries to replace and expand its production base. In EXPLOR, a forecast of annual requirements for investment is provided for each commodity sector. Forecasts for investments are provided as a ratio of investment to total output. These forecasts are based upon historical trends and upon available data and information describing or indicating changes in requirements for investment capital to implement known or anticipated changes in technology. Examples of investment forecasts for agricultural crops and coal mining sectors for the U.S. are illustrated in Figure 5. 

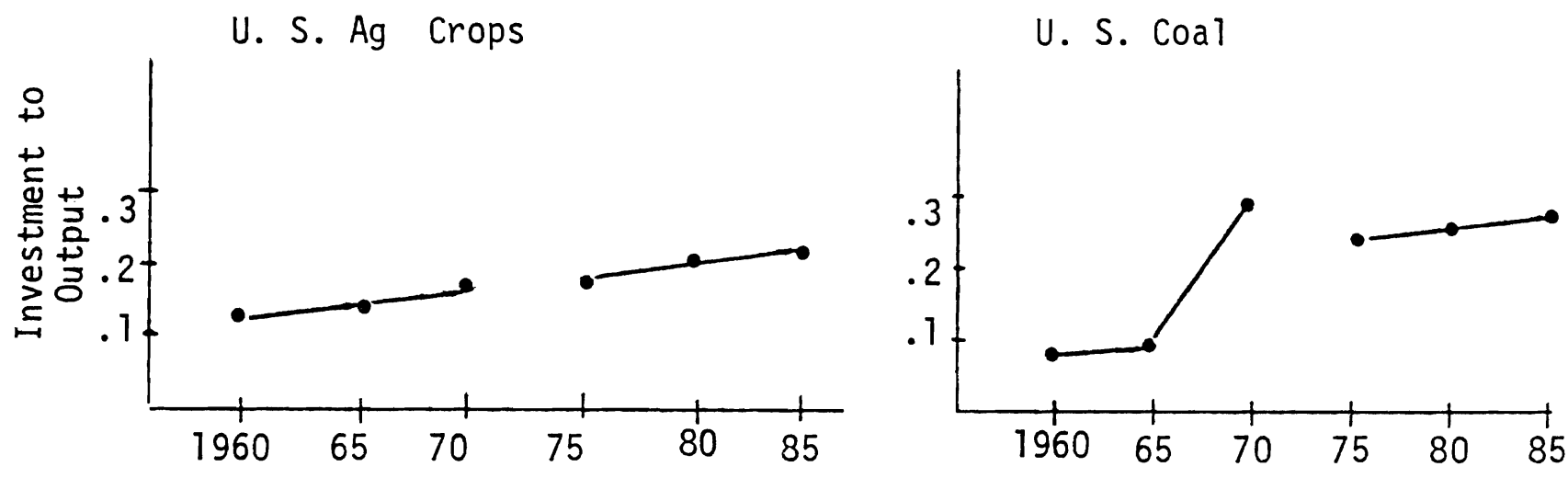

FIGURE 5. Typical EXPLOR forecasts of Requirements for Investment Capital in Specific Sectors

The forecast for the agricultural crops is basically a straight-line projection and represents a rather "traditional" sector; that is, a sector where investments have been made to replace labor and one that possibly reflects a slow implementation of improved technology. Alternatively, the coal sector has undergone a rapid increase in investment requirements per unit of output. Much of this change in investment ratios has been associated with the regulations imposed by the Federal Coal Mine Heal th and Safety Act of 1969, which began to be implemented in 1970. The balance of the increased investment can be attributed to the introduction of more costly but highly efficient machinery.

\section{Step 10: Investment Supplies}

In forecasting net final demand, EXPLOR and other input/output models require investment supplies (a component of net final demand) as opposed to investment requirements which were previously described (Figure 2). The investment supplies are the commodities purchased by firms; i.e., tools, machines, buildings, equipment, motors, and, of course, investment supplies equal investment requirements in the aggregate. An investment matrix or converter matrix is used once again to convert requirements to supplies (Figure 6). 


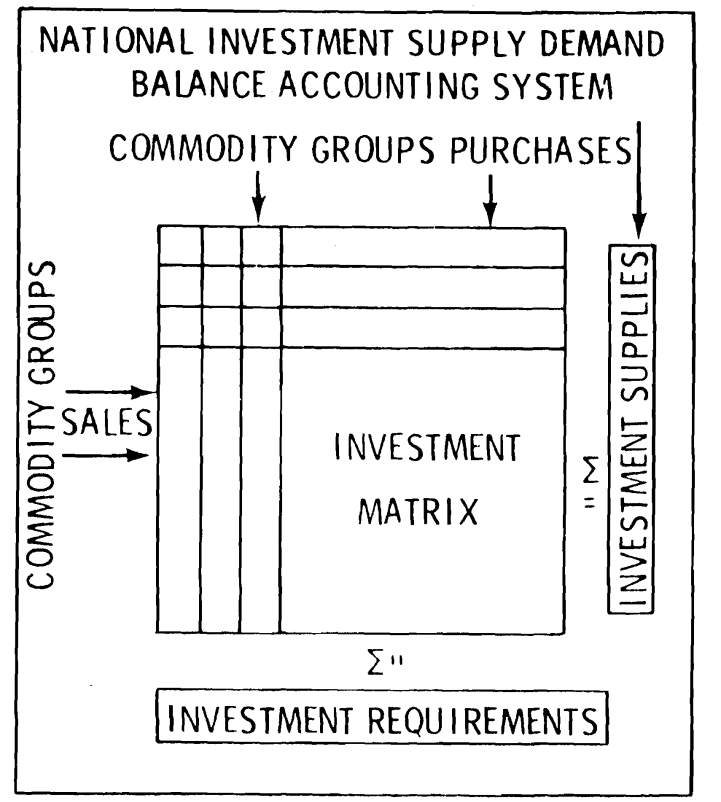

FIGURE 6. Matrix for Converting Forecasts of Purchases of Commodities to Investment Supplies for Use in EXPLOR Model

One may note that, under normal conditions, all sectors make investments (they have investment requirements), but not all sectors supply investment goods; e.g., service sectors usually do not provide investment goods and thus the sum of investment supplies will zero for some rows.

Steps 11 and 12: Domestic Market and Imports

Imports are directly related to the domestic consumption or the domestic market. In EXPLOR the domestic market is defined as the total consumption occurring within a country and includes government, private, and industrial consumption; that is,

$$
D M=I 0+P E+G S+I
$$

where

$$
\begin{aligned}
& \text { DM }=\text { domestic market } \\
& I 0=\text { intermediate output }
\end{aligned}
$$




$$
\begin{aligned}
P E & =\text { private expenditure } \\
G S & =\text { government spending } \\
I & =\text { investment supplies } .
\end{aligned}
$$

Imports for each sector are calculated or forecasted within the EXPLOR model. The value of imports is obtained using the domestic market previously calculated and a ratio of imports to domestic market. The ratio was previously forecasted and reflects anticipated changes in trade flows as well as recent trends in the ratio of imports to domestic consumption.

For this analysis the methodology used in forecasting of crude oil and refined products was an exception to the previously described process. In this study alternative energy sources were assumed to be developed, to supply a portion of the Nation's energy requirements, and, in turn, to reduce our imports of crude oil or refined oil products. In addition, for this analysis domestic production and total consumption were held constant. Thus, imports become dependent upon the Nation's ability to find alternative energy sources and less dependent upon its consumption and production of crude. For these sectors EXPLOR forecasts import requirements through an iterative process.

\section{Step 13: Exports}

The EXPLOR program regards exports as proportional to output; that is, as a country's production increases, its exports increase and vice versa. This assumption holds because, as a country's production increases, prices can be decreased without eroding profits, products become more attractive to importing countries, and, in turn, exports increase as production increases.

In EXPLOR, export to total output ratios are forecasted. Again, the forecasted ratios reflect any anticipated changes from historical trends which have been generally smooth. The ratios are forecasted for target years and usually have a minimal variation from target year to target year. Exports are thus calculated by multiplying the export ratio by total output. 
Step 14: Net Final Demand

Net final demand can now be calculated by summing the previously forecasted private consumption, government spending, investment supplies, exports, changes in stocks, and subtracting imports; i.e.,

$$
N F D=P E+G S+I+C S+X-M
$$

This completes one computational sequence with the model and a forecast of net final demand is available. The new net final demand is used in Step 1 and an iteration is begun. Additional interations are performed until a solution is obtained which satisfies the convergence constraints placed upon total output, profits, and prices. (The constraints are usual1y $\leq 0.5 \%$.) 
THE LINEAR EXPENDITURE SYSTEM SUBMODEL

The annual time series data on consumer expenditure data were analyzed in EXPLOR Phase I model as one of the submodels in the overall economic system. The submodel included analysis of 30 to 70 linear expenditure function categories, called spending functions, depending upon the available data. This analysis covers the 10 EXPLOR countries and the data used represent a series of up to 20 years.

The linear expenditure system (LES) submodel is used in EXPLOR to forecast private consumption expenditure by commodities. Although the LES has the highly desirable trait of complete cross-elasticity among all household commodities, it is possible for essential levels of activities distributed over a number of commodities to fall below acceptable levels when price changes are dramatic. An example would be the transportationoriented activities where gasoline, automobile, and public transportation costs may all rise simultaneously resulting in a decline in usage of all three, when in fact, a substitution of mass transient for automobiles should occur. By grouping commodities with like functions into sub-LES categories, this deficiency may be effectively overcome.

\section{ESTIMATION OF THE LES COEFFICIENTS}

The main purpose of the LES submodel is to forecast private consumption for numerous commodities. These forecasts are based on two parameters which the function estimates. The ' $c$ ' parameters, the so-called "committed expenditures," represent a kind of minimum need in that the consumer feels he must acquire at least this amount of the various spending function categories. The ' $b$ ' parameters, so-called discretionary expenditures coefficients, distribute the remainder of the consumer's purchasing power (supernumerary income) after the consumer has settled on what he considers to be his minimum amount of purchase for each consumption group of commodities. The equation used for estimating consumer expenditure by spending function utilizes the above information and divides the total expenditure into committed and discretionary expenditures. The actual equation used in estimating consumption is given in the following: 


$$
q_{j}=c_{j}+\left[\frac{R-\sum_{i} c_{i} \cdot P O P}{P O P}\right] \frac{b_{j}}{p_{j}} / \sum_{i} \frac{b_{i}}{p_{i}}
$$

where

$q_{j}=$ Per capita expenditure for spending function ' $j$ ' (total of committed plus discretionary).

$\mathbf{C}_{\mathbf{j}}=$ Per capita committed expenditure.

$R=$ Total expenditure by the population $\left(q_{j} \cdot P o P\right)$.

PoP = Population

$p_{j}=$ Price of commodity group ' $j$ '.

$b_{j}=$ Fraction of discretionary expenditure spent in commodity group ' $j$ '.

Total per capita expenditure of spending category ' $j$ ', which cons ists of ' $c_{j}$, the committed expenditure, is represented by $q_{j}$. The remaining term in the expenditure represents the discretionary expenditure distributed in proportion to the term ' $b_{j} / p^{\prime}{ }_{j}$. The LES parameters ' $c$ ' and ' $b$ ' are estimated by using the nonlinear method of estimation as the coefficients $b$ and $c$ appear in nonlinear form. (a) As can be seen from the equation, the discretionary expenditure is price sensitive.

\section{VALIDATION OF THE LES RESULTS}

The ' $b$ ' and ' $c$ ' parameters were estimated for the U.S. economy using 39 spending functions and 17 years of annual data for the years 1957-73. The last three years 1971, 1972 and 1973 were omitted from estimation. The results for these years were forecast on the basis of the data for the previous 14 years and were compared against the actual data. Table 1 gives a comparison of actual and calculated total per capita expenditure

(a) For a detailed discussion of the methodology, see "A Description of the Methodology Used for EXPLOR Multitrade-85, Phase I", Battelle Publication, May 1974 (Ref. 8). 
ผ 의

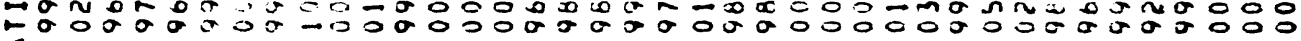
$\therefore$

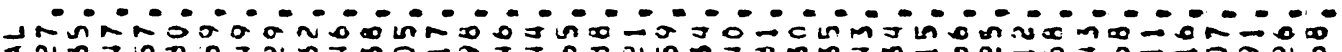

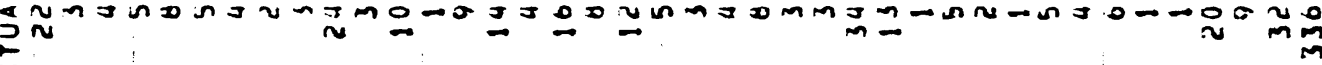
ษ

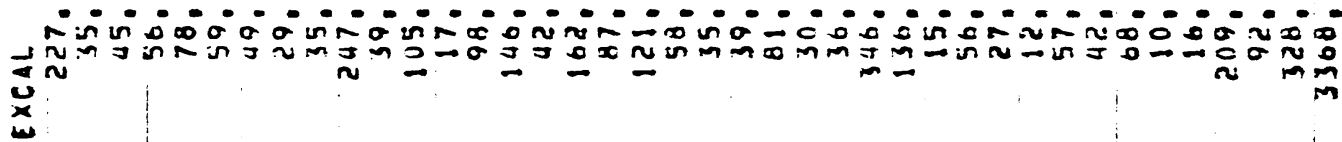

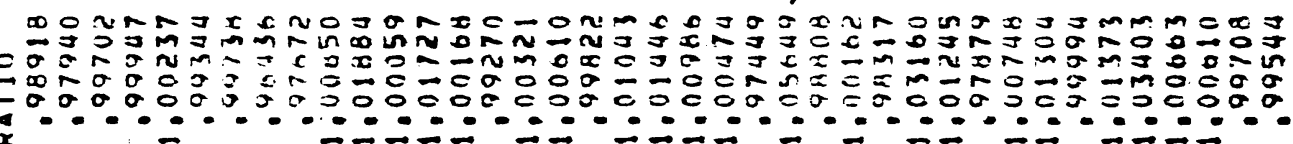
$\underset{\substack{n \\ \frac{a}{x}}}{\frac{N}{2}}$

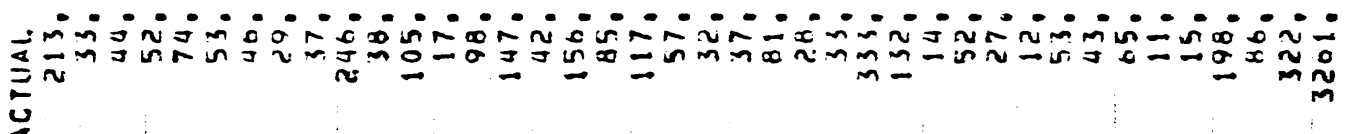

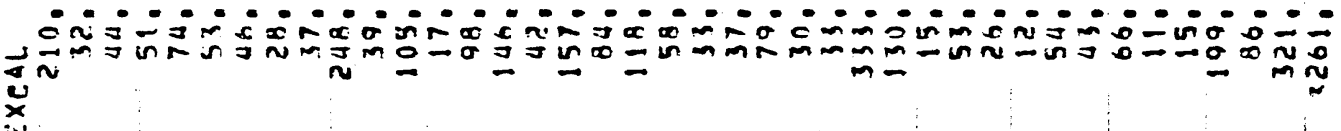

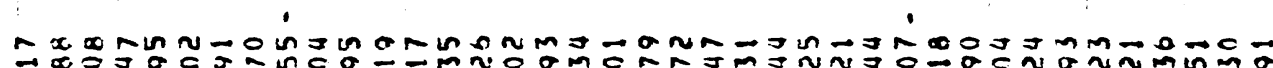

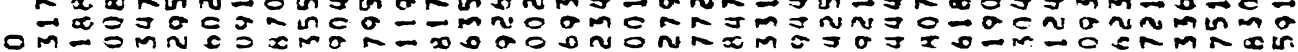
w

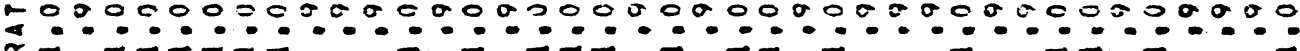

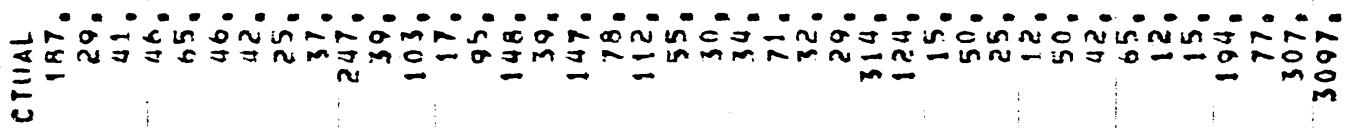

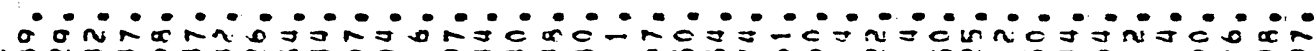

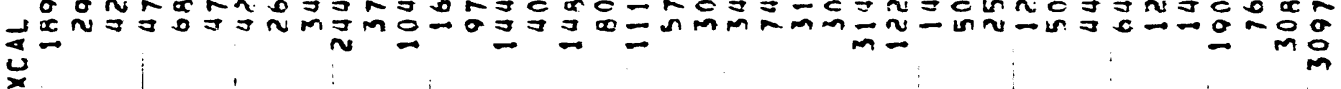
w

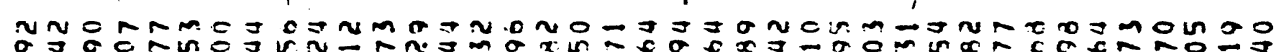
c

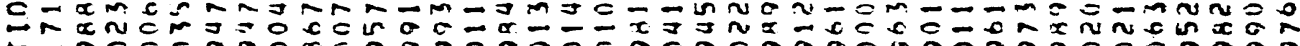
с

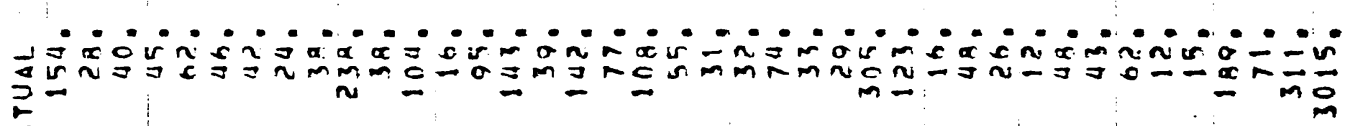
ús

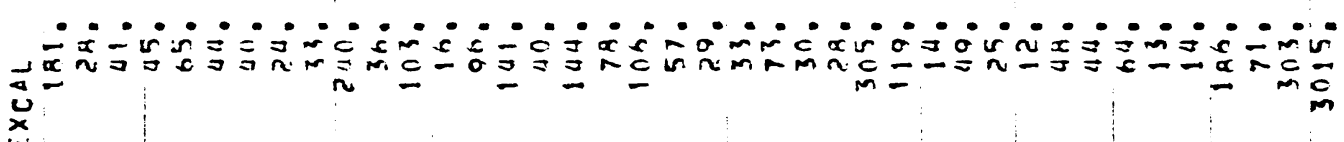

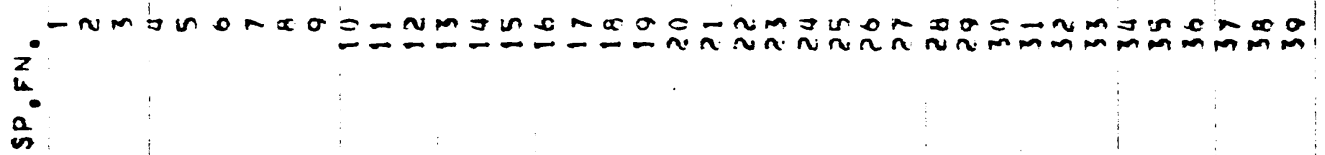


by 39 spending functions for these years. For the test years (1970 through 1973) the estimated results were very close to the actual values in most cases; the difference being $\pm 2 \%$. Only in a couple of cases is the difference as large as $4 \%$.

The LES forecasts were also compared against similar forecasts prepared using other techniques. For the comparison, the LES coefficients were used to prepare a forecast for 1979. The results were then compared against forecasts prepared by NPA ${ }^{(9)}$ and Houthaker and Taylor. (10) (A11 forecasts were based on similar assumptions of macro economic growth and prices.) The results of the LES and NPA forecasts compare very well and are given in Table 2. for selected commodities. Forecasts for the other commodities agreed similarly.

TABLE 2. Comparison of Battelle and NPA Personal Expenditure Projections for 1979(a)

(1970 Constant \$ Million)

\begin{tabular}{lcc}
$\begin{array}{c}\text { Selected } \\
\text { Expenditure } \\
\text { Category }\end{array}$ & $\begin{array}{c}\text { Battelle } \\
\text { Projections } \\
1979\end{array}$ & $\begin{array}{c}\text { NPA } \\
\text { Projections } \\
1979\end{array}$ \\
\cline { 2 - 2 } Electricity & 14,708 & 14,832 \\
Food & 155,848 & 167,041 \\
Autos (New and Used) & 58,306 & 53,217 \\
Dwellings & 128,123 & 128,402 \\
Gas and Water & 10,060 & 9,717 \\
Clothing & 62,926 & 63,455 \\
Tires and Parts & 10,094 & 9,092 \\
Gas and 0i1 & 28,716 & 30,320 \\
Total Expenditure & 878,614 & 878,614 \\
(\% Annual Growth Rate) & $(4.00 \%)$ & $(4.00 \%)$ \\
& & \\
Ta) Based on same assumptions on growth and prices. &
\end{tabular}


IMPROVED FORECASTING

During periods of escalating prices, consumers usually search for a means of substituting less expensive goods for more expensive commodities. PNL desired to evaluate the relative savings and economic impact of changes in consumer patterns during the recent years when oil prices quadrupled. This type of analysis would reflect the savings in energy at the final demand, changes in balance of payments, etc., level during periods of rapid price increases for major forms of energy. To achieve this analysis, PNL expanded LES to better reflect rapid, major price increases. As the LES is currently designed, it has complete cross-elasticities among all commodities; that is, a price increase in one commodity causes a change in the consumption of all other commodities. This is a desirable trait except in times of cartels such as OPEC when prices increase frequently and to unprecedented levels. During these times of rapid price increases, it is possible for the LES to forecast unacceptably low levels of consumption of some commodities due to the LES's high dependence upon price. Also of concern was that, with rapid increases in the price of gasoline, for future years the LES might predict a reduction in purchase of all forms of transportation without adequate substitution of mass transit, etc. for the private automobile. Consequently, the system might forecast consumption of inadequate levels of all forms of transportation.

PNL addressed this problem of substitution, anticipating that the LES could be improved to reflect desired levels of substitution within general groups during periods of rapid price increase. A series of experiments and tests were designed to check the systems ability to project substitution The first effort was to regroup the 39 commodities describing private consumption into eight broad groups of similar classification (Table 3 ). Each of the 39 elements contained in each of the eight broad groups is also specified.

FORECAST FOR EIGHT MACRO GROUPS

The private expenditure data were aggregated into eight groups representing similar commodities. The aggregation was completed according 
TABLE 3. Definition of Macro Groups in Terms

of 39 Micro Groups for United States

Broad Group

1. Food and Tobacco Products

2. Clothing and Shoes

3. Housing

4. Durable Furnishings and Appliances
Micro Group

10. Mean and Dairy Products

11. Poultry and Eggs

12. Fruit and Vegetable Products

13. Fats and 0ils

14. Misc. Food N.E.S., Including Bakery and Cereal Products

15. Purchased Meals and Beverages

20. Tobacco Products

16. Shoes and 0ther Footwear

17. Women's \& Children's Clothing and Accessories

18. Men's and Boy's Clothing \& Accessories Including Military Pers. Clothing

26. Owner-Occupied Dwellings

27. Tenant-0ccupied Non-Farm Dwellings

28. Misc. Housing Repair, etc.

33. Misc. Housing Operations

(Moving, Warehousing, Insurance, etc.)

3. Furniture Including Mattresses and Bedsprings

4. Kitchen and 0ther Household Appliances

5. Kitchen, Glasswares, Utensils and Other Durable Furnishings

6. Radio, TV, Records, and Musical Instruments

7. Opthalmic \& Orthopedic Appliances, Drug Preparations and Sundries

8. Wheel Goods, Toys \& Pleasure Aircraft

9. Misc. Durable Goods (Jewelry, Watches, Books, Maps \& Durable Toys) 
5. Nondurable Furnishings \& Appliances

6. Utilities

7. Automobile and Transportation

8. Business and Personne1 Services
21. Toilet Articles \& Preparations

22. Semi-Durable House Furnishings

23. Clean, Polish., \& Misc. Supplies \& Paper Prod., Including Misc. Nondurable Goods

24. Other Fuel \& Ice

25. Nondurable Toys \& Sports Goods

29. Electricity

30. Gas

31. Water \& Other Sanitary Services

32. Telephone (Telegraph)

1. New Cars \& New Purchases of Used Cars

2. Tires, Tubes, Accessories \& Parts

19. Gasoline and $0 i 1$

34. User Operated Transportation Services

35. Purchased Local Transportation Services

36. Purchased Inter-City Transportation Services (Rail, Bus, Airlines, etc.)

37. Medical Care Services (Including Physicians, Dentists and Others)

38. Services Furnished W/O Payment by Financial Intermediaries Except Insurance Comp.

39. Misc. Services N.E.S. (Health, Hosp., Private Educ. \& Research, and Prof. Service) 
to the definition of categories indicated in Table 3. Using the aggregated data, the LES program was rerun as if consumers spent the same amount of money, but only purchased eight different commodities. This experiment was conducted as an attempt to improve the forecasting ability of the LES during periods of rapid price increases. Forecasts for the eight macro groups were developed and compared with historical data for 1970, 1971, 1972 and 1973. In addition, the results of macro forecasts were compared with the sum of the forecast values for micro groups \#10, 11, 12, 13, 14, 15 and 20. The results of each of these forecasts and the historical values are provided in Table 4 for 1971 through 1973.

With the exception of 1970, the forecasts for the macro groups represent a slight improvement over the accumulated forecasts of the appropriate commodities selected from the 39 commodities.

An evaluation of the LES forecasts within the macro groups was also completed to determine if the forecasting ability of the LES could be improved by grouping the historical data. For this analysis each macro group was run as if it represented the total private expenditure. For this analysis the LES program was run eight times using the appropriate share of total expenditures for each of the macro groups. The results of these forecasts for macro groups 1, 3, 6, and 7 are provided in Table 5 . Generally, the results obtained from this forecast were a slight improvement over the original LES forecasts. Forecasts for macro groups 2, 4, 5 and 8 were also prepared and a slightly more accurate forecast obtained. Additional research should be conducted to evaluate the statistical significance of these improvements.

\section{POSSIBLE FUTURE USES OF LES SUBMODEL}

Individual commodity expenditure forecasts can be analyzed in depth with an emphasis on evaluating the impact of rapid, significant price changes and the resulting substitution in private consumption expenditure patterns. The complete cross-elasticity of LES has been desirable during eras with small uniform price changes. Recent changes in the cost of energy and food, however, have neither been slight nor uniform. The 
TABLE 4. Comparison of Private Expenditure Forecasts for Eight Macro Groups, Summation of 39 Groups and Historical Data for the United States(a)

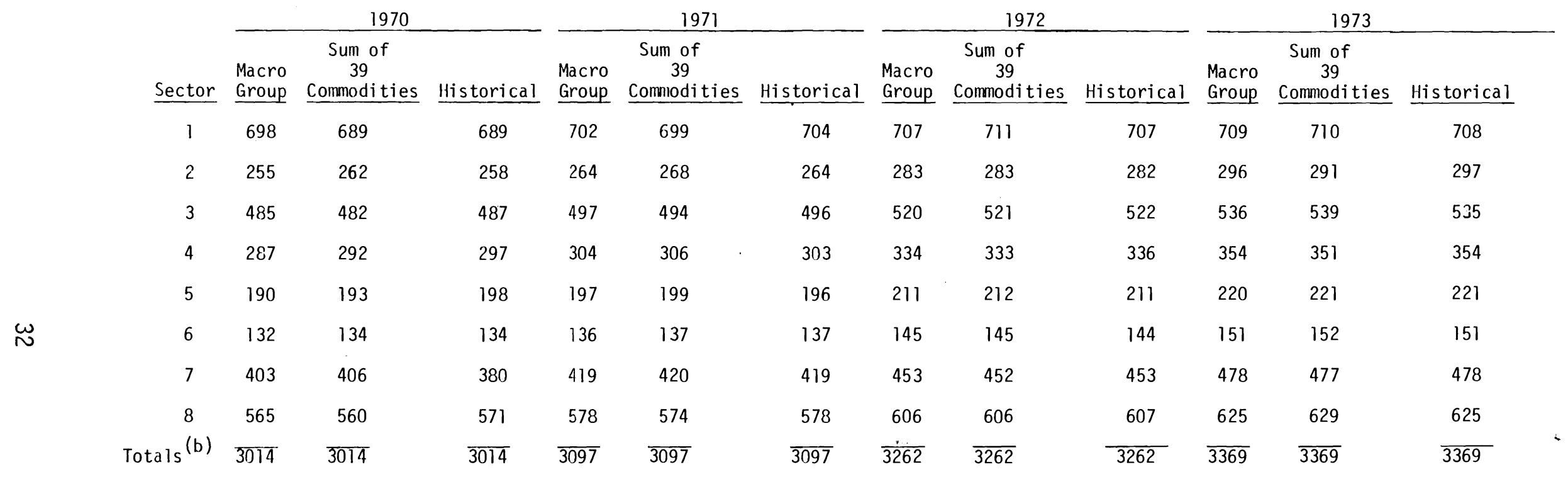

(a) Forecasts prepared using the LES and data for 1963 through 1973.

(b) All totals are equivalent to historical values, however, the individual values do not equal the total due to rounding of individual values. 
TABLE 5. Comparison of Private Expenditure Forecasts for Elements in Macro Groups with Forecasts for Each of the 39 Commodities for the U.S.

Macro Group \#1

Food and Tobacco Products

\begin{tabular}{|c|c|c|c|}
\hline & & 1970 & \\
\hline ector & $\begin{array}{l}\text { Macro } \\
\text { Group }\end{array}$ & $\begin{array}{c}39 \\
\text { Commodities }\end{array}$ & Historical \\
\hline
\end{tabular}

$\frac{10}{10}$ Grou
1971

Macro 39

Group

238
38
104
16
95
143
55
$\frac{689}{689}$

$\frac{55}{689}$

246
38
103
16
95
149
55
704

Commodities

$\begin{array}{r}244 \\ 37 \\ 104 \\ 16 \\ 97 \\ 144 \\ 57 \\ \hline 699\end{array}$

Historical

Macro

1972

39

Group Commodities Historical

Macro

1973

247
39

247

248
39
105
17
98
145
58
711

Group Commodities Historical

103
17

95

148

$\frac{55}{704}$

395
17

99

145

$\frac{56}{708}$

Macro Group \#3

Housing

$\stackrel{\omega}{\omega}$

$\begin{array}{crr}26 & 308 & 305 \\ 27 & 120 & 119 \\ 28 & 15 & 14 \\ 33 & 45 & \frac{44}{482} \\ \text { Total } & \frac{488}{488} & \end{array}$

$\begin{array}{rrr}305 & 315 & 314 \\ 123 & 123 & 122 \\ 16 & 15 & 14 \\ \frac{43}{487} & \frac{45}{488} & \frac{44}{494}\end{array}$

\begin{tabular}{rrr}
314 & 333 & 333 \\
124 & 130 & 130 \\
15 & 14 & 15 \\
42 & $\frac{43}{520}$ & 43 \\
\hline 496 & & 521
\end{tabular}

$\begin{array}{rrr}333 & 345 & 346 \\ 132 & 134 & 136 \\ 14 & 15 & 15 \\ \frac{43}{522} & \frac{42}{536} & \frac{42}{539}\end{array}$

$\begin{array}{r}247 \\ 39 \\ 105 \\ 17 \\ 98 \\ 146 \\ 58 \\ \hline 710\end{array}$

$\begin{array}{r}246 \\ 38 \\ 105 \\ 17 \\ 98 \\ 146 \\ 59 \\ \hline 708\end{array}$

Macro Group \#6

$\begin{array}{rr}29 & 49 \\ 30 & 25 \\ 31 & 12 \\ 32 & \frac{48}{134}\end{array}$

$\begin{array}{rrr}49 & 48 & 50 \\ 25 & 26 & 25 \\ 12 & 12 & 12 \\ \frac{48}{134} & \frac{48}{134} & \frac{50}{137}\end{array}$

$\begin{array}{r}50 \\ 25 \\ 12 \\ 50 \\ \hline 137\end{array}$

\begin{tabular}{rr}
50 & 53 \\
25 & 26 \\
12 & 12 \\
50 & 53 \\
\hline 137 & $\frac{144}{144}$
\end{tabular}

$\begin{array}{rr}53 & 53 \\ 26 & 26 \\ 12 & 12 \\ \frac{53}{144} & \frac{54}{145}\end{array}$

$\begin{array}{r}52 \\ 27 \\ 12 \\ 53 \\ \hline 144\end{array}$

\begin{tabular}{rr}
55 & 56 \\
27 & 27 \\
12 & 12 \\
57 & 57 \\
\hline 157 & $\quad \frac{152}{157}$
\end{tabular}

56
25
12
58
151

Macro Group \#7

Automobile and Transportation

$\begin{array}{rrr}1 & 166 & 181 \\ 2 & 25 & 28 \\ 13 & 101 & 106 \\ 34 & 62 & 64 \\ 35 & 14 & 13 \\ 36 & \frac{13}{381} & \frac{14}{406}\end{array}$

\begin{tabular}{rr}
154 & 190 \\
28 & 29 \\
108 & 110 \\
62 & 64 \\
12 & 12 \\
15 & 14 \\
\hline 380 & 419
\end{tabular}

$\begin{array}{rrr}187 & 212 & 210 \\ 29 & 32 & 32 \\ 112 & 117 & 118 \\ 65 & 66 & 66 \\ 12 & 12 & 11 \\ \frac{15}{419} & \frac{15}{454} & \frac{15}{452}\end{array}$

$\begin{array}{rrr}213 & 228 & 227 \\ 33 & 35 & 35 \\ 117 & 120 & 121 \\ 65 & 67 & 68 \\ 11 & 11 & 10 \\ 15 & \frac{16}{477} & \frac{16}{477}\end{array}$

$\begin{array}{r}227 \\ 35 \\ 121 \\ 68 \\ 11 \\ 16 \\ \hline 478\end{array}$


existing forecasting technique can be further improved to study the impact of rapid price changes or rationing. The objective of the research would be to improve the system such that proper substitution can occur and that one's required level of consumption is satisfied. The LES forecasting system is, in fact, price sensitive and this property could be used extensively to develop effects of price changes upon substitution of consumption expenditure.

\section{DISAGGREGATION OF SELECTED ENERGY USING SECTORS}

The data base used for Japan in Phase I of EXPLOR MULTITRADE-85 was designed to have general appeal for a cross-section of sponsors that included large, multinational, multiproduct firms and government agencies. This data base, coupled with the advanced input/output and econometric techniques incorporated into the EXPLOR MULTITRADE-85 mode1, proved to be useful to the sponsors in simulating the economies of EXPLOR countries into the future. However, designing the data base for general appeal required compromises as to the level of disaggregation in some areas of the economy. On the other hand, the EXPLOR model was designed to handle any level of disaggregation and to be sufficiently versatile to handle special studies of interest to individual sponsors.

To develop the capability of analyzing Japan's future energy requirements relative to the world and the U.S., PNL reworked the Japanese data base used in Phase I of EXPLOR to include a disaggregation of energy sectors and a disaggregation of other sectors of the economy that were deemed to be intensive energy users. (The energy sectors are discussed in the next section.) The Japanese data base was disaggregated so that six specific energy-intensive sectors would stand alone. The six sectors along with their respective new sector numbers are listed in Table 6 .

Petroleum products $(\# 28)$ and coal products $(\# 29)$ are two other energy intensive sectors which also exist in the EXPLOR Japan model. (Similar energy intensive sectors also exist for six other EXPLOR countries.) The disaggregation allows the sponsor the option of conducting impact analys is with the EXPLOR model to identify the results of policy changes or parameter 
TABLE 6. Disaggregated Energy Intensive Sectors

\begin{tabular}{lc}
\multicolumn{1}{c}{ Sector Name } & Japan EXPLOR Sector Number \\
\cline { 2 - 2 } Plastics \& Syn Resins & 49 \\
Basic Iron \& Steel & 31 \\
Glass \& Glass Products & 51 \\
Fertilizer & 40 \\
Industrial Chemicals & 26 \\
Other Chemicals & 27
\end{tabular}

changes and in general how these changes might affect important individual sectors of the Japanese economy. For example, we may want to know the effect of forced fuel substitution on Sector 31 (basic iron and steel). This change would be effected by changing technical coefficients representing the changing sales of fuel to Sector 31 . At the same time the investment matrix would be changed to represent either the retrofitting of oil boilers and/or investment in new boilers which will be needed to accommodate the fuel change. Other changes would also be made to the rest of the data base but can be ignored in this discussion. If the EXPLOR model is now run with the adjusted data, the savings (if any) in the fuel can be determined. What may appear, at least in the short run, is instead of a saving there is an increased use of the fuel in question. The reason being, in this case, the increased investment in boilers which are energy intensive in their production.

To sum up, the disaggregation of the data base allows use of the power of input-output analys is to capture all secondary effects of any action taken by individual sectors, either by their own initiative or because of government policy, on the entire economy.

\section{DISAGGREGATION OF SELECTED ENERGY PROVIDING SECTORS}

In addition to the disaggregations described above, the data base was reworked so that the sectors listed in Table 7 would be in separate sectors. 
An identical set of data was developed for each sector. The names of each element of the data set are listed below:

Investment Requi rements \& Supplies

Total Domestic Output

Production Price Index

Wage Compensation

Land Rent

Employment

Column Sum of "A" Matrix

Change in Stocks

Exports

Imports

Import Price
Technical Coefficients

Gross Profits

Taxes

Subsidies

Private Consumption

Nonproductive Investment (Dwellings)

Government Spending

Intermediate Input

Intermediate Output

Population

(With the exception of population, data for each sector and the summation of the sectors are provided.)

Each of the new sectors will be included in any future economic analysis of the Japanese economy. As in all EXPLOR forecasts, a forecast will include for each sector values of total output, intermediate output, net final demand, imports, exports, investment requirements, profits, prices, employment, productivity, etc.

The EXPLOR MULTITRADE-85 model was run using the new expanded data base for Japan 1975, the added energy intensive sectors, as well as the power generating results. The results for all sectors (currently 55) for 1975 are contained in Appendix C. The computer analysis was completed to test the validity of the expanded data base required to represent the added sectors. The forecast reflects a scenario based upon a GNP growth rate of $5.4 \%$ per annum which is a close approximation to reality $(5.3 \%)$ for Japan during the 1970 through 1975 time period. This computer run was made as a test case to "debug" the data base changes to determine if all changes were incorporated into the data base successfully. It is included here for illustration only. At present, the Japan data base 
contains a total of 55 sectors including the disaggregations described here. It has been "debugged" and is available for impact runs for analyzing Japan's energy future.

A look at the partial EXPLOR output in Appendix $C$ will give the reader an awareness of what is available from EXPLOR. This output contains 30 separate reports for the 55 sectors in the Japanese economy ranging from intermediate outputs, net final demand and total production (p. $c-1$ ) to productivity, volume taxes and subsidies which are shown on the last page. Each report gives a value for the current year and the preceding EXPLOR year (i.e., in this report 1970) plus the growth rate between the two time periods where applicable. Where a growth rate is meaningless (e.g., from a plus value to a negative value) asterisks are printed. Also available, but not printed for this example, are commodity sector analysis reports which devote one entire page to desired sectors. These reports show all interindustry transactions (i.e., sales and purchases), both for commodities consumed in production and for investment goods and 111 results from the 30 reports discussed above which relate to the given commodity sector. 


\section{JAPANESE DATA BASE ANALYSIS}

Without actually analyzing specific scenarios for the evolution of the Japanese situation, some observations can be drawn from the existing EXPLORJapan data base. By far, the most important single factor about the Japanese economy is its tremendous dependence on importina new materials and exporting manufactured goods. Of all of the industrialized nations, Japan is the most dependent on energy from imported sources. Ninety-eight percent (p. C-4, Appendix C) of al1 crude oil is imported and nearly $80 \%$ of coal requirements and 100\% of uranium. Other raw materials with high import rates are: iron ore, 100\%; nonferrous ore, $92 \%$; forest products, $38 \%$; and agricultural grains, $25 \%$. The percentage of agricultural products imported is increasing at $3 \% / \mathrm{yr}$, while forest products increase at $4 \% / y r$. The primary exports of Japan required to pay for these imports are motor vehicles, representing $15 \%$ of all exports, followed closely by transportation equipment, primarily ships, representing $14 \%$ of all exports. The remainder of their exports is fairly evenly distributed over a wide range of manufactured equipment and chemicals. The U.S. is the largest single importer of Japanese goods, almost entirely in the form of manufactured goods. These goods are found to be sensitive to price competition in the U.S. and in most other countries importing Japanese goods. This is in marked contrast to the Japanese situation with regard to import price sensitivities. Due to their strong dependence on imports, price increases for raw materials have had very little effect on the Japanese demand for these materials. This set of conditions requires that Japan be relatively more efficient in the process of converting raw materials into manufactured goods than any other developed economy. Over the past 20 years, this has essentially been the case - during the first 10 years of this period primarily through lower labor costs and, in more recent years, through more extensive capital investment. Relative to the U.S. and in most other developed countries, the share of GNP which Japan reinvests in new capital facilities, primarily for manufacture of export goods, is twice the rate as in the U.S. (18\% versus $37 \%$ for 1973). 
The Japanese must convert raw materials (i.e., fuels) into electricity and eventually manufactured products at a rate that is more efficient than other competing countries which may have more alternative fuel sources available to them.

Two factors used in EXPLOR describing the relative production efficiencies are the productivity of labor and the investment-to-output ratios. The productivity in motor vehicle manufacture is 7.37 billion yen per 1000 employees and has improved at a rate of nearly $5 \% / y r$ since 1970 as compared to the U.S. which produces $\$ 63.5$ million per 1000 employees and improving at $2 \% / y r$. Similar comparisons exist for electric machinery, another one of Japan's large export categories, where the productivity is 6.8 billion yen per 1000 employees and increasing at the rate of $4.3 \% / \mathrm{yr}$.

With the EXPLOR data base for two countries (i.e., Japan and the U.S.), many such comparisons and analyses can be made from the available data wi thout actual simulation studies. 


\section{TABLE 7. Disaggregated Energy Providing Sectors}

\begin{tabular}{lc}
\multicolumn{1}{c}{ Sector Name } & Japan EXPLOR Sector Number \\
Coal & 5 \\
Crude 0il & 8 \\
Electric (0il) & 42 \\
Natural Gas & 52 \\
Electric (Coal) & 53 \\
Electric (Nuclear) & 54 \\
Electric (Hydro) & 55
\end{tabular}

The rows of the technical coefficient matrix ("A" Matrix) for the electric sectors $(42,53,54 \& 55)$ change over time in proportion to the relative shares of fuels in the total generation of electricity. The percentage of each source of energy in the production of electricity for 1970 is shown in Table 8. Also shown is an estimate of these shares for 1975.

\section{TABLE 8. Japan Electric Power Generation} By Source of Energy (\%)

\begin{tabular}{lrr} 
& \multicolumn{1}{c}{1970} & $\underline{1975}$ \\
Coal & 5.8 & 6.1 \\
Oil & 68.5 & 65.3 \\
Hydro & 23.3 & 19.3 \\
Nuclear & 2.4 & 9.3
\end{tabular}

The rows of the "A" matrix Sectors 42, 53, 54, and 55 were upgraded from 1970 to 1975 using multipliers suggested by the changing percentage shares. With the addition of these new sectors to EXPLOR Japan, data for each of these sectors had to be collected, key punched and added appropriately to the data file. New data were required to describe how each of these sectors fit into the Japanese economy. Once the historical data for the seven added sectors were part of Japan's historical data base, individual forecasts for each of the added sectors were prepared using the EXPLOR model. 
APPENDIX A

\author{
PROPOSED METHODOLOGY FOR \\ EVALUATING INTERNATIONAL IMPACT \\ IMPLEMENTING NEW ENERGY TECHNOLOGY
}




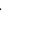

. 


\section{PROPOSED METHODOLOGY FOR \\ EVALUATING INTERNATIONAL IMPACT OF \\ IMPLEMENTING NEW ENERGY TECHNOLOGY}

\section{ORGANIZATION FOR EVALUATION}

A methodology for the evaluation of international energy economics is proposed which integrates the capabilities of BNL, LLL, PNL, VPI, and RAND. This plan requires a cooperative effort and should achieve an in-depth, systematic evaluation of the economic impacts of new or improved technology relating to important aspects of energy. In addition, the proposed laboratory cooperation will avoid duplication of efforts which might occur if the laboratories worked independently.

By integrating the capabilities and experience of each organization a a total, in-depth impact of an R\&D or policy change can be determined. For example, demand oriented models assume that adequate supply will be available. Conversely, supply oriented models usually assume that desired level of demand will develop. By linking a supply and demand model the need for exogenous data and assumptions can be minimized. The proposed methodology is to loosely link EXPLOR, LORENDAS, and BNL models with supporting research provided by LLL and RAND. This integration should allow the results of each laboratory to be used by other laboratories and thus eliminate or minimize the need for exogeneous inputs.

Figure A-1 illustrates the major elements of the proposed organization for integrating the research of the respective laboratories and the research or results to be provided by each. (Organizations to be involved and the lab with lead responsibility, noted with an asterisk, are also suggested in Figure $A-1$. )

The program begins with a definition of the base scenario which includes the anticipated economic status of each country or region in the analysis (block 1). The national economic growth rates, degree of energy independence and OPEC price assumptions are particularly important. 
FIGURE A-1.

Organization of Laboratories for

Evaluation of International Economics

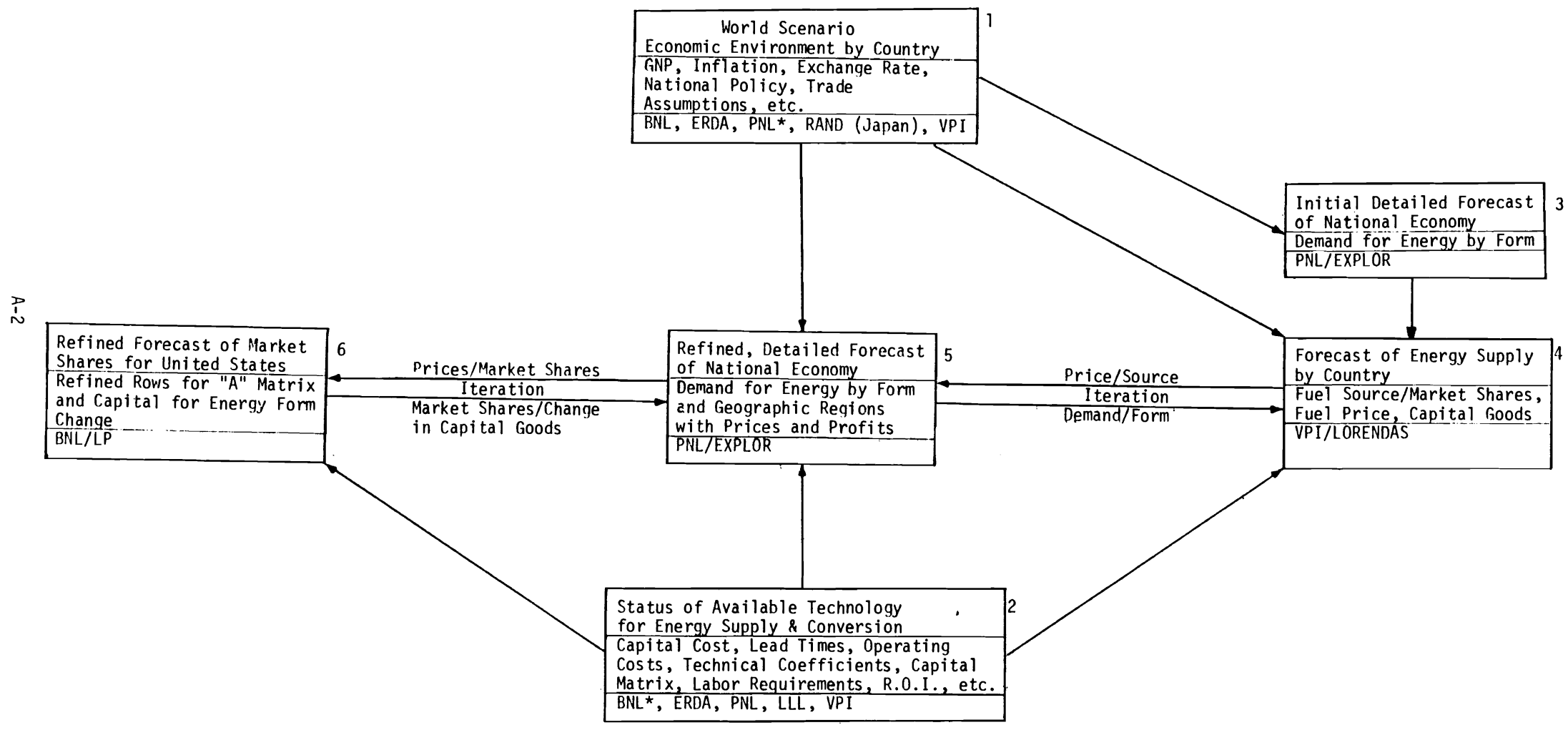


The status of technology expected to be available for energy supply and conversion must be projected early in the program (block 2). BNL should lead this activity with support from the other four organizations and ERDA. The status of technology should be described in terms of capital costs, lead times, operating costs, technical coefficients, labor requirements, return on investments (ROI), etc. Appropriate values and results could then be supplied to blocks 4, 5, and 6 .

With the scenario defined and the status of technology projected, PNL would provide an initial forecast for each country's economy for the specified years. The forecast would include the usual macro-variables such as GNP, population, balance of payments, etc., as well as providing a detailed economic description for important sectors of each nation's economy (block 3 ).

VPI would use these forecasts to estimate energy supply by form and geographic region for the initial forecast of demand (block 4). This forecast of energy supply (via the LORENDAS model) will provide fuel source, market share, fuel price, capital goods, etc. The results of the initial forecast of supply will be fed into block 5 .

Given input from blocks $1,2,3$, and 4 , PNL can develop a refined forecast of national economies and provide an improved forecast of demand for energy (block 5). The refined forecast will include demand for energy by form and geographic region with prices and profits.

The results of this forecast should then be fed back to VPI for one or more iterations. An improved projection of supply by souce of energy by country with prices would then be determined. The new supply projection would parallel the refined demand projection obtained in block 5 .

For treatment of the United States, one additional refinement to the market share is possible and should be provided. BNL via their LP model can refine projections of market shares coming from EXPLOR (block 5). BNL 
could use EXPLOR's estimates of prices and market shares for each form of energy. Using these data, BNL could refine the market shares and provide estimates of capital investments required to affect the change in market shares.

BNL's forecasts should then be supplied to PNL and be included in refining the forecasts of the U.S. economy. The refined forecasts of energy demand could then be fed to VPI for further refinement of their supply forecast. The exchange of output between PNL, BNL, and VPI should be done for at least one iteration.

\section{IMPACT STUDIES/QUESTIONS FOR ANALYSIS}

The proposed program is flexible and could be used for analys is of several energy based economic studies. Most of the impacts or questions to be evaluated will be changes in national policies or changes resulting from implementation of new energy technology. The impacts can be generally described in terms of economic parameters such as changes in employment, production, trade flows, GNP, etc. (See the section on results.) Most impact studies will cover a five to fifteen year period. Shorter time periods would not allow implementation of new technology.

The flexibility of the program will permit evaluation of a wide array of energy related subjects. A few subjects for study are suggested below. More subjects worthy of evaluation will evolve as the initial studies are completed. (The labs may wish to develop a prioritized list of subjects for analysis as one of their earliest items of business.)

\section{DEVELOPMENT OF NEW ENERGY TECHNOLOGY}

- Estimation of "relative value" to selected countries; e.g., the value of new coal technology to a country not possessing nor consuming large quantities of coal may be essentially zero. Alternatively, the same country might be keenly interested in 
the development of geothermal power. The relative value may be expressed in several forms such as increased energy independence, slower rate of increase in energy prices, improved trade balance, increased GNP, increased employment, etc.

- Importance of the time of development and rate of implementation.

- Equitable contractual arrangement for purchase or transfer of new technology; i.e., lump sum payment, royalties, gift, exchange in form of valued commodities, etc.

\section{U. S. ENERGY INDEPENDENCE AND POLICY CHANGES}

Increased energy independence can be achieved by the United States, but probably at an increase in "cost". Analysis can identify where the added costs might occur and how the effects of the added costs might be minimized. (The increased costs would increase consumer prices and also production costs. The increase in production costs would probably increase the cost of exported goods. This would lead to a reduction in export of goods, employment, production, relative value of dollar, changes in balance of payments and, in turn, revaluing of the dollar.) These added costs could be evaluated via the proposed program.

Some of the policy changes which could lead to increased energy independence are:

Limitation on Import of Energy Forms. This would require a concurrent stimulus to domestic producers who must be encouraged to increase domestic production to compensate for reduction in imports. If not, private consumption and/or industrial consumption must be curtailed which would restrict the nation's economic growth. A price increase could provide the stimulus. (A price increase is probably required because the market place usually provides goods at minimum costs.)

Price Increase/Profit Increase. The effect of a price increase or an increase in profit margin might be achieved in several ways. The 
obvious is to increase the price of energy to all consumers and let consumption readjust reflecting the new price. The price increase will probably increase profits. Other ways of increasing profits to energy producers can be implemented and the probable effects estimated. For example, tax policies applying to energy producers might be modified by one or more of the following:

- The depletion allowance might be increased for selected industries.

- Investment credits might be increased for energy industries.

- Changes in allowable depreciation schedules for investment in new energy recovery processes.

- Deregulation of price of energy in all forms.

- Increased tax at the private consumer level.

The first four items would provide incentives to increase production of domestic energy while the last example would reduce private consumption and allow more energy to be available for industry.

The impact of each of these suggested policy changes would be different while all would improve energy independence. For example, if the real price of energy were increased directly, production of all goods and services would diminish. The U.S. would also become less competitive in international markets if energy costs were greater in the U.S. than in other countries. Our exports would decrease, our balance of payments would become less favorable, and the dollar would need to be revalued.

Alternately, if a tax were placed on consumption to the consumer, private consumption of energy would decrease, and a more adequate domestic supply should be available for industrial production. The price increase to industrial users should also be less than if the price were increased to all. 
The impact of changing investment credits, depletion allowances, deregulation, and depreciation schedules is to increase the profit margins of the energy producers. This should provide incentives to invest in new energy conversion processes such as oil shale and make the nation less dependent. Alternately, revenues to government might decrease leading to deficit spending and more inflation.

An analysis could estimate the cost of additional storage, the materials required, and required supply to survive an embargo. In addition, the analysis could estimate the changes in balances of payments caused by increased imports of energy or the increase in exports necessary to avoid a change in balance of payments.

CHANGES IN NATIONAL POLICIES OF OTHER COUNTRIES

Two basic types of policy decisions should be evaluated. The first involves the OPEC countries and the second involves countries which are large consumers of energy.

OPEC

The OPEC countries are in a position to either change the supply or price of crude oil available for export. The impact of a reduction in supply would have essentially the same impact as if the United States restricted its imports (this was discussed in the previous section on energy independence). Assuming OPEC reduced their export of 011 products to all countries, the relative impact on each country would be in proportion to its dependence on imported energy. An assessment of these relative impacts could be performed and necessary reductions in production, consumption, employment, etc. identified.

An increase in price by OPEC would also affect each country in proportion to its dependence on imported crude $0 i 1$ and refined products. The price increase would affect each country's production, consumption, 
employment, etc. More importantly, an OPEC price increase would change a country's relative competitiveness in export markets; that is, export prices would probably reflect the increase in energy prices. Export goods from countries more dependent upon OPEC crude would be more costly and those countries would become less competitive in international markets.

The proposed program can project export prices including the impact of energy prices. The primary impacts could be a change in trading partners and increased prices of imported goods.

\section{OTHER TRADING PARTNERS}

The United States trading partners might change several of their policies in order to minimize the impact of their cost of energy. Some of the potential changes are:

- Change in form of taxation to reduce cost of products for exports; e.g., some countries do not collect value added taxes for products entering export markets. Other taxes might be modified to reduce export prices further, essentially subsidizing goods for export.

- Subsidized development of nuclear power. This would reduce a country's dependence on imported forms of energy. This reduction would reduce demand for OPEC 0il. If the reduction in demand were significant, OPEC might be forced to make concessions regarding price and supply to other countries. (The domestic impact of accelerated development of nuclear power could also be evaluated, if desired.) In any event the country with nuclear power would probably be competitive in international markets.

- Domestic tax on consumption. An increased tax on domestic consumption should diminish private consumption of energy and allow a larger percent to be available for industry. The private tax might also be used to subsidize industry and in turn allow them to improve their.competitive position in international markets.

\section{RESULTS OF ANALYSIS}

The proposed technique for evaluating energy economics is rather flexibie and in turn the results obtained from these studies would also be varied. The need for additional results will probably expand as the researchers gain additional insight into each problem. Table A-1 presents examples of 
critical results which would be provided routinely. Additional economic results could also be supplied upon request with probably no additional research.

TABLE A-1. Examples of Key Outputs and Results

General Category

1. New Technology

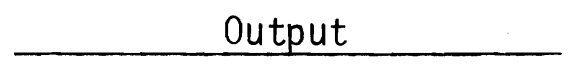

Market Share

Profitability

Capital Demands

Critical Materials \&

Equipment

Labor Requirement

2. Trade

3. Prices (Costs) by

Energy Form

\section{Energy Imported/Exported \\ Trade Balance \\ Trade of Capital Equipment for Energy Recovery \\ Probable Adjustment in \\ Exchange Rates}

Extraction

Conversion

Transportation

Distribution

ROI

Gasoline
Source

VPI, BNL

PNL, VPI

VPI, PNL, BNL

PNL

PNL

VPI

PNL

VPI

PNL

VPI

PNL, VPI

PNL, VPI

PNL, VPI

PNL, VPI

PNL

The primary value of these results is for impact analysis; that is, comparing the results of changes associated with a new technology or policy with the results of the base case. The results will also contain forecasts of national economies useful for making comparisons. The absolute values of the forecasts should be used cautiously, however, because development of a forecast was not of primary importance. Therefore, the accuracy of values within the forecasts are unknown. 


\section{DATA BASE REQUIREMENTS}

A few important data agreements will be needed before the proposed plan can be adopted and the work of the individual labs integrated. None of the items requiring change are technical in nature nor should they complicate using existing models for future research programs. Nevertheless, the 'following items will need agreement.

1. Definition and number of sectors.

2. Time and degree of new technology available.

3. Reference or base year.

4. Geographic regions of the world.

5. Computer facilities - type and possibly location of computer.

The laboratory indicated in parenthesis is suggested to have the responsibility of obtaining agreement among those laboratories directly involved. 
APPENDIX B

EXPLOR MULTITRADE

SEMINAR

AGENDA AND ATTENDEES 


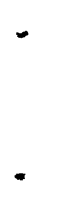


NAME

Lee Abramson

Philip M. Ritz

Ray Tessmer

Bi11 Marcuse

Bob 0lson

Glenn Gardner

Bud Tardiff

S.M. Worthington

Michael Pfetsch

James L. Kelley

Herbert A. Cochran

Ches Jesina

Charles M. Boudrye

Tom Foley

Marv Clement

Duane Deonigi

Jack Vanderryn

E. L. Salkin

J. L. McDonnel

C. W. Bullard
AFFILIATION

International R\&D Programs, ERDA

Bureau of Economic Analysis, Commerce 523-0683

Brookhaven National Laboratory

Brookhaven National Laboratory

LLL

APA-ERDA

AIA (IRDP), ERDA

AIA (IRDP), ERDA

Department of Commerce

Department of Commerce

Department of State, INR/REC/TR

FEA, International Energy Affairs

Management Science Systems/LORENDAS

Battelle

Battelle

Battelle

ERDA，IRDP

Federal Preparedness Agency

LLL

Univ. of Illinois
PHONE

$376-4322$

(516) 345-2002

(516) 345-2412

(415) 447-1100×4559

$376-4350$

$376-4323$

$376-4321$

967-3658

967-3986

$632-1187$

254-6770

(703)951-6506

(509)946- 2809

(509)946-2270

(509)946-2475

376-4319

343-8865

(415)447-1100X4561

(217)469-7227 
EXPLOR MULTITRADE SEMINAR

Outline of Presentation

to International Affairs

I. Introduction $(9: 00 \mathrm{am})$ *

A. History

1. Initiated at Battelle Geneva

2. 12 years and $\$ 3$ million investment

3. Seven European countries, Canada, Japan \& United States

4. Technology \& investment orientation

B. Status

1. National forecasts through 1985 completed (Phase I)

2. Forecasts of trade flows (Phase II) and special studies to be completed summer of 76

II. Flow of Mode 1

A. Introduction

B. Wigley production function, labor productivity, and labor force

C. Forecast of investment requirements

D. Computation of investment supplies via converter matrix

E. Computation of commodity production costs

Forecast of prices and profits via minimization routine

F. Computation of market prices and consumer prices via classification converter

G. Computation of net final demand

1. Private expenditure (PE)

2. Government spending (GS) and changes in stock $(\Delta S)$

3. Inves tment

Productive and non-productive

4. Imports (M)

5. Exports (E)

6. Taxes

*Proposed schedule of start times for major tasks are specified in parentheses. 
H. Computation of domestic production via Leontief Inverse, intermediate output (I0) via technical coefficients, and domestic market (DM) by summing PE + GS + I + IO.

(Break for soft drinks \& coffee in conference room at 10:40 am)

I. Discussion of open loops in mode1

1. Investment and savings

2. Government spending and revenue

3. Labor force and employment

III. Data Base

A. Common format for 10 countries

1. Limited by common denominator for data

2. Source: government publications. Reviewed for consistency and reformatted by Battelle

B. Specific elements

1. Private expenditure for 20-60 elements

2. Technical and capital coefficients for 43 to 79 national sectors

3. Components of final demand: $P E+G S+I+\Delta S+E-M$

4. Components of value added: employment income, aross profits, indirect taxes, subsidies

LUNCH

IV. Applications $(1: 30 \mathrm{pm})$

A. Introduction

1. Used by multinational firms and government agencies (Primarily policy makers and investors)

2. Results of Phase I

3. Evaluation of specific economic changes and impacts

4. Proprietary results 
B. Recent examples of applications of basic forecasts and special studies

1. Investment analysis utilizing sector analys is and re?ative growth rates

2. Evaluation of economic impact of pollution controls

3. Nuclear power expansion

4. Fuel substitution

5. Critical resource analysis

6. Import forecast

7. Price changes

8. Capital requirements and supplies

(Break for soft drinks and coffee)

V. Origin/Destination of World Trade (Phase II) (3:00 pm)

A. Introduction to Battelle's approach to forecasting world trade

B. Evaluation of existing trade data (origin/destination)

C. Cross impact survey and analysis; interviews with national authorities.

D. Use of 5 sector mini-model to account for each country's total economy and trade

E. Trade flows at 5 sector level

F. Expansion of trade flows to common 31 sectors

G. Expansion of trade flows at 31 sectors to country level (43 to 69 sectors)

VI. Open Discussion (4:00 pm) 
(SECOND DAY): Technical Discussion of Forecasting Techniques Used in EXPLOR and Validation of Results.

I. Private Consumption (LES) Forecast $(9: 00 \mathrm{am})$

A. Analysis and forecasting of private expenditure via linear expenditure system (LES)

1. Interpretation of LES equations and results

2. Importance of length of time series

3. Committed vs. discretionary consumption and changes with time

4. Comparison of elasticity coefficients

5. Comparison of forecasts vs. actual data and error analysis

B. Alternative approaches

1. Houthakker and Taylor

2. NPA, Clambering Through the Eighties, Vol. 2, Consumption and Industry Detail

3. LES - Cross elasticities and plans to evaluate subgroups or sub-LES categories to compensate for minimal uses during periods of large price increases as opposed to substitutions within groups.

(Break for soft drinks and coffee in conference room at 10:30 am)

II. Production Function/Employment Forecast

A. Purpose - Evaluate productivity of labor force and coupled with growth rate of economy, project labor requirements

B. Concept of production function and $\alpha, \beta$, and $T$; i.e., efficiency of labor raw material input for new vs. old plants, and economic life of plant (technology turnover or time to approach 0.0 profits)

C. Equations (also for $\alpha, \beta$ and T) for forecasting labor

D. Capital required for replacement; expansion

E. Substitution of capital and labor

1. Capital shortage: life of plant is extended by maintenance to extend economic life 
2. New technology with capital shortage: even when new technology is available, investment may be delayed for lack of outside and self-generated capital. (Minimal capital substitution occurs.)

F. Need to adjust for base year (readjust 1970)

G. Validation/ability to forecast

1. Discussion of recent evaluation of results via production function and comparison with available alternatives.

Lunch

III. Forecast of I/0 and Capital Coefficients (1:30 pm)

A. Trend analysis based upon existing tables with judgment

B. SYNTECH-I - preselection of critical coefficients

1. Identify the coefficients which have a major effect on output if changed and determine the relative change required in a technical coefficient to increase total output of the most affected sector by $1 \%$. (Most coefficients have minimal effect on output.)

C. Use of "technical experts"

IV. Prices and Profits

A. Consumer goods via LES

B. Production via price/profit minimization

C. Taxes and associated efrect on consumption

V. Imports/Exports

A. Price dependence

B. Time Dependent

C. Effect of domestic production capabilities and capacities

VI. Open Discussion (3:00 pm) 
APPENDIX C

EXPLOR MULTITRADE

JAPAN - 1975

Sample Computer Run for Debugging Data Base 


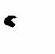


1 落

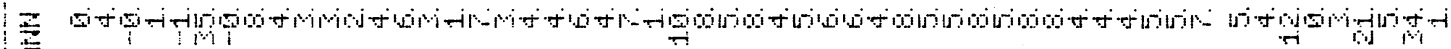

49 -

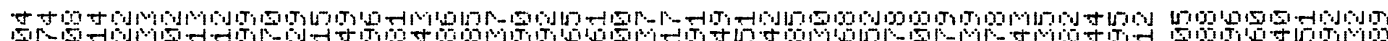
s n-

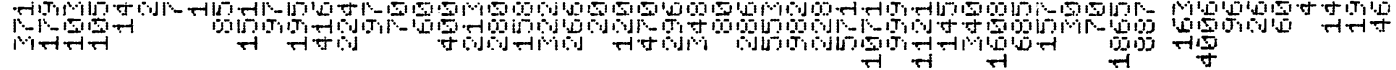

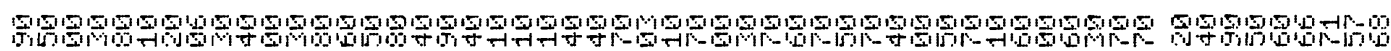
wir of तन

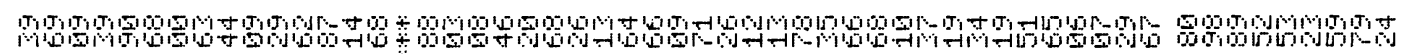

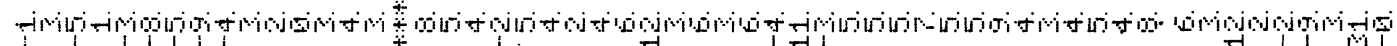
吝 章 Nong Tin-

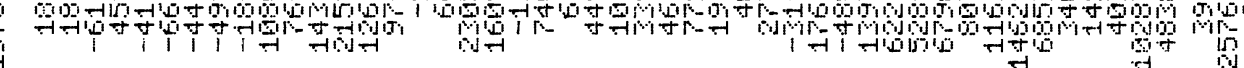

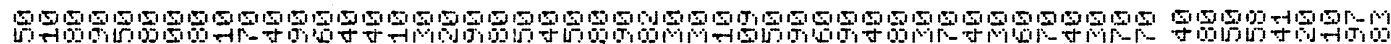
mbring

9 atron (1)

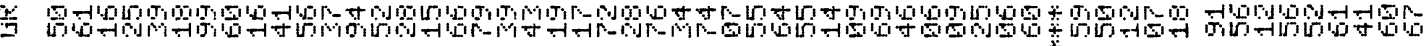

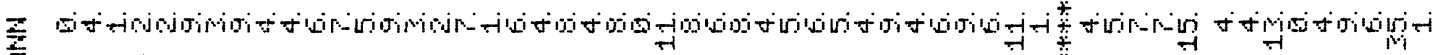
高 7. arar $\checkmark$ 至

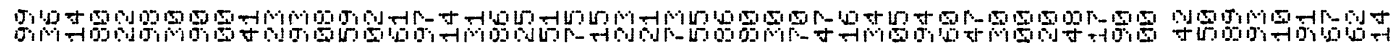
4 rop क

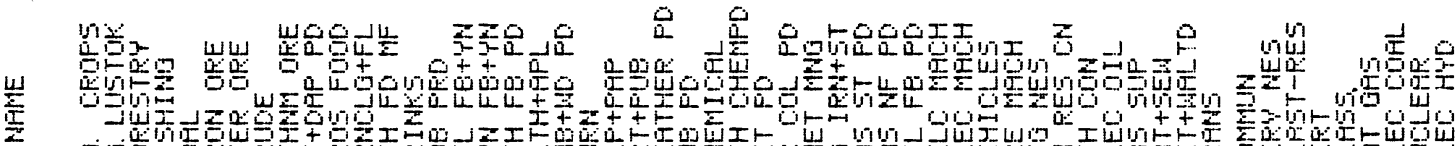

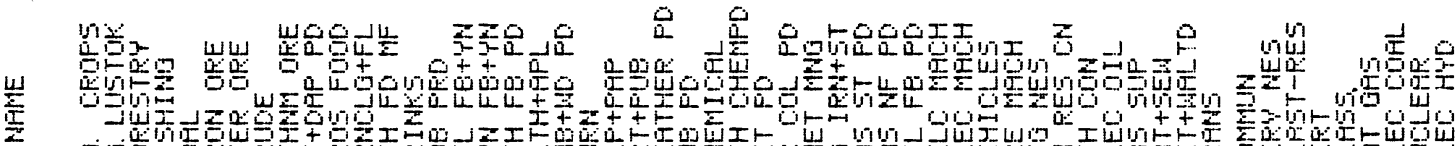

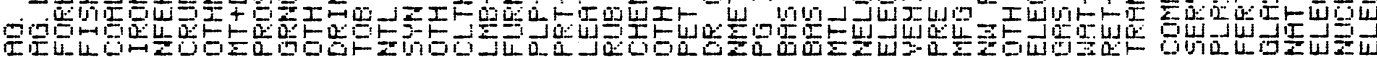




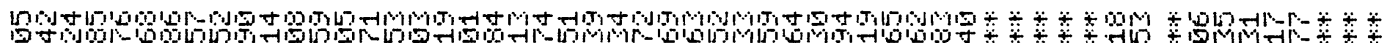

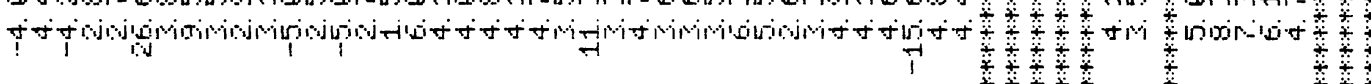

Wण

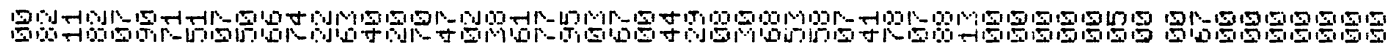

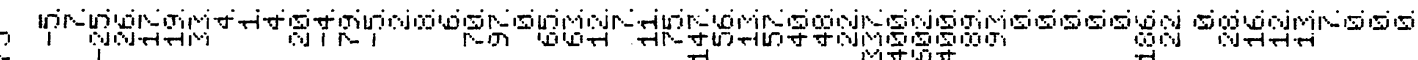

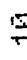

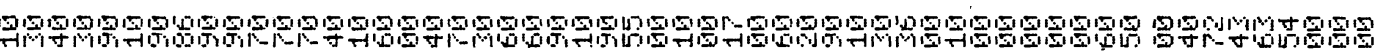

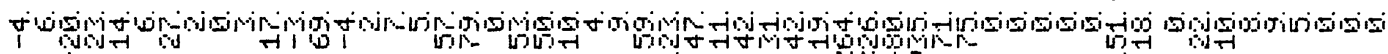

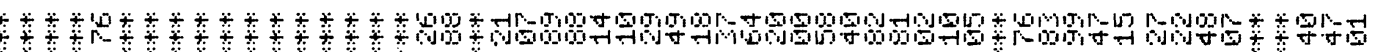

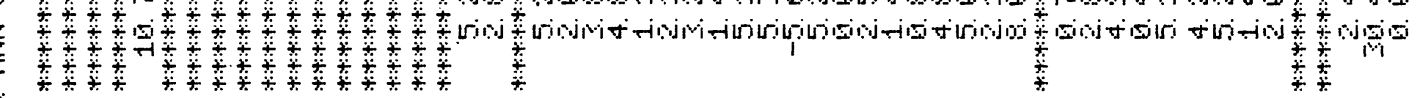
wing

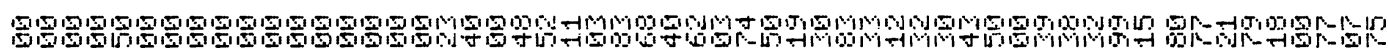

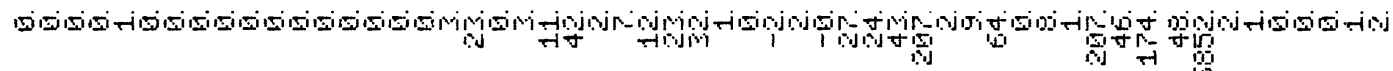

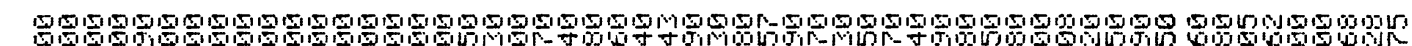

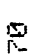

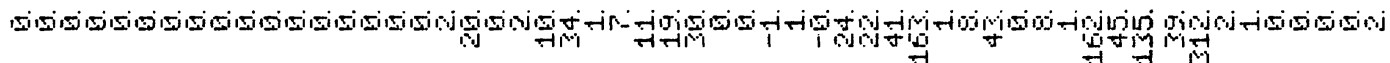

总

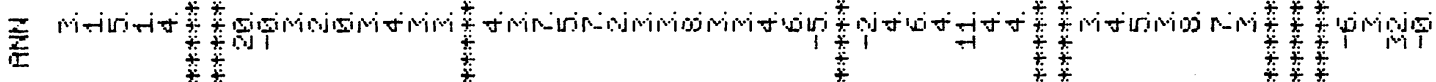

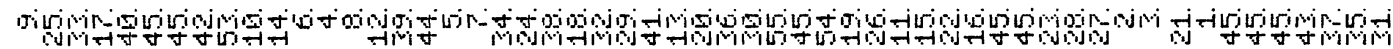

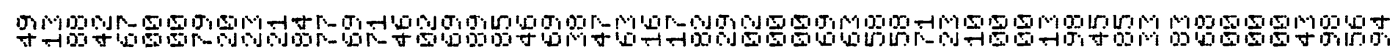
त न grogrsosing (1)

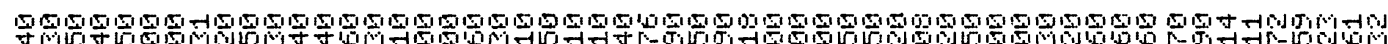

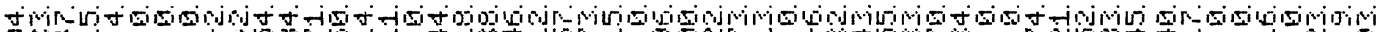




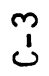

程

煦 恵

高

两 10

专喿

宸

空

栗

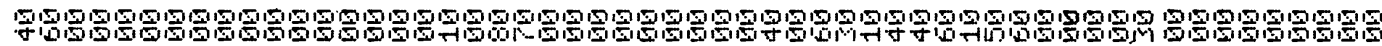

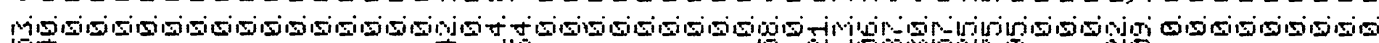

in

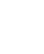

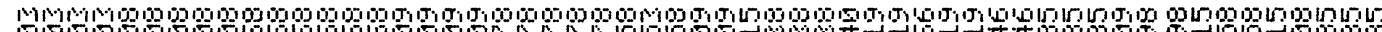
Citi

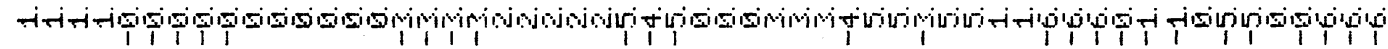

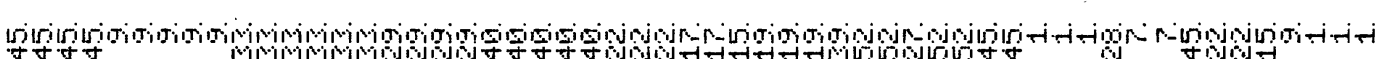

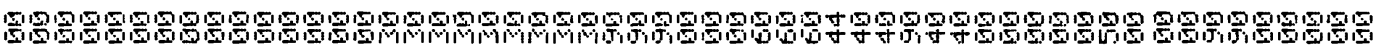

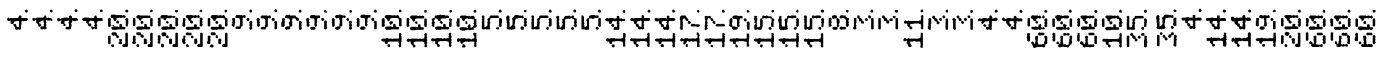

紫

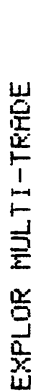

章

1

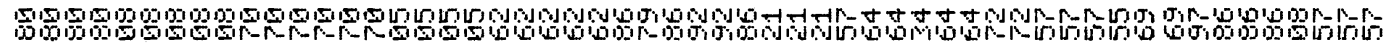
Mm

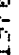

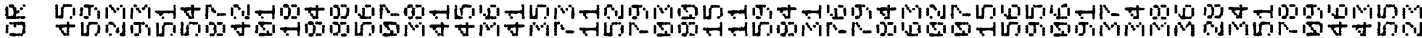

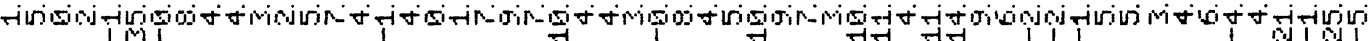

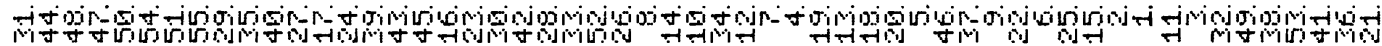

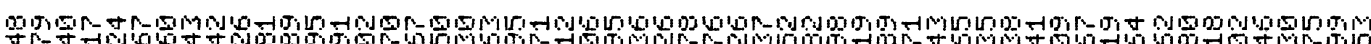
20 a

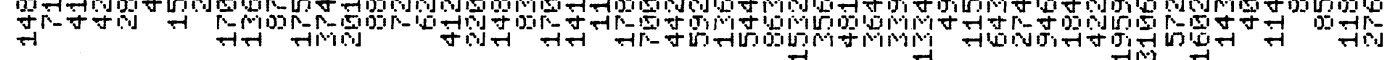

9日9

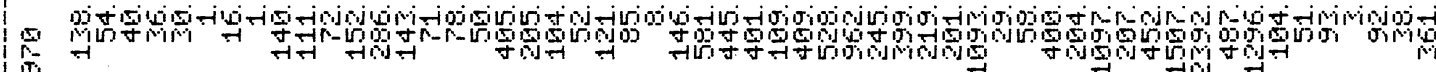
is risiog

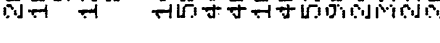

䨛 


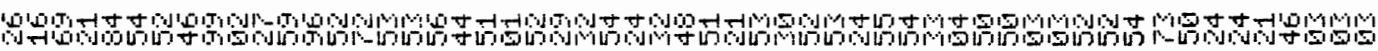

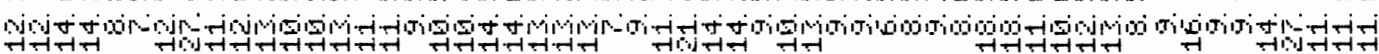

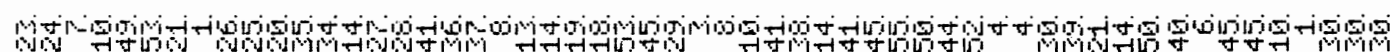
prody

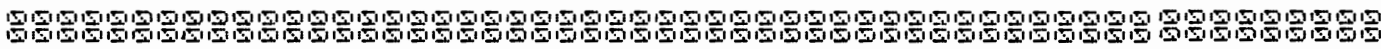

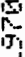

तं

全

م-ging

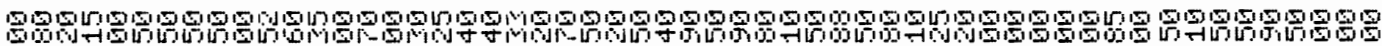

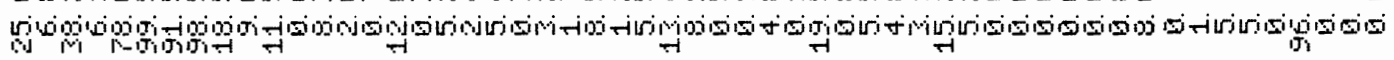

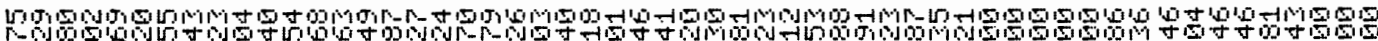
तु

Derag

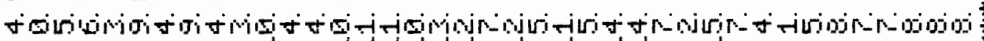
-ind

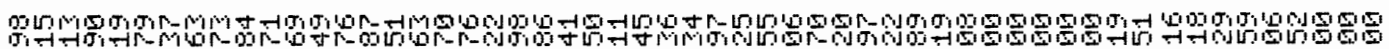

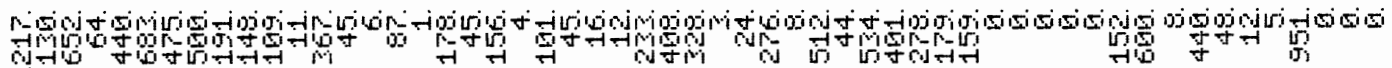
总

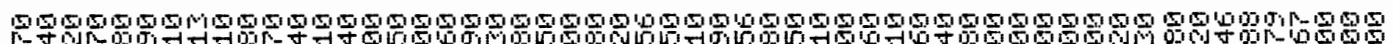

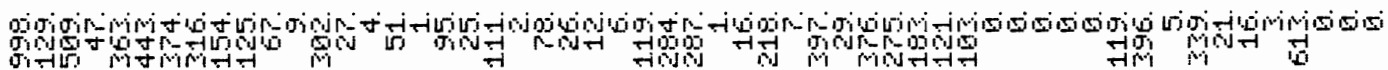
2 


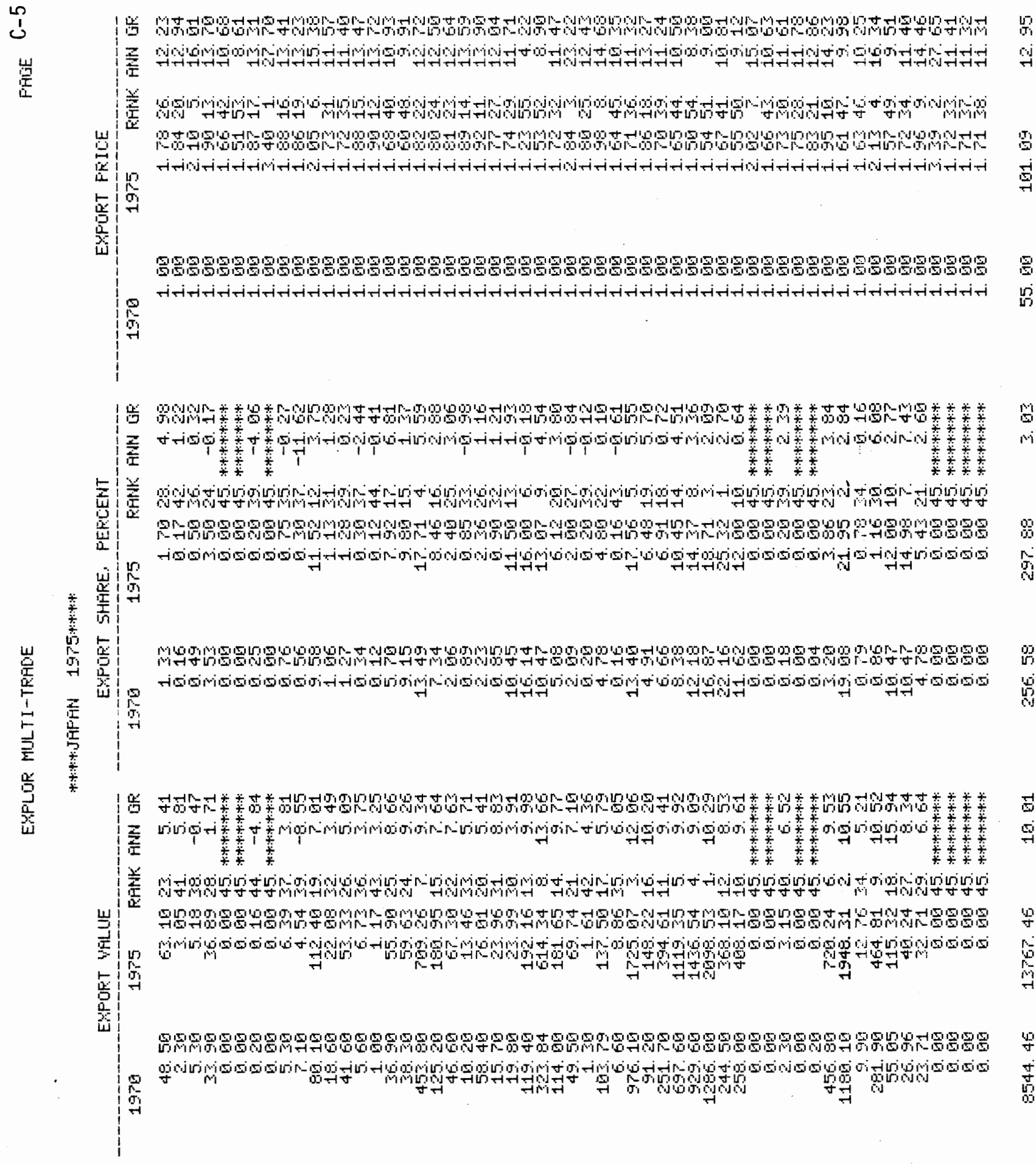

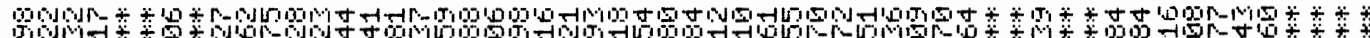


告

I

竞

पे M. कि

年

जी

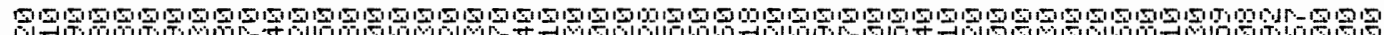
तु

点

罗

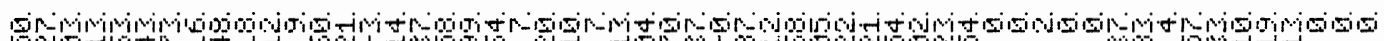

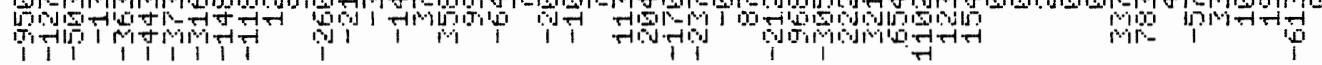

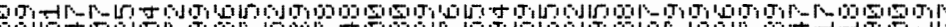

2

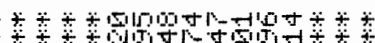

焉

agd

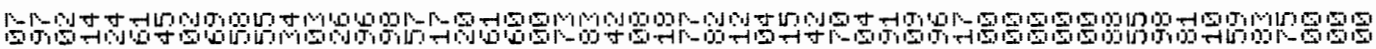
-

-

焉

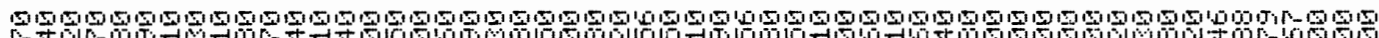
(1) कि 5

\section{1 新}

政

(2)

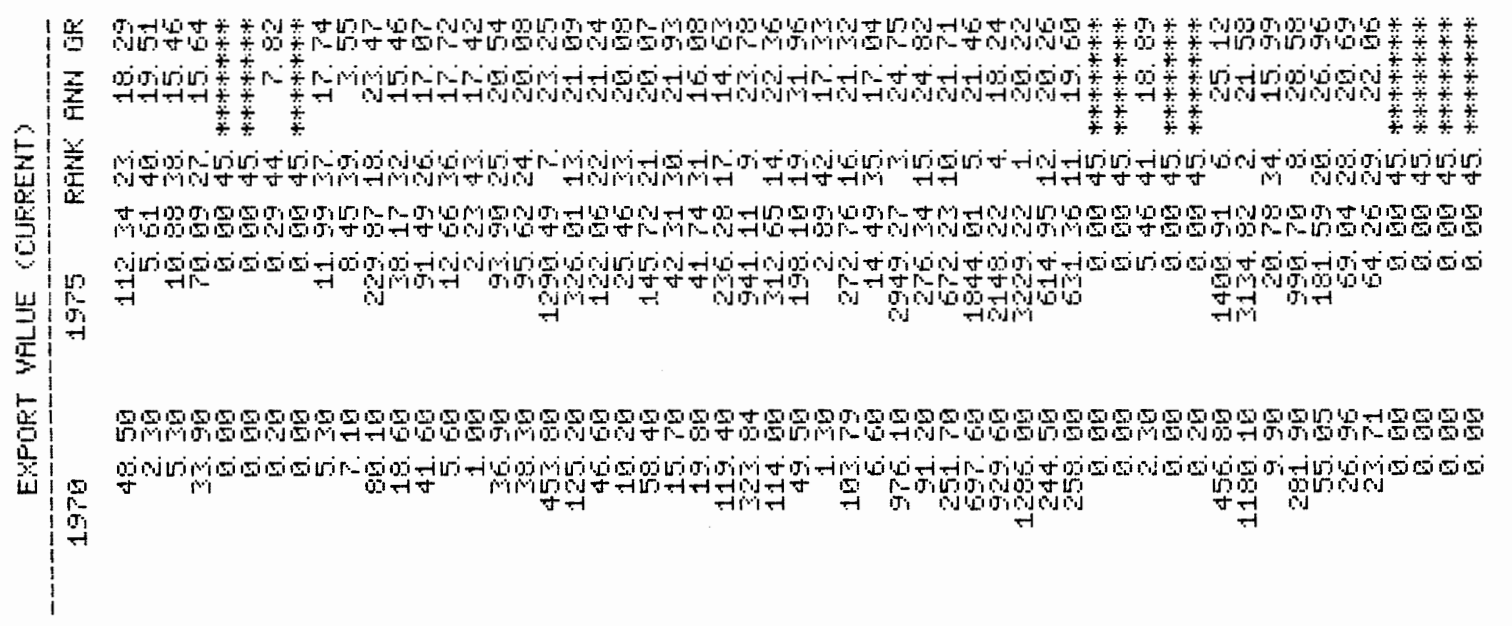

T-

में 
$\vdots$
$\vdots$
㟶

告
总

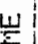

10

$\frac{1}{4}$

5

崇

点

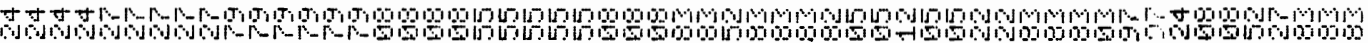
th

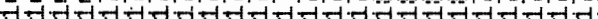

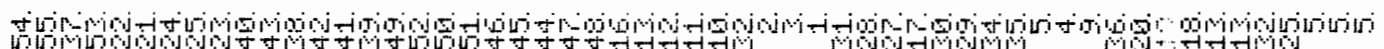

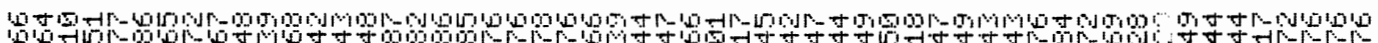

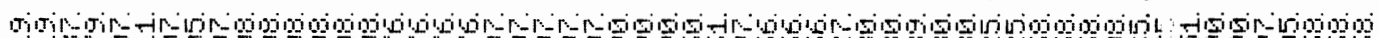

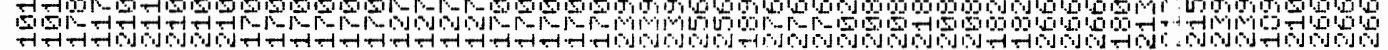

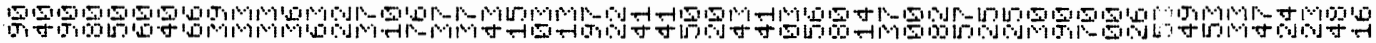
सं1

章

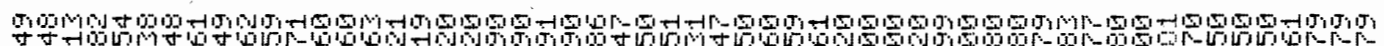
Sing 2 $\rightarrow$

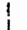

莒

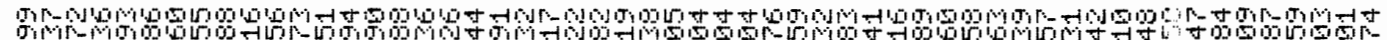

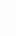

tisingirining

$\pi$

ving -

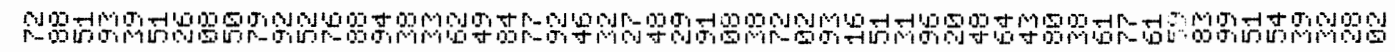
मng

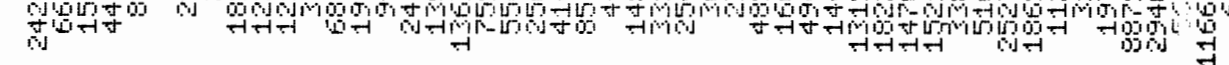

i)

客

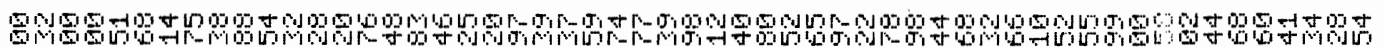

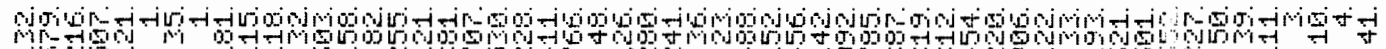

iint

40 
$\infty$

$\dot{\omega}$

崖

袋

10
0
0
0
0
0
0
0
10 क日十,

₹

竞

मि-

97न

- Wh

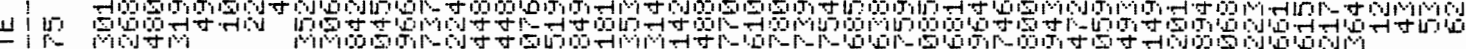

I ind

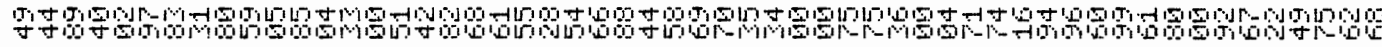
sind Wu

营 率 (1)

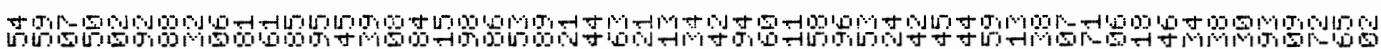
सु 思

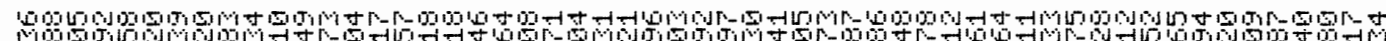

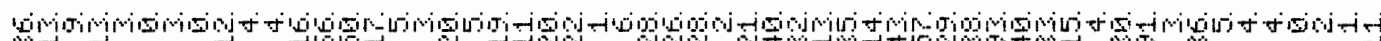

Mong

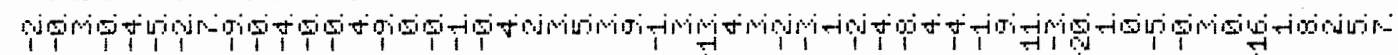

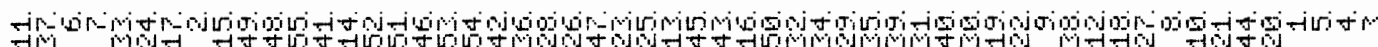
- r

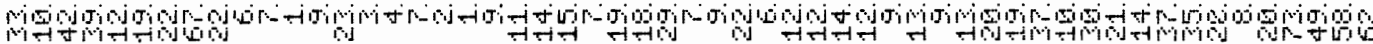

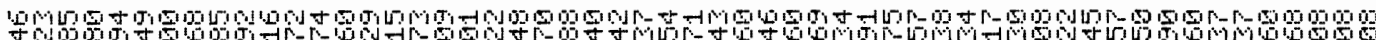
Pिय
Tis 

बु.

Sping

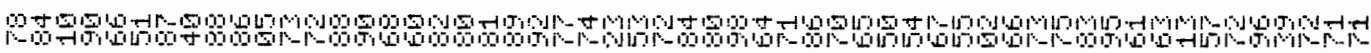

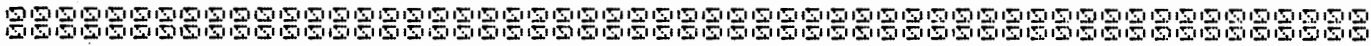

mon

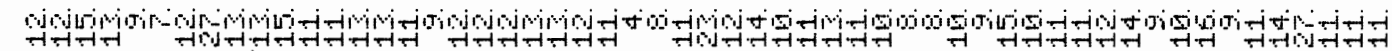
ong posing

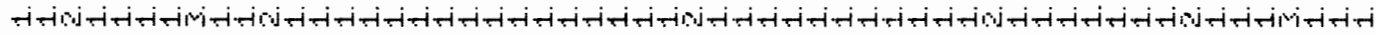
10

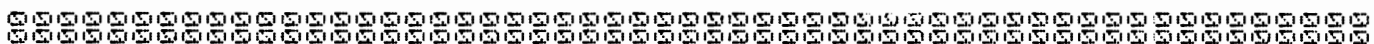

+

.

总

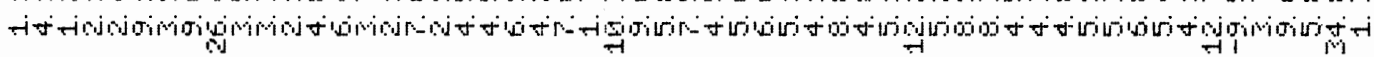

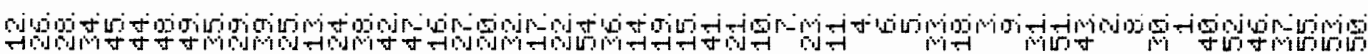

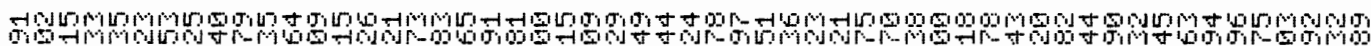
-

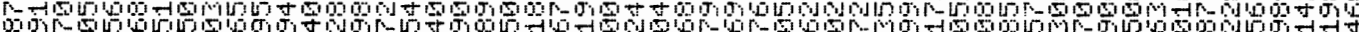

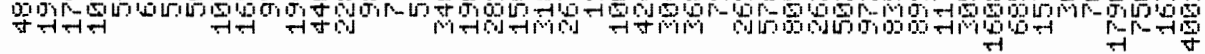

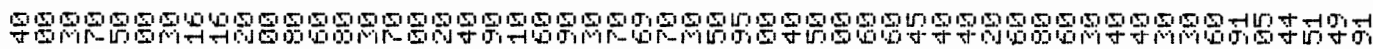

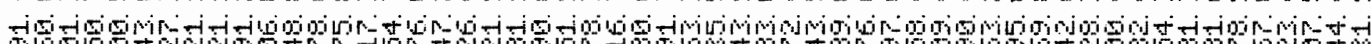
The

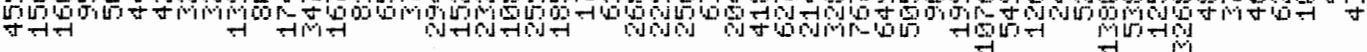




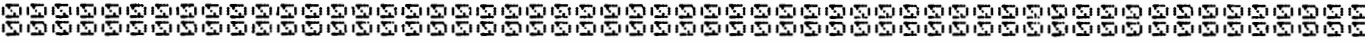
tiv

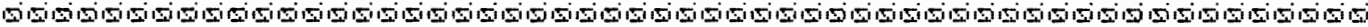

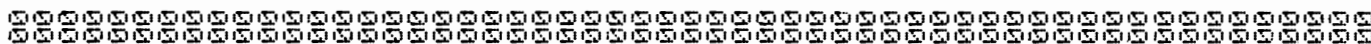

sisisising

舀

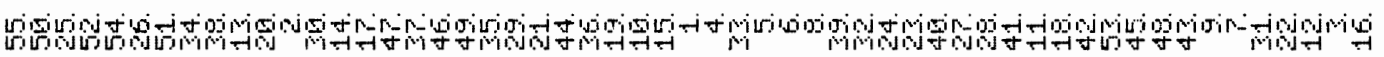

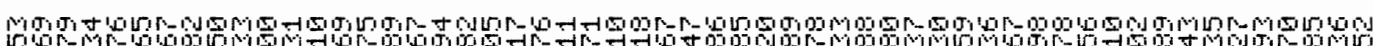

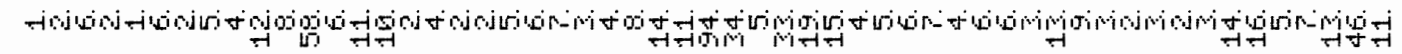
照

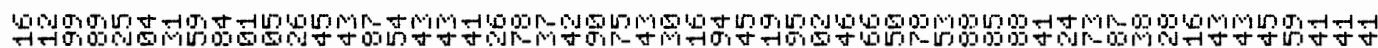

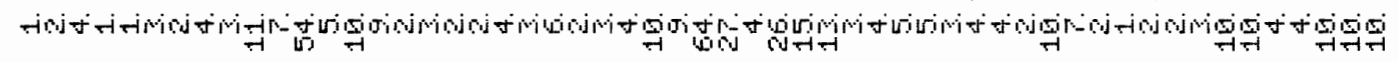



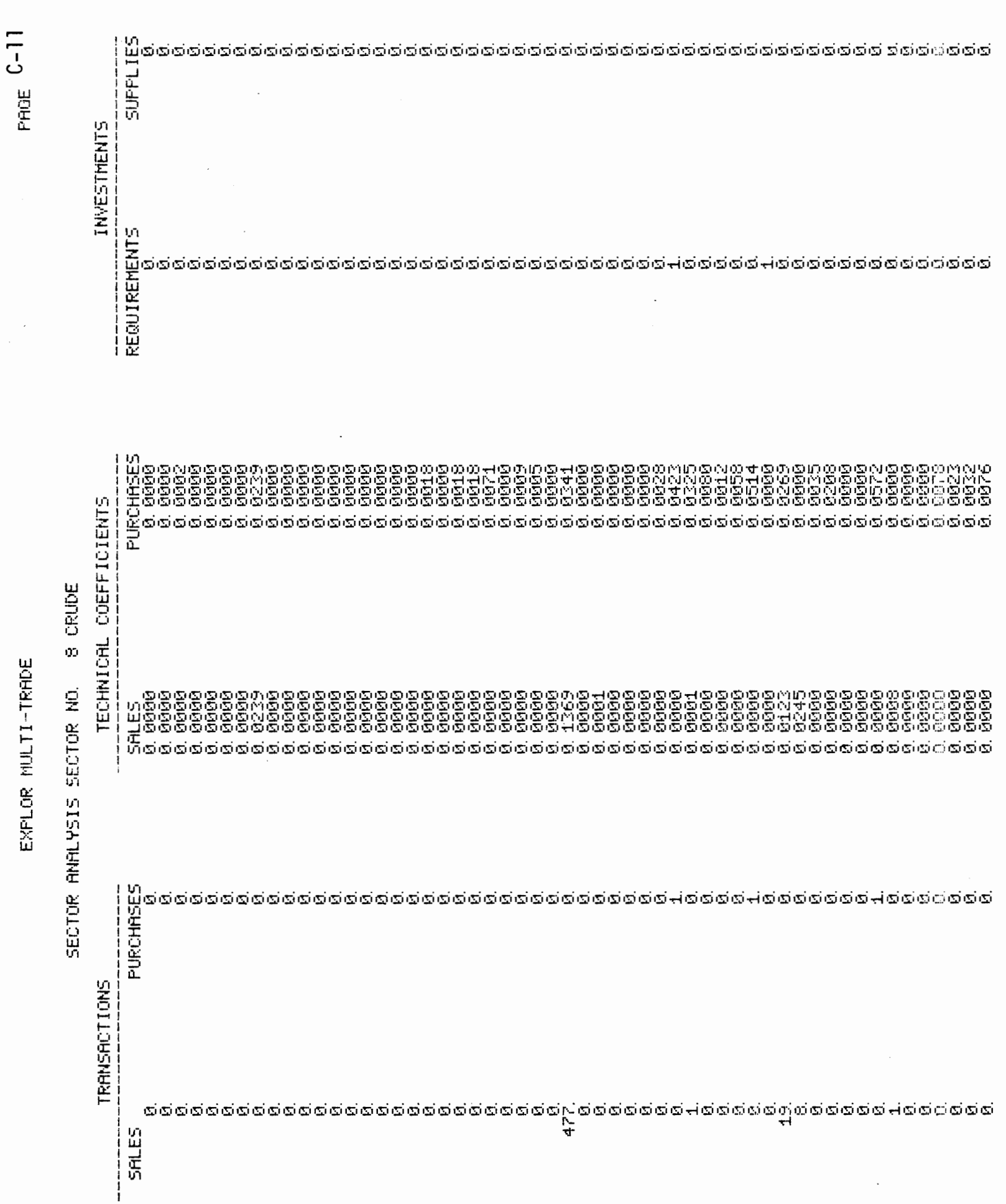

\footnotetext{
竞
}

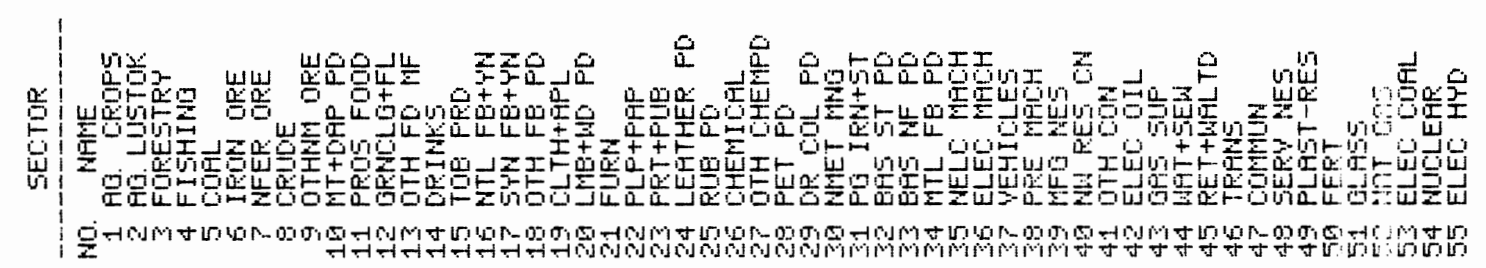

尊圆

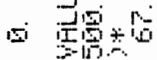

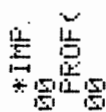

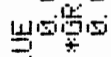

焉。

落密

o

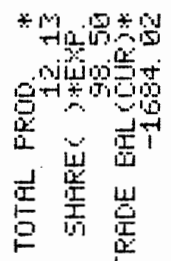

* 100

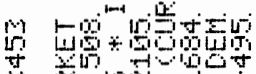

स

ij

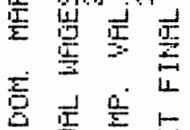

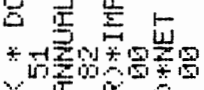

पर

曹 *

至 豈崖

号象果

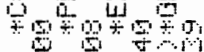

윤 5304

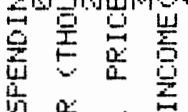

$\forall$

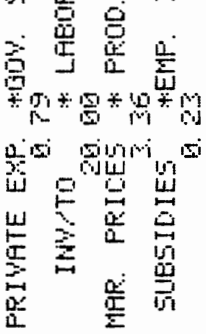

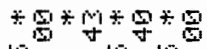

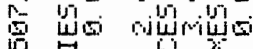

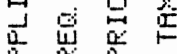

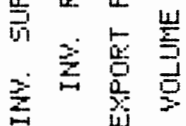

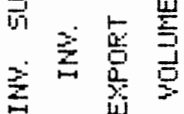
果:

Sn-ving

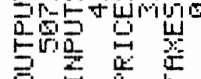
背

品苫点点 

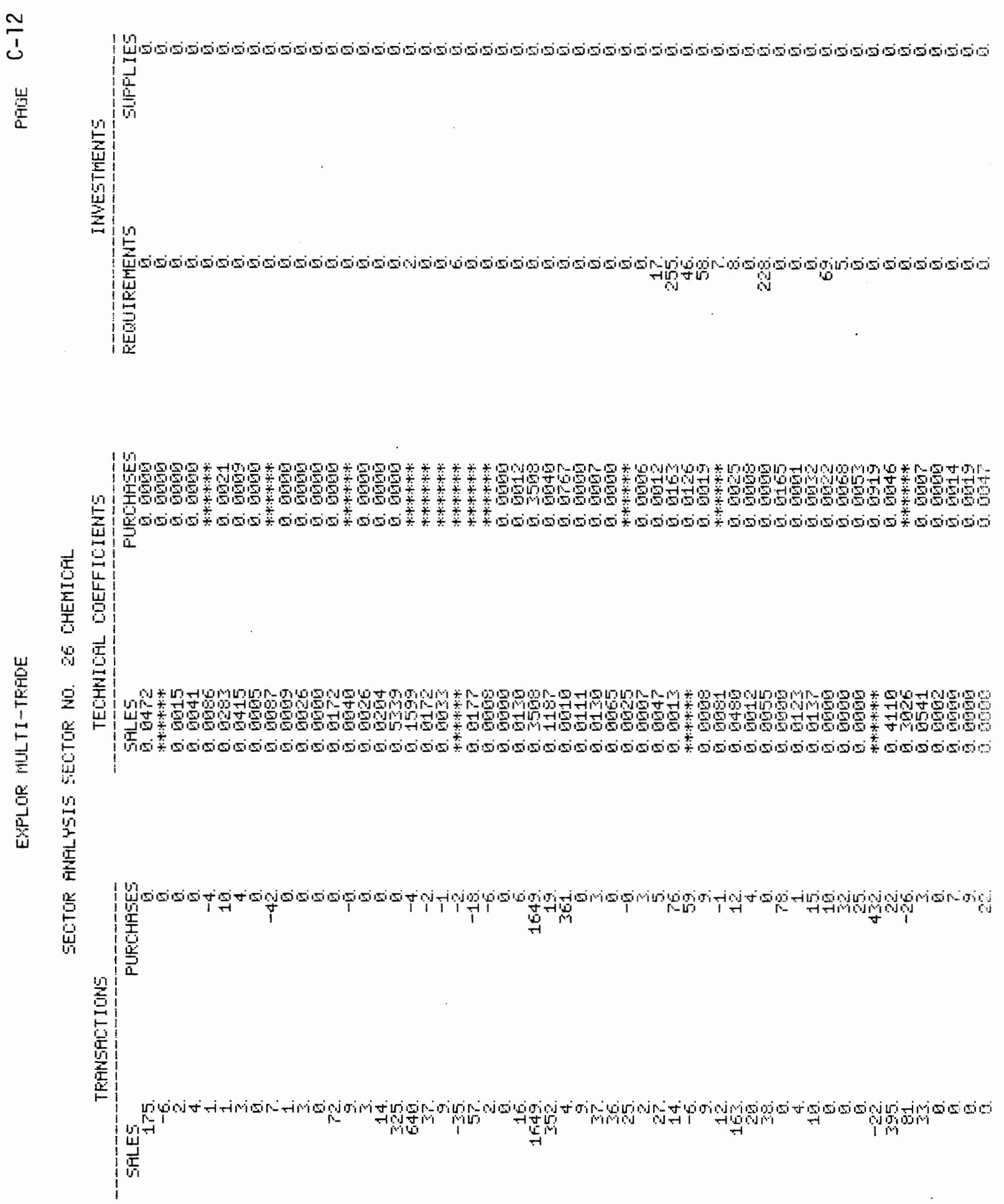

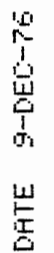

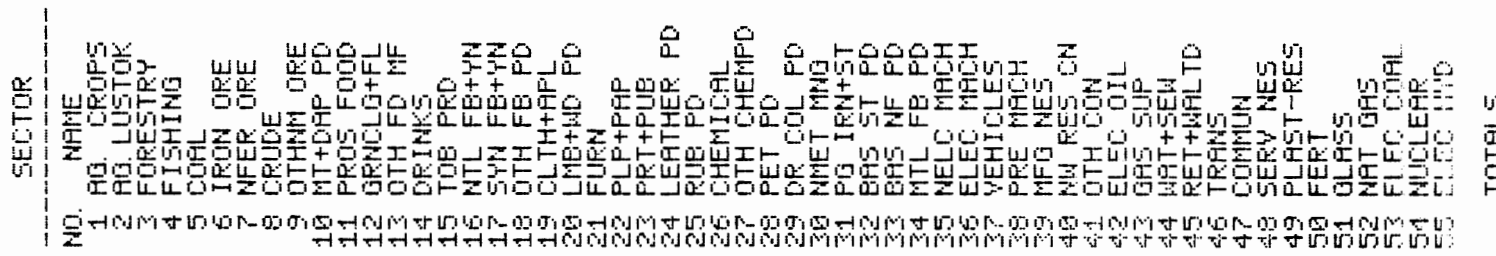

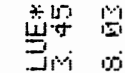

s

点

券整高

要

荅崖

害

$\because$ M

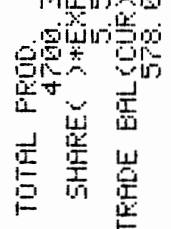

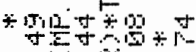

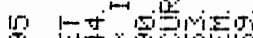

3 ب.

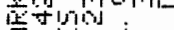

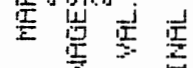

E.

定突

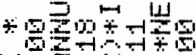

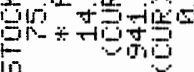

$\sum_{i=1}^{i}$

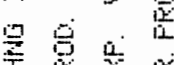

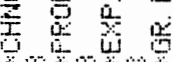

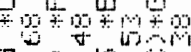

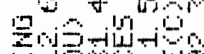

和尉

出比呚

点

兽官

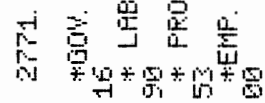

०सं

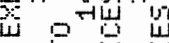

山田

密密总

㗊

*

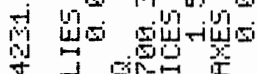

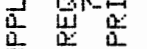

量

紫

至量是

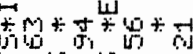

5 -

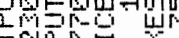

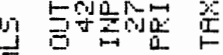

齿岕点虽 

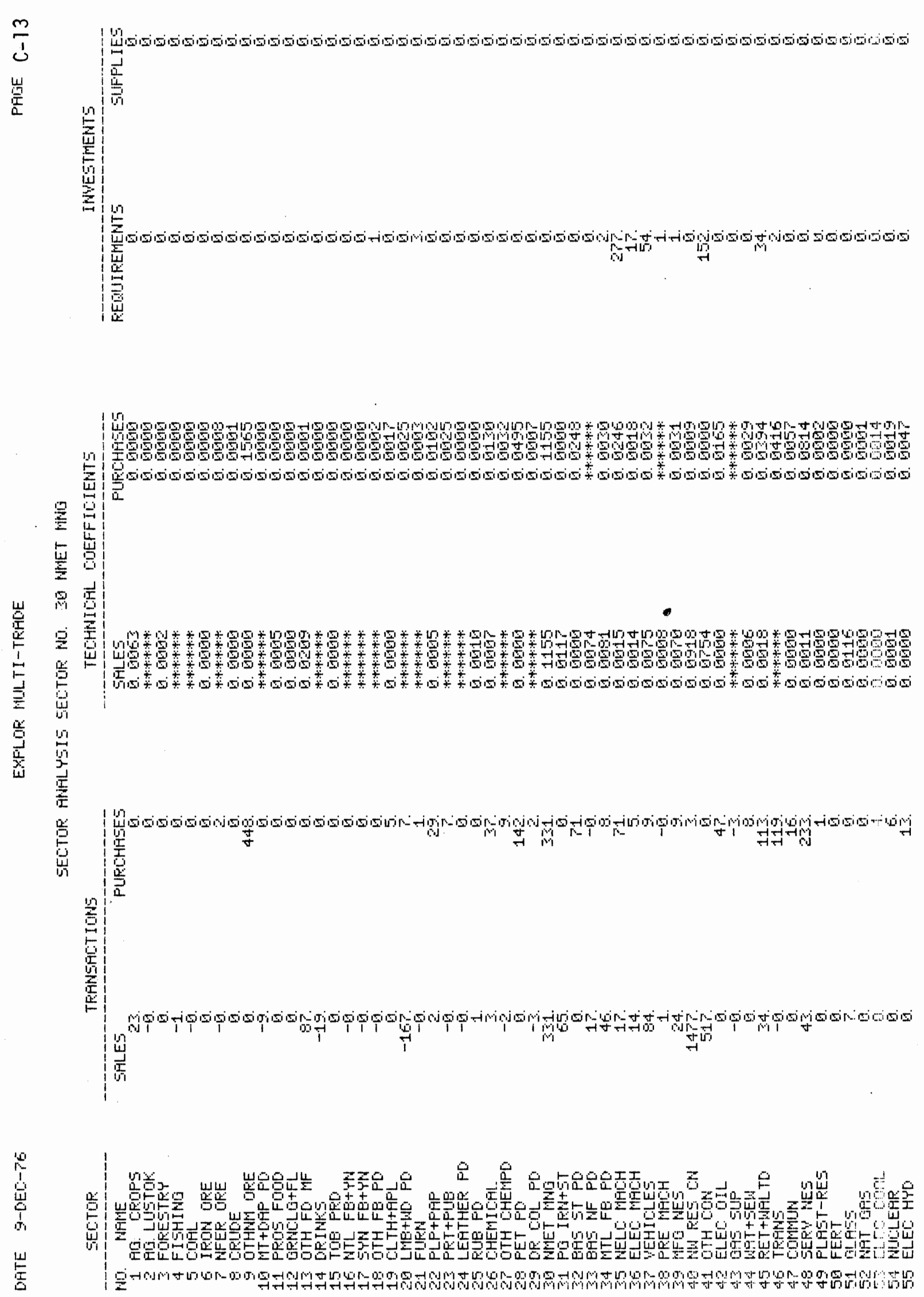

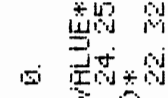

突落

紫紫

背㻤寸

焉.

炭密

is

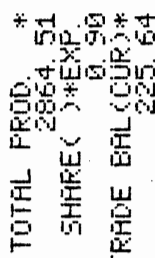

*

$4 \frac{10}{40}$

空窒焉

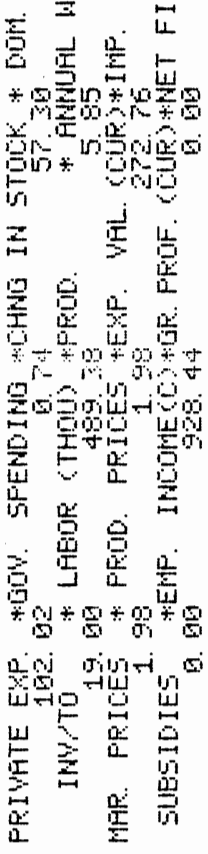

$* 9 * 9 \% 9$

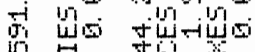

8

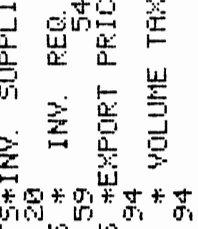

E-17

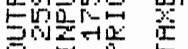

点点点点

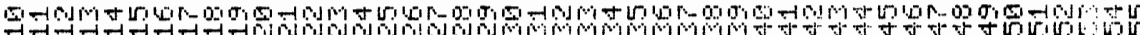


$\frac{\vec{J}}{u}$

光

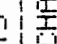

15

5 ONOW 至

官

要

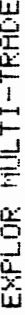

要

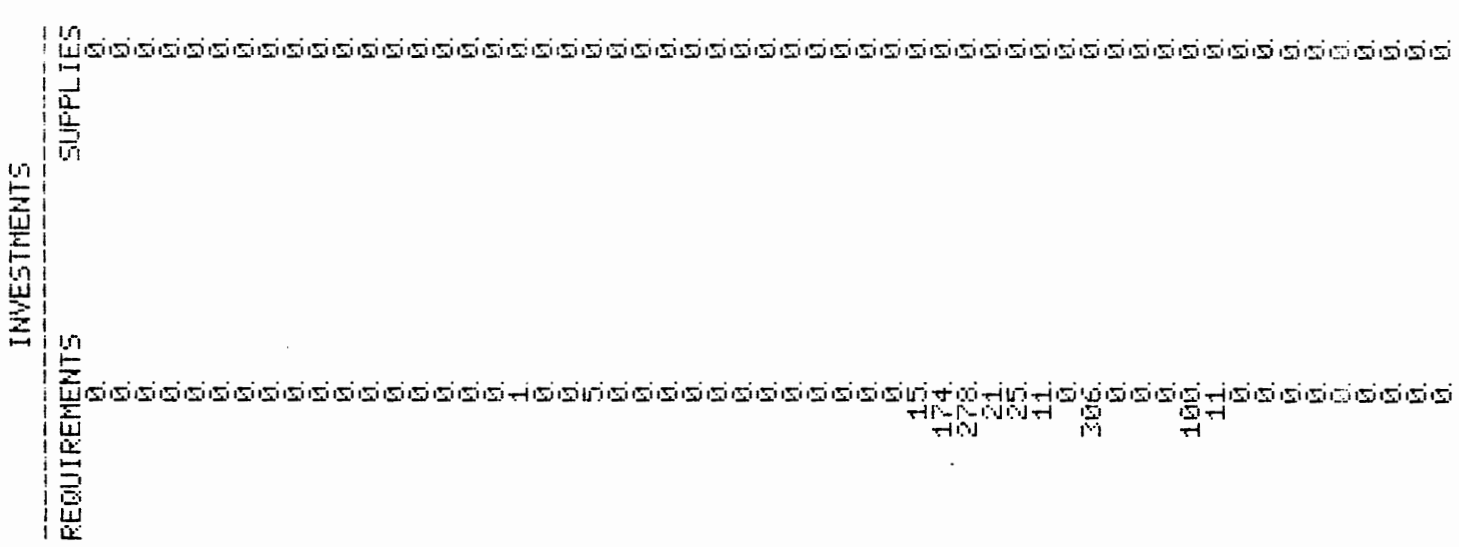

is

些

-

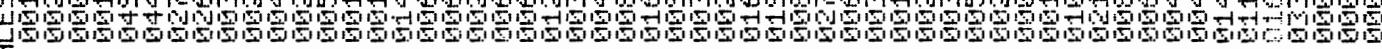

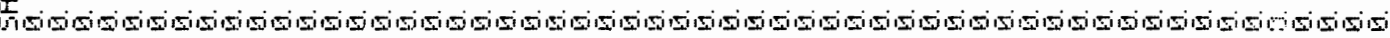

is

监

害

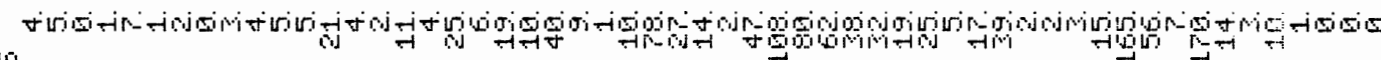

|

|

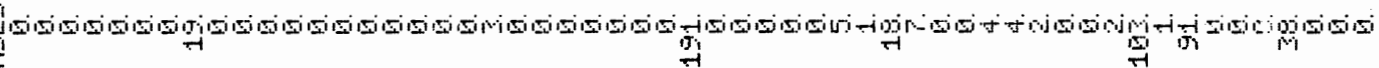

总

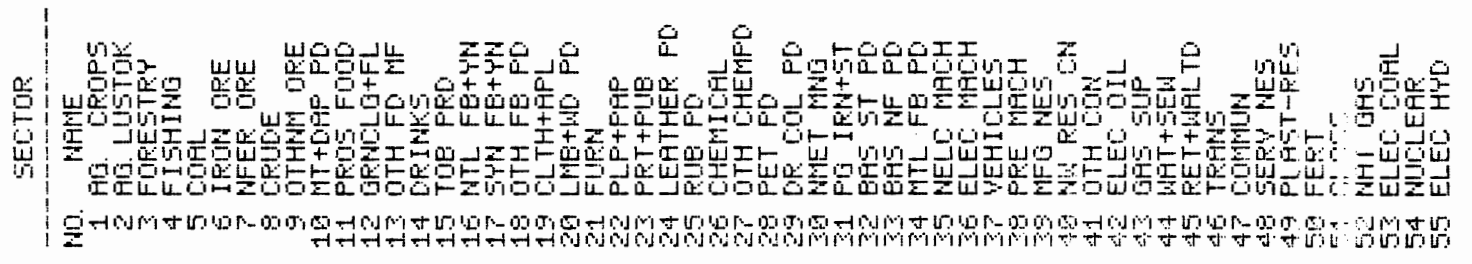

兽

si

空窝

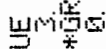

疍.

落 岁

$\because 40 \%$

舟然

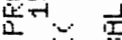

峲眾

豆空崇

* $\mathrm{s}^{2}$

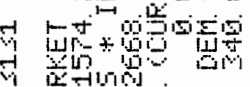

整

空焉

害焉总占

*

四

品

至焉背

章官的貼

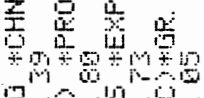

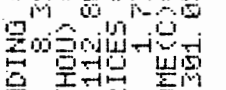

F

is

总

票总

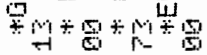

पiv

जine u

点焉点

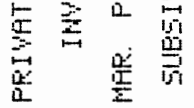

* 瞍*

的心

可额是产

高崖落

俩 $\therefore$ 崖

紊总焉

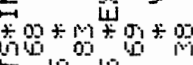

41010

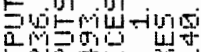

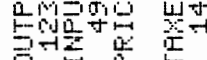

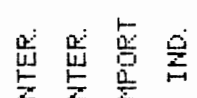



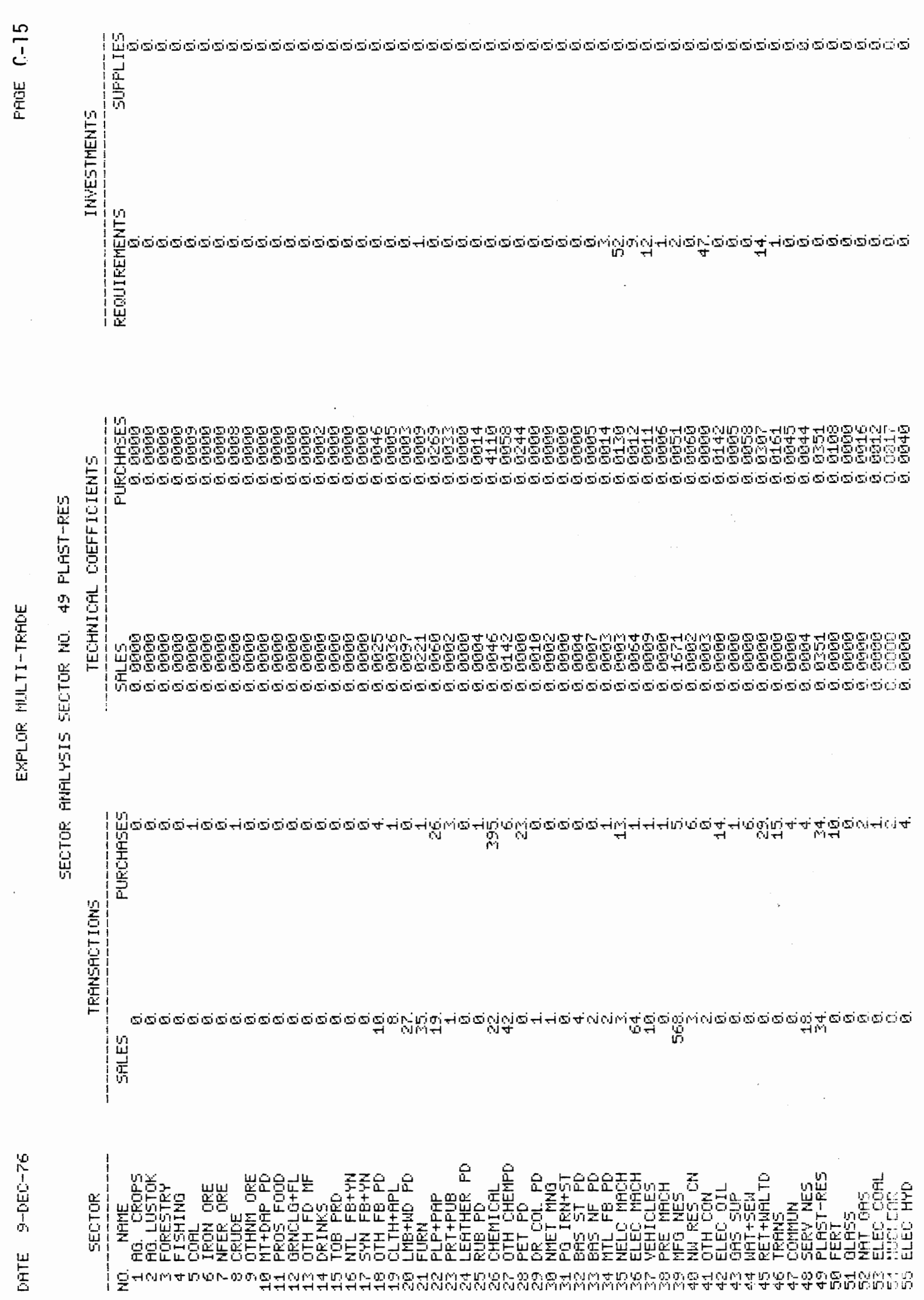

प्रिं भुज

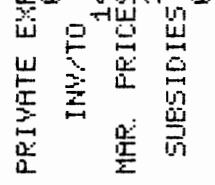

*9:

品 可 苟藏

亭岩苔 


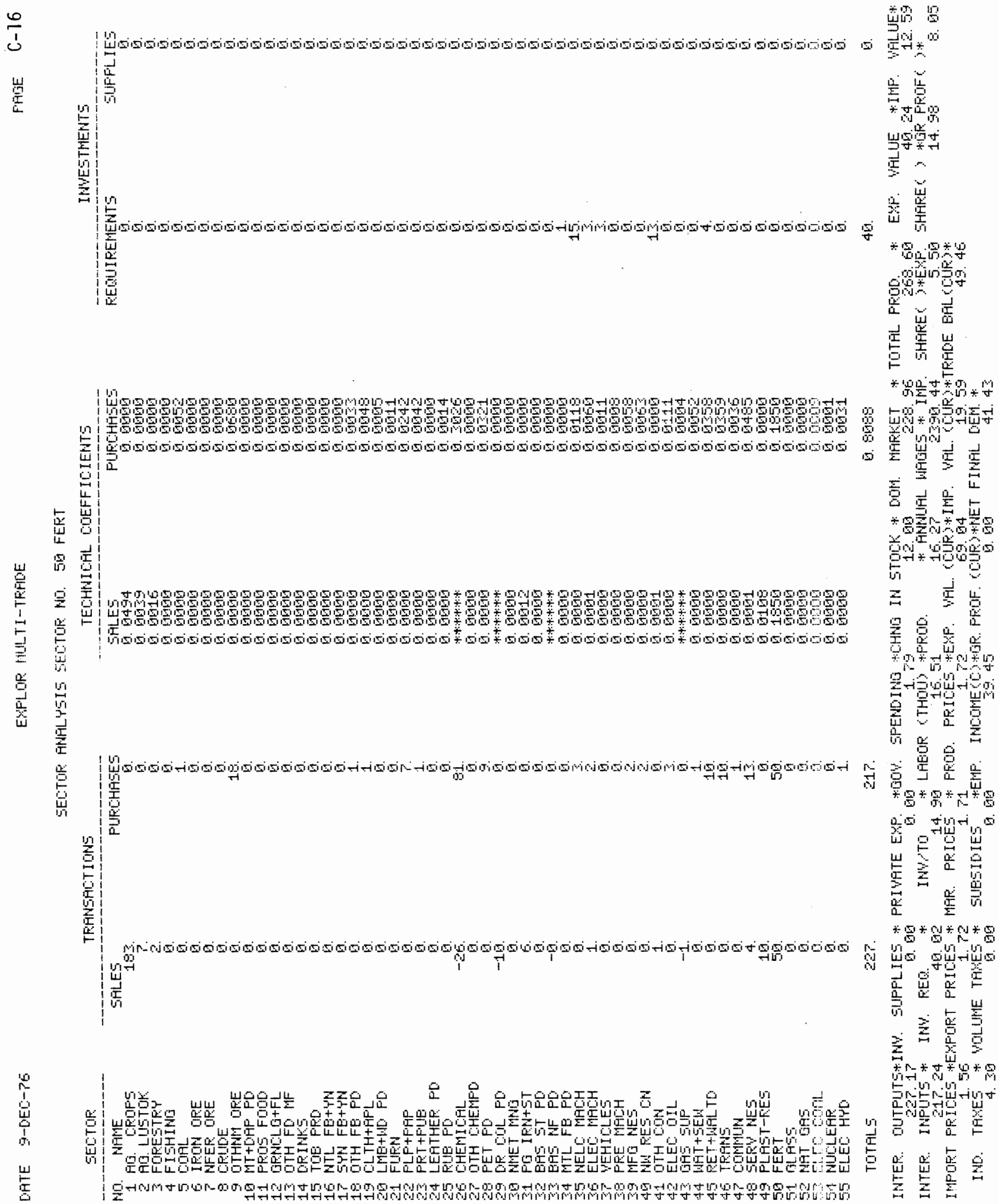



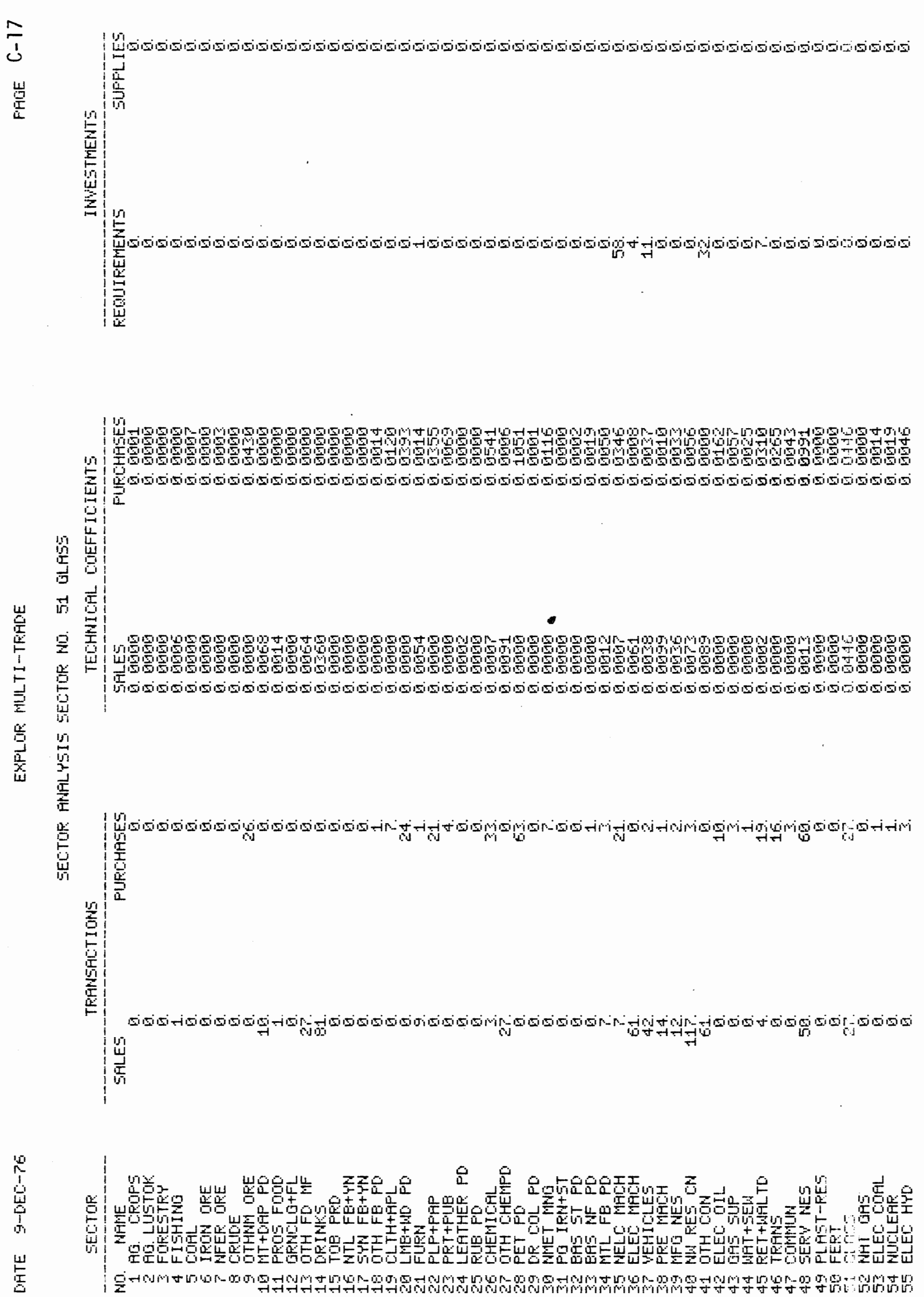

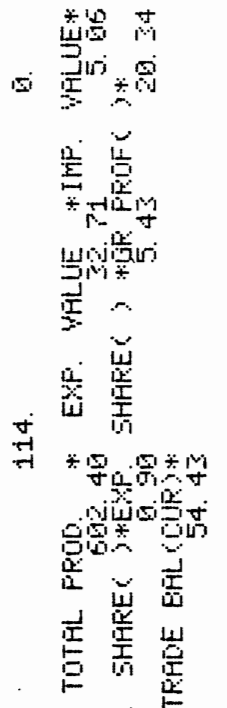

$\because 1000$

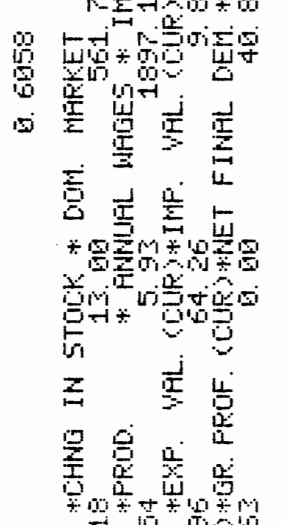

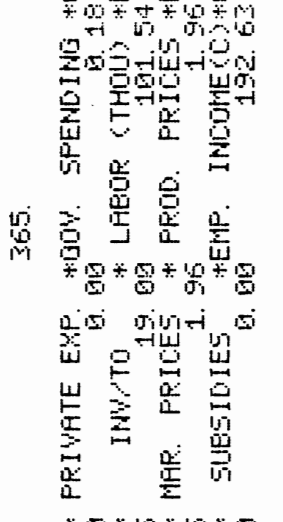

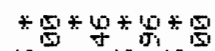

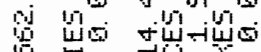

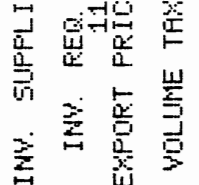

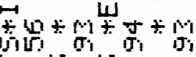

5 .

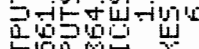

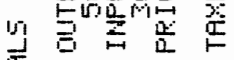

官

总点点点 
$\infty$

ú

宸
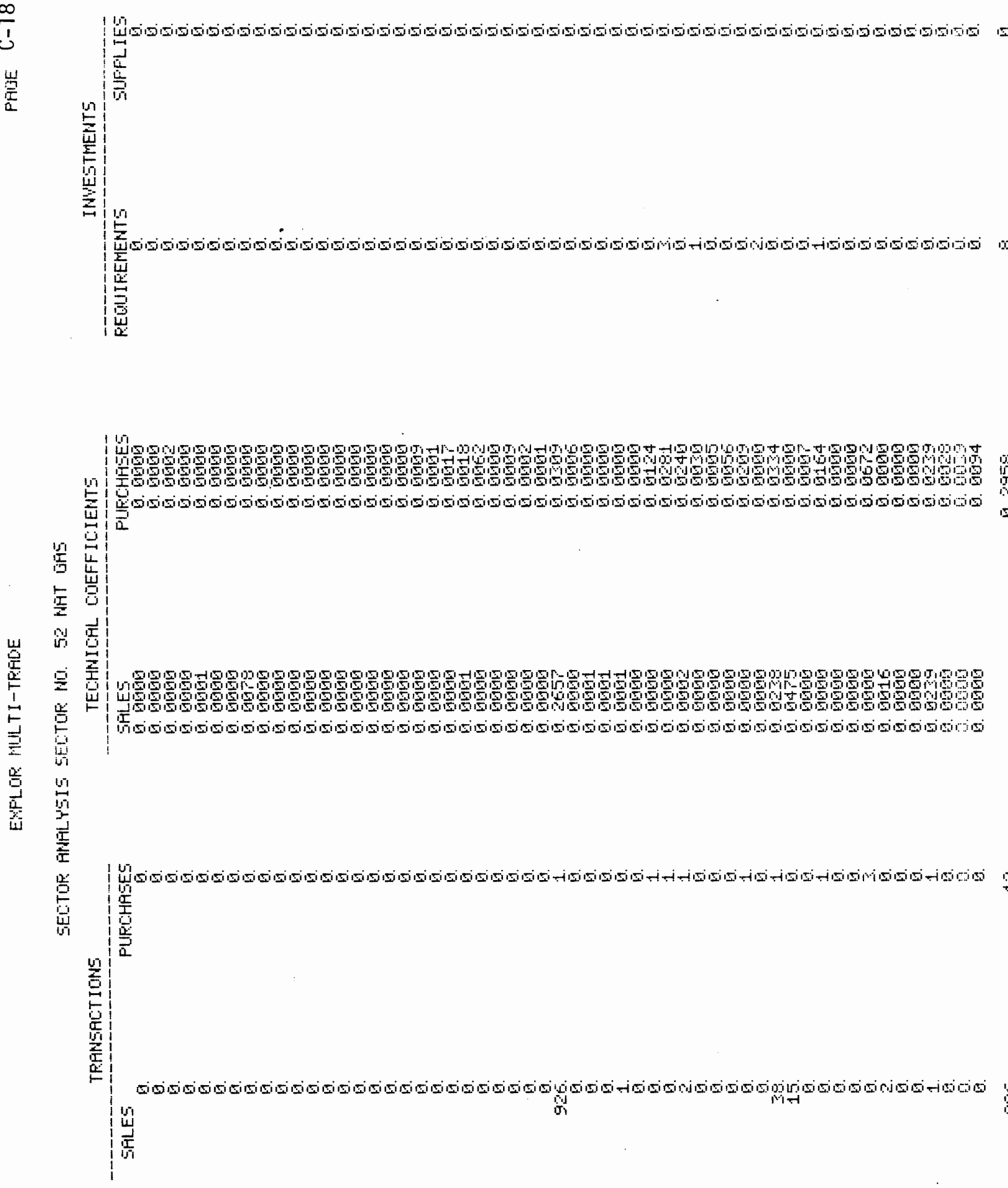

फ़े

焉舟舟

焉息

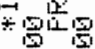

岁整要

蛋?

$\therefore$

密

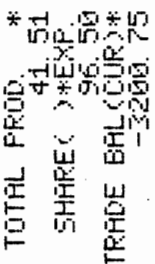

*

1 -

T.

政

受崖焉焉

$\dot{5}$

ह

至

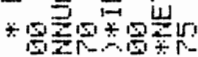

药

in

I

뭉

90

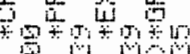

96 ㄱำ

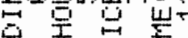

害点

公

学。

票焉

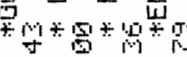

visis sis

s

品要

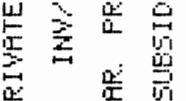

然

*

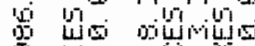

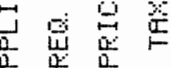

量岩吡

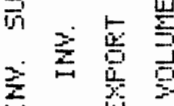

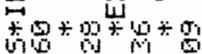

vivisur

answum

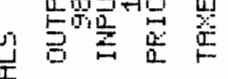

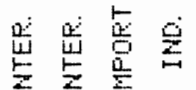



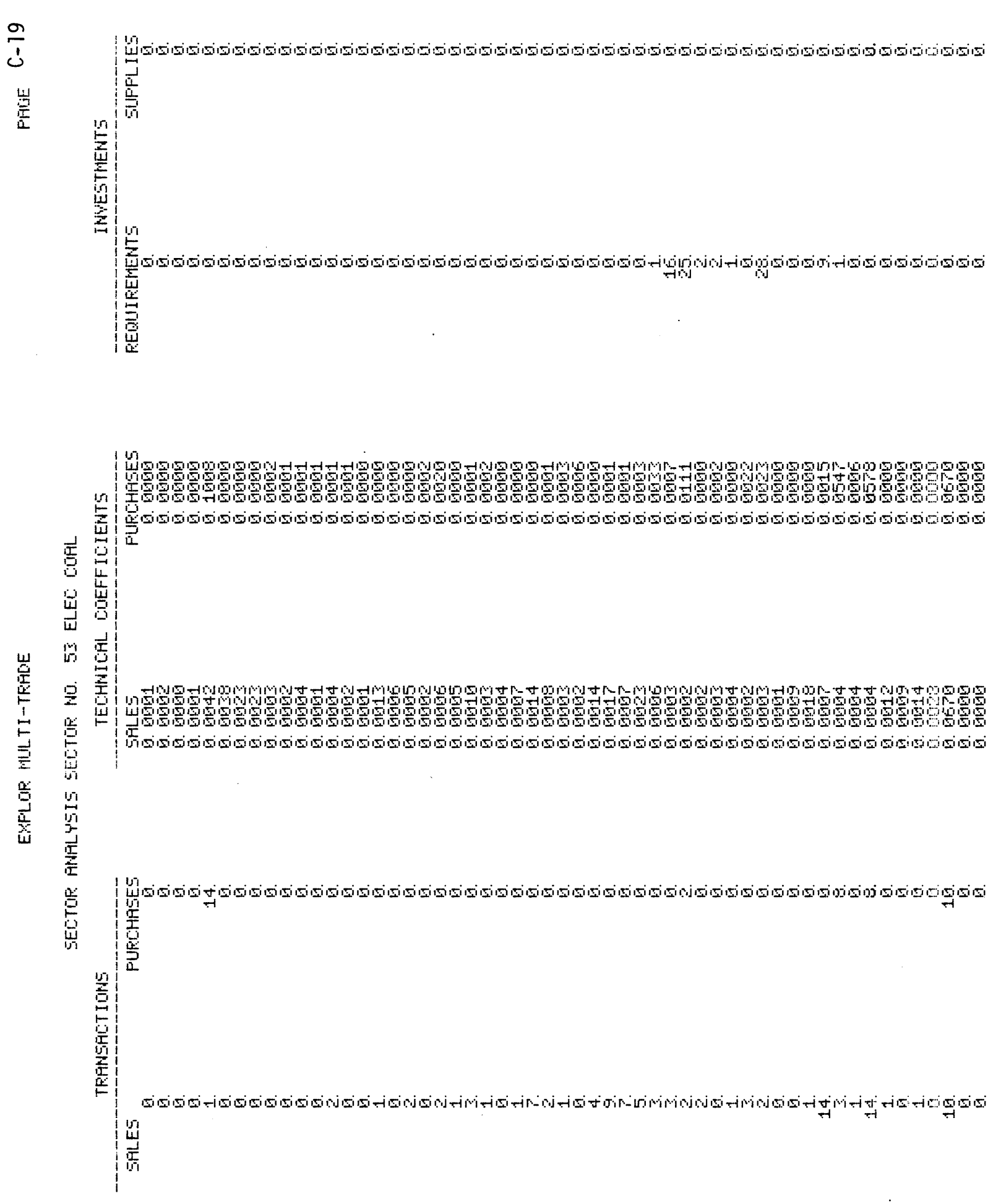

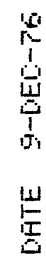

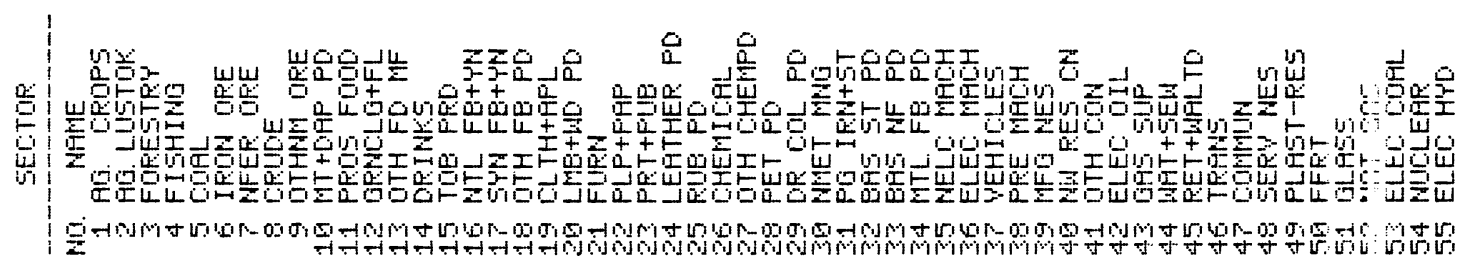

曾䍐

s 焉罚 资望 嵌装

寽

若喜 界罗罗

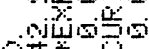

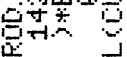

范空

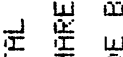

E I

*

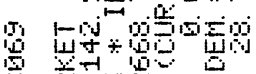

M

i

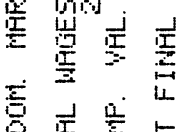

它量占

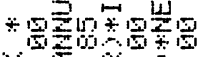

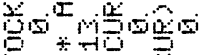

$=\quad$ 王

-

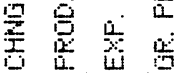

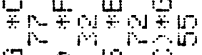

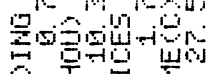

完至官

is

范

i

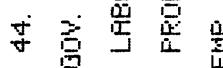

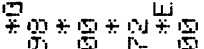

on

क

世苫

恣

点

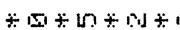

E

苟出

可密

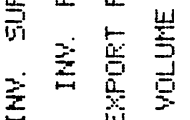

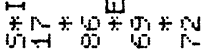

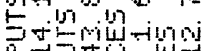

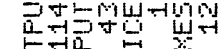

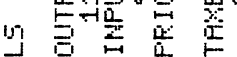

$E$

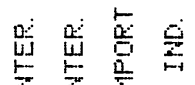
g-am 

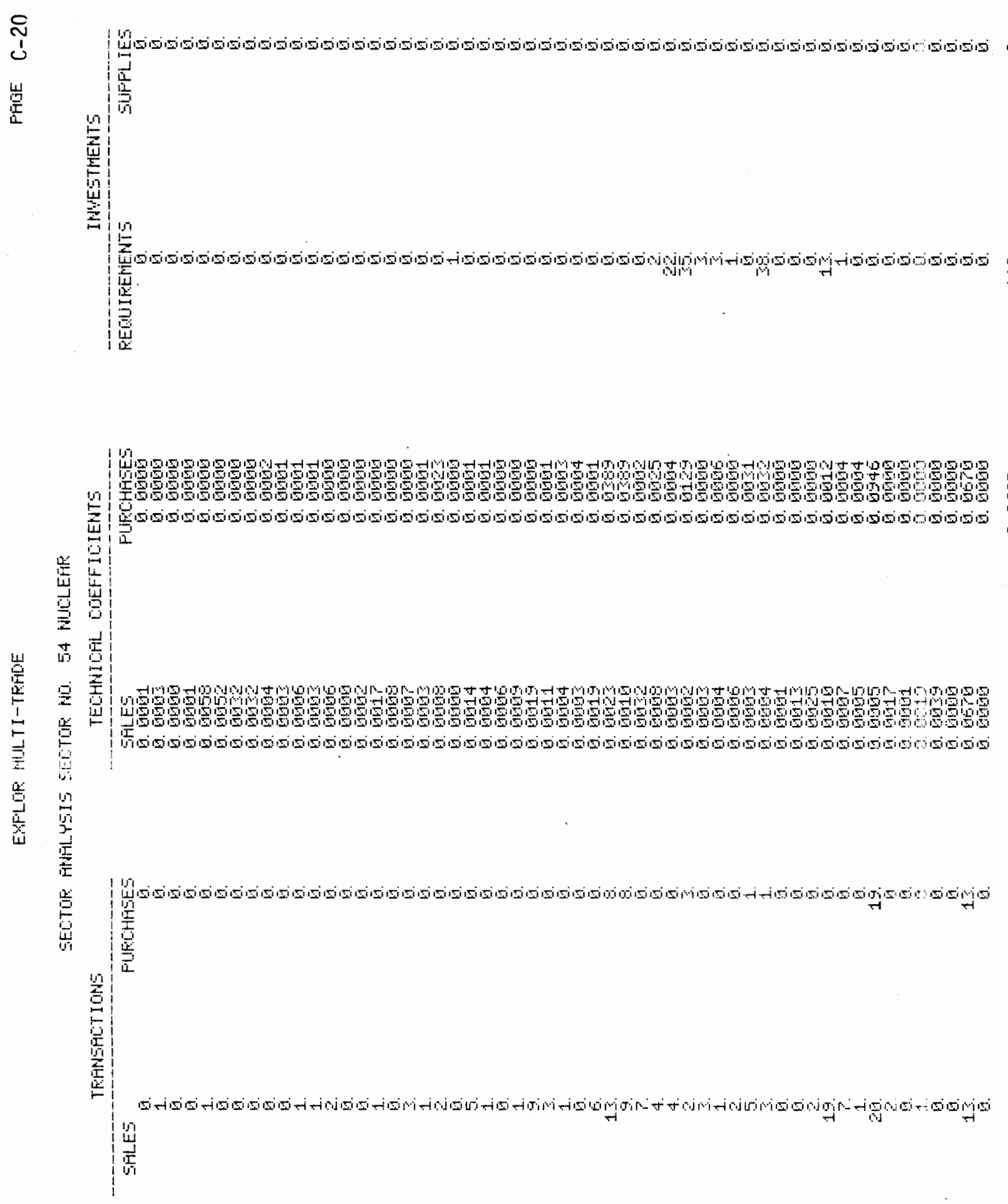

柋

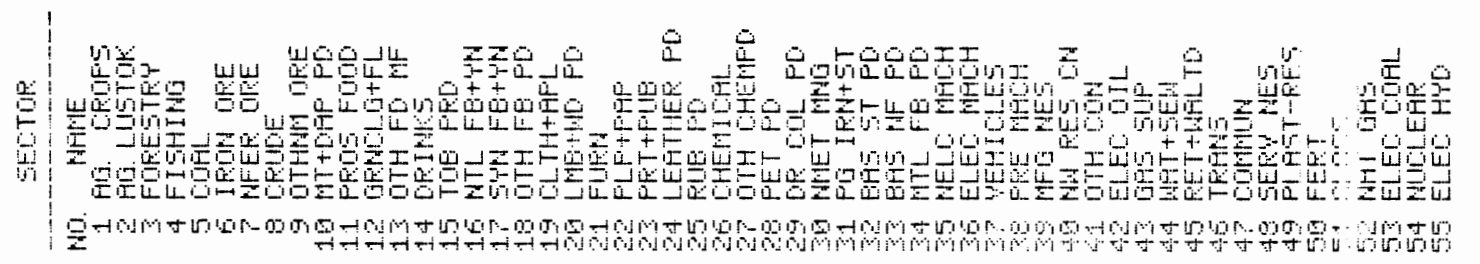

蓠罾

s

空点

密罗

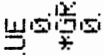

突

论雚 7

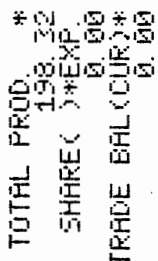

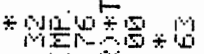

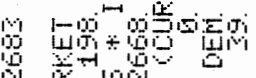

空兽焉害

运要

宫焉至

*

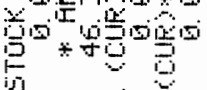

要它

을

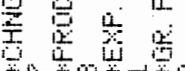

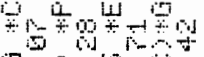

몰

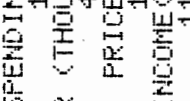

总兽总

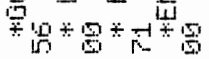

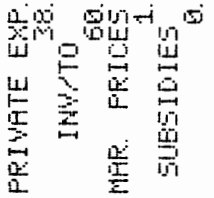

*

g

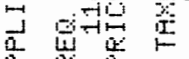

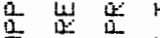

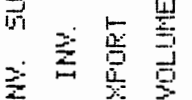

究

50 क

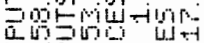

5 资

E

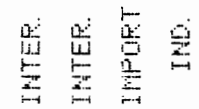



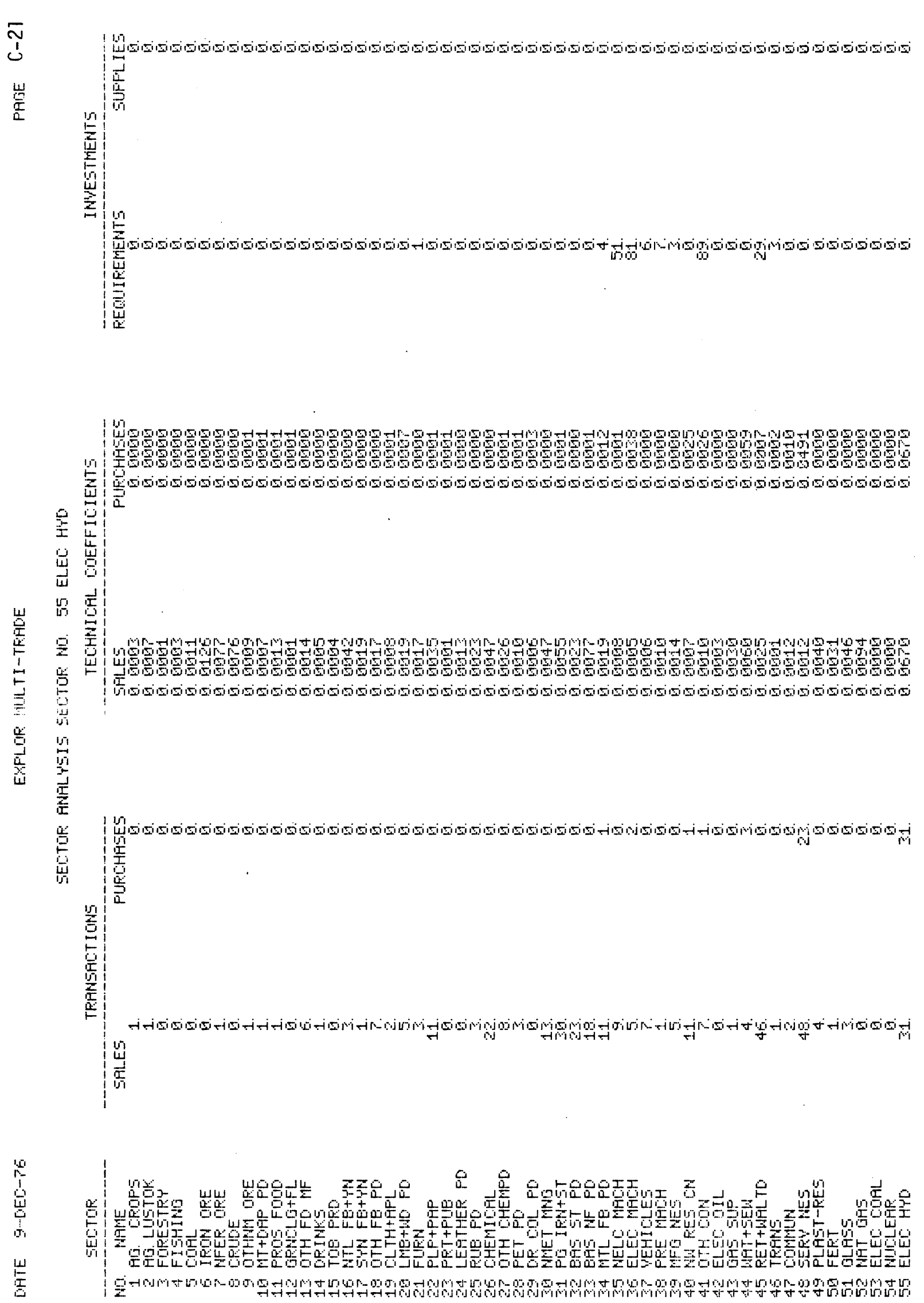

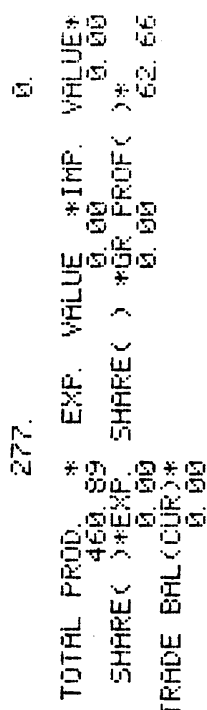

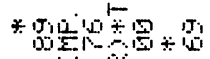

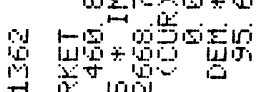

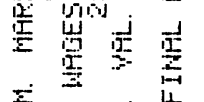

窇

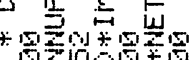

它 * -

定

济焉

学总它

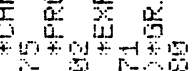

900

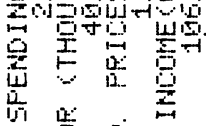

的

空

的

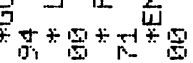

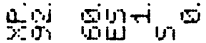

औิ

w

焉

疎

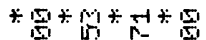

س

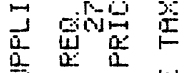

只

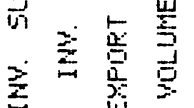

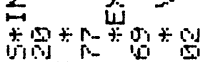

(1)

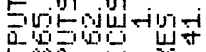

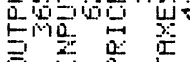

I.

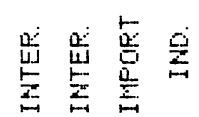



APPENDIX D

SECTORIAL CONCORDANCE FOR

PNL AND BNL VESIONS OF

UNITED STATES I/O MODEL 


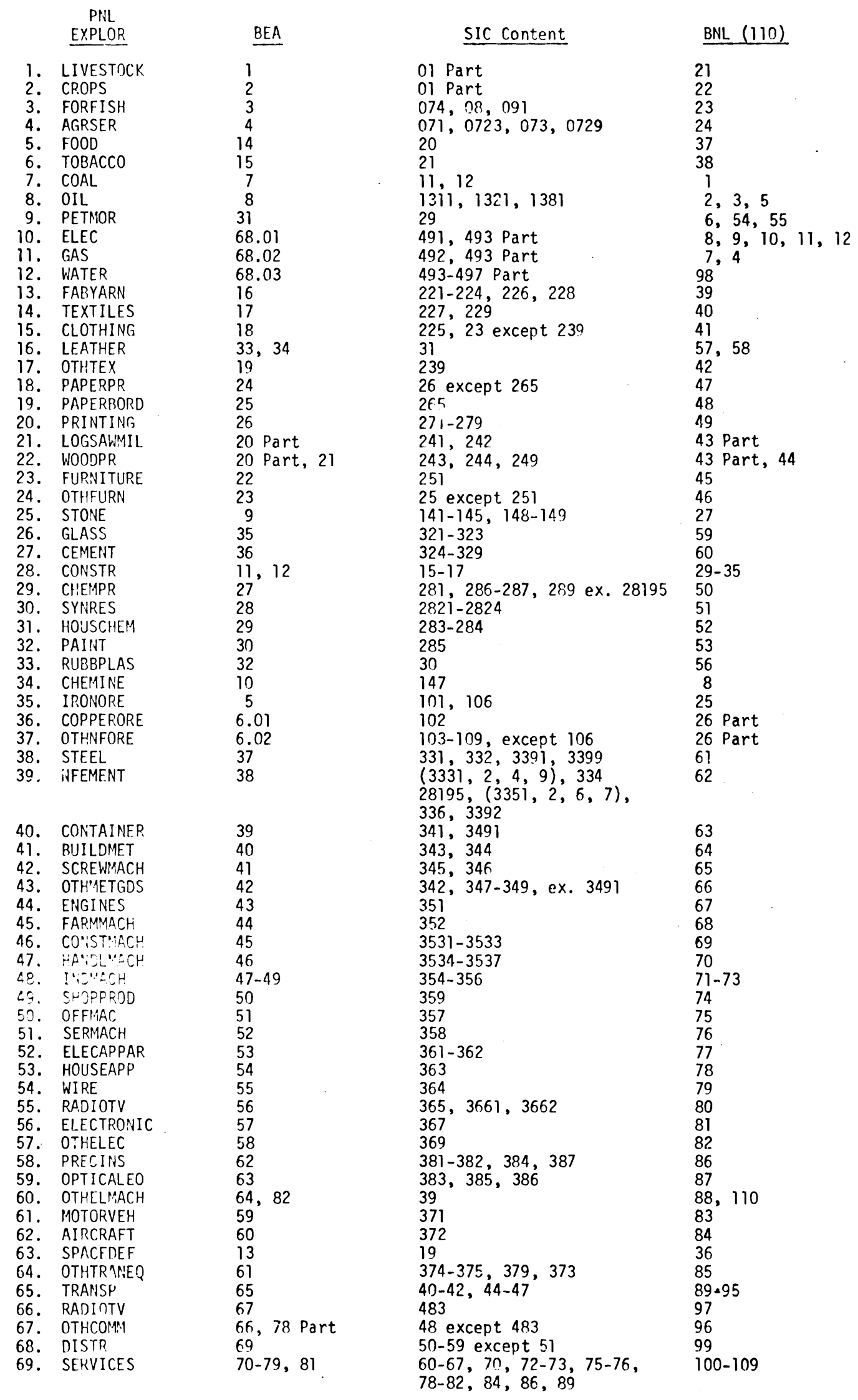




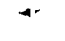




\section{DISTRIBUTION}

No. of

Copies

OFFSITE

1 ERDA Chicago Patent Group U.S. Energy Research and Development Administration Argonne, IL 60439

A. A. Churm

159 ERDA Technical Information Center

1 ERDA, Richland Operations office

1 Office of International R\&D Programs U.S. Energy Research and Development Administration Washington, D.C. 20545

Jack Vanderryn, Director

4 Division of International Security Affairs U.S. Energy Research and Development Administration Washington, D.C. 20545

Lee Abramson

Ray E. Chapman

Mark A. Alexander

Robert Rosenthal

1 Rand Corporation

1700 Main Street Santa Monica, CA 90406

Fred Hoffman
No. of

Copies

1 Program Development - Fossil

Energy

U.S. Eneray Research and Development Administration 2100 M Street

Washington, D.C. 20545

David J. Beecy

2 Office of Assistant Secretary for International Affairs U.S. Department of the Treasury 15th \& Pennsylvania Ave., NW Washington, D.C. 20220

Robert Blake

Victoria S. Farrell

1 Office of Energy Policy U.S. Department of the Treasury 15th \& Pennsylvania Ave., NW Washington, D.C. 20220

John Borkman

1 Science \& Technology Branch U.S. Energy Research and Development Administration Technical Information Center P.0. Box 62

Oak Ridge, TN 37830

David E. Bost, Chief

1 Fuels and Energy Office of Economic and Business Affairs Department of State Washington, D.C. 20540

Stephen W. Bosworth, Director 
1 Analysis \& Evaluation Department Oak Ridge National Laboratory P.0. Box X, Building 3550 Oak Ridge, TN 37830

Roger S. Carlsmith, Head

1 OASD/ISA/IEA

Room 4C800

Pentagon

Washington, D.C. 20301

James N. Carnes

1 Assistant Director for Policy

Analysis

U.S. Energy Research and

Development Administration

1016 16th Street, NW

Washington, D.C. 20545

Jack Ebetino

1 Center for Energy Research

Virginia Polytechnic Institute and State University

Blacksburg, VA 24061

M.C. Edlund

1 Office of Quantitative Methods Federal Energy Administration New Post Office Building Washington, D.C. 20461

\section{Ali Ezzati}

1 Chief/CTAC/OSI Central IntelTigence Agency, $\mathrm{HQ}$ Washington, D.C. 20545

J. P. Herring
2 Office of Systems Integration and Analysis National Science Foundation 1800 G Street, NW Washington, D.C. 20550

Charles J. Johnson

Bruce A. Smith

1 Economic Mcdeling and Research Division

Federal Energy Administration 12th and Pennsylvania Avenue, NW hashington, D.C. 20461

John Kraft

1 Engineering \& Systems Division Building 902A Brookhaven National Laboratory Upton, NiY 11973

William Marcuse

1 U.S. Bureau of Mines

U.S. Department of the Interior 2401 E. Street, NW

Washington, D.C. 20241

George Markon

1 Economic Analys is Branch

Office of Management and Budget

Room 8017, NEOB

Washington, D.C. 20503

\section{Ben Masse 11}

1 Division of International Security Affairs U.S. Eneray Research and Development Administration

Washington, D.C. 20545

Barbara Moyers

Dist. -2 
No. of

Copies

OFFSITE

1 Lawrence Livermore Laboratory $[-531$

P.0. Box 808

Livermore, CA 94550

Robert 01 son

1 Division of Reactor Research and Development

U.S. Energy Research and Development Administration

Washington, D. C. 20545

Andrew J. Pressestky

1 Virginia Polytechnic Institute

and State University

LORENDAS Project

617 N. Main Street

Blacksburg, VA 24061

Leo A. Rapoport

1 Council on International Economic Policy

OEOB, Room 204

17th \& Pennsylvania, NW

Washington, D.C. 20500

James A. Rooney

1 Assistant National Intelligence

officer for E.conomics and Energy

Central Intelliqency Agency, $\mathrm{HQ}$

Washington, D.C. 20505

Ronald Smith
No. of

Copies

1 Division of Advanced Productivity

Research and Technology

National Science Foundation

1800 G Street, NW!

Washington, D.C. 20550

Frederick T. Sparrow

1 Office of Energy Systems

Federal Energy Administration

12th \& Pennsylvania Avenue

Washington, D.C. 20461

James Sweeney

1 Office of Policy Evaluation

Nuclear Regulatory Commission

Washington, D.C. 20555

Norman Terrell

1 Office of Technology Assessment

U.S. Congress

Washington, D.C. 20510

Jon M. Veigel

3 International Energy Affairs

Federal Energy Administration

2000 M Street, NW

Washington, D.C. 20461

James $A$. West

Cecil Thompson

Clement B. Malin

1 Office of Conservation Planning and Policy

U.S. Energy Research and Development Administration

Washington, D.C. 20545

George Murray 


\section{DISTRIBUTION (Continued)}

No. of

Copies

\section{OFFSITE}

1 Division of Geothermal Energy

U.S. Energy Research and

Development Administration

Washington, D.C. 20545

James Bresee

1 Office of Solar, Geothermal and

Advanced Energy Systems

U.S. Energy Research and

Development Administration

Washington, D.C. 20545

John E. Mock

\section{ONSITE}

\section{Battelle-Northwest}

C. H. Bloomster

J. B. Burnham

M. Clement

B. W. Cone

J. W. Currie

D. E. Deonigi

L. E. Erickson

E. A. Eschbach

T. J. Foley

J. C. Fox

D. W. Fraley

P. L. Hendrickson

J. J. Jacobsen

J. C. King

T. P. Kula

S. A. Rao

W. A. Reardon

W. H. Swift

R. D. Widrig

K. E. Yandon

Economics Library (10)

Technical Files (3) 